Cover: Photographs showing examples of water-use categories.

Top left, Irrigation. Photograph obtained from U.S. Geological Survey image library.

Top right, Self-supplied domestic. Photograph by Jorge Barrios, September 3, 2004, accessed from Wikimedia Commons at https://commons.wikimedia.org/wiki/File:Fregadero.jpg.

Bottom left, Public supply. Photograph by Cheryl Dieter, U.S. Geological Survey, on June 12, 2018.

Bottom right, Thermoelectric. Photograph by Alan Cressler, U.S. Geological Survey. 


\section{Factors Affecting Uncertainty of Public Supply, Self-Supplied Domestic, Irrigation, and Thermoelectric Water-Use Data, 1985-2015-Evaluation of Information Sources, Estimation Methods, and Data Variability}

By Carol L. Luukkonen, Kenneth Belitz, Samantha L. Sullivan, and Pierre Sargent

Water Availability and Use Science Program

Scientific Investigations Report 2021-5082 


\section{U.S. Geological Survey, Reston, Virginia: 2021}

For more information on the USGS - the Federal source for science about the Earth, its natural and living resources, natural hazards, and the environment—visit https://www.usgs.gov or call 1-888-ASK-USGS.

For an overview of USGS information products, including maps, imagery, and publications, visit https://store.usgs.gov/.

Any use of trade, firm, or product names is for descriptive purposes only and does not imply endorsement by the U.S. Government.

Although this information product, for the most part, is in the public domain, it also may contain copyrighted materials as noted in the text. Permission to reproduce copyrighted items must be secured from the copyright owner.

Suggested citation:

Luukkonen, C.L., Belitz, K., Sullivan, S.L., and Sargent, P., 2021, Factors affecting uncertainty of public supply, self-supplied domestic, irrigation, and thermoelectric water-use data, 1985-2015-Evaluation of information sources, estimation methods, and data variability: U.S. Geological Survey Scientific Investigations Report 2021-5082, 78 p., https://doi.org/10.3133/sir20215082.

Associated data:

Sullivan, S.L., Luukkonen, C.L., and Belitz, K., 2021, Public supply, self-supplied domestic, irrigation, and thermoelectric water-use data from 5-year compilation datasets from 1985 to 2015 used to assess data variability and uncertainty: U.S. Geological Survey data release, https://doi.org/10.5066/P9TA1DI9.

U.S. Geological Survey, 2021, USGS water data for the Nation: U.S. Geological Survey National Water Information System database, accessed July 29, 2021, at https://doi.org/10.5066/F7P55KJN.

ISSN 2328-0328 (online) 


\section{Acknowledgments}

This report would not be possible without the water-use compilations and assistance provided by the many State and local agencies that manage water resources and operate data-collection programs.

The authors also gratefully acknowledge the U.S. Geological Survey personnel in each State who have managed the information necessary to create the national compilations. 



\section{Contents}

Acknowledgments ……...................................................................................................................





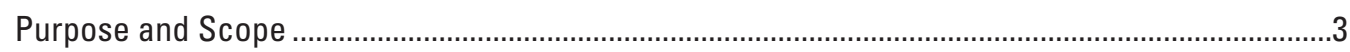

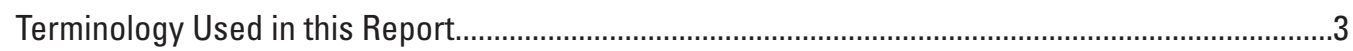



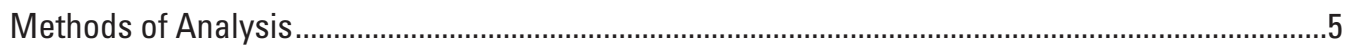



Sources of Information and Methods Used to Estimate Water-Use Data by

Category Element ...................................................................................................

Sources of Information and Methods Used to Estimate Water-Use Data by State ..................

Characterization of Information Relevant to the Water-Use Data Elements for the 2015



2015 Water-Use Program Method Codes ……....................................................................

Reported and Estimated Water-Use Data...............................................................................12

Spatial Scale of Reported or Estimated Water-Use Data ......................................................16

Apportionment of Source of Water Between Groundwater and Surface Water ....................16



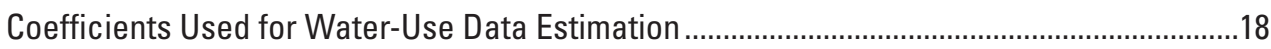

Assessment of the Variability of Water-Use Data Values by State and Category ............................28



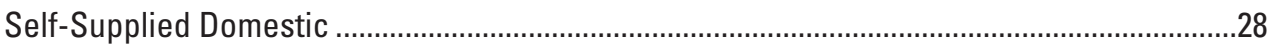

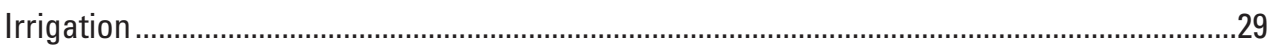

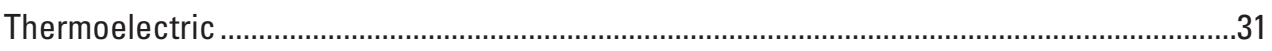

Assessment of the Variability of Water-Use Data by Region and Compilation Year ........................33



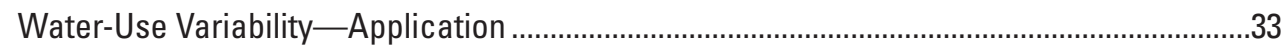

Guidance for Additional Uncertainty Assessments and Water-Use Compilations ...........................58





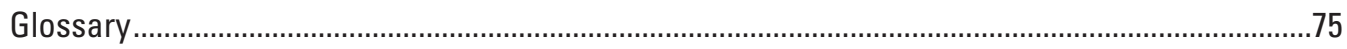



\section{Figures}

1. Map showing public supply groundwater withdrawal method codes, by county, for the 2015 compilation indicating whether values are site-specific, areal aggregated, estimated, or a combination.

2. Map showing public supply population served method codes, by county, for the 2015 compilation indicating whether values are site-specific, areal aggregated, estimated, or a combination

3. Map showing public supply domestic delivery method codes, by county, for the 2015 compilation indicating whether values are site-specific, areal aggregated, estimated, or a combination 
4. Map showing irrigation groundwater withdrawal method codes, by county, for the $\mathbf{2 0 1 5}$ compilation indicating whether values are site-specific, areal aggregated, estimated, or a combination.

5. Map showing irrigated acres by sprinkler method codes, by county, for the 2015 compilation indicating whether values are site-specific, areal aggregated, estimated, or a combination

6. Map showing thermoelectric groundwater withdrawal method codes, by county, for the 2015 compilation indicating whether values are site-specific, estimated, or a combination

7. Map showing thermoelectric power generation method codes, by county, for the 2015 compilation indicating whether values are site-specific, estimated, or a combination

8. Boxplots showing the primary year of information sources used for public supply, irrigation, and thermoelectric values for the 2015 compilation.

9. Boxplots showing the primary years U.S. Geological Survey personnel used for determining coefficients for estimating the data....

10. Radar chart showing public supply delivery per capita rates, by State, for 1985-2015

11. Radar chart showing public supply surface-water percentages, by State, for 1985-2015

12. Radar chart showing percentage of total State population on public supply for 1985-2015

13. Radar chart showing percentage of total public supply withdrawals delivered for domestic uses, by State, for 1985-2015

14. Scatter plot showing county public supply withdrawal per capita rate for 1985-2015.

15. Scatter plot showing county public supply delivery per capita rate for $1985-2015 \ldots . . . . .40$

16. Radar chart showing self-supplied domestic per capita rates, by State, for 1985-2015

17. Scatter plot showing county self-supplied domestic population for 1985-2015.............43

18. Scatter plot showing county domestic per capita rates for 1985-2015 ..........................46

19. Scatter plot showing irrigation ap plication rates, by State, for $2000-15$..........................48

20. Radar charts showing consumptive use percentage, by State, for 2015.........................51

21. Scatter plot showing county irrigation application rate for combined crop and golf and total irrigation for 1985-2015 ........................................................................52

22. Radar charts showing thermoelectric power rates, by State, for 2005-15 ....................54

23. Radar charts showing consumptive use percentages for thermoelectric power,



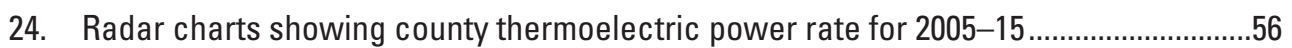

\section{Tables}

1. Mandatory and optional county water-use category data element reporting requirements, 1985-2015.

2. Summary of primary source of data, by number of States, for the public supply and self-supplied domestic categories for the 2000, 2005, 2010, and 2015 water-use compilations 
3. Summary of primary source of data, by number of States, for the irrigation category for the $2000,2005,2010$, and 2015 water-use compilations................................8

4. Summary of primary methods used by the U.S. Geological Survey, by number of States, for estimating crop irrigation withdrawals for the 2000, 2005, 2010, and 2015 water-use compilations...

5. Summary of primary source of data, by number of States, for the thermoelectric category for the 2000, 2005, 2010, and 2015 water-use compilations....

6. Primary sources of information for the public supply withdrawal, population served, and deliveries for domestic use data elements by State, grouped into three categories for the 2000, 2005, 2010, and 2015 compilations

7. Classification of the primary sources of information for the crop irrigation withdrawals and irrigated acre data elements by State, for the 2000, 2005, 2010, and 2015 compilations.

8. Classification of the primary sources of information for the thermoelectric withdrawals and power generation data elements by State, for the 2000, 2005, 2010, and 2015 compilations.

9. Table of method codes that provide information on the class, source, and types of data

10. Summary of the most frequently used $\mathbf{2 0 1 5}$ method codes by category .

11. Summary of the number of States by category, element, and primary reporting scale, for 2015 .

12. Summary of information, by numbers of States, on groundwater and surface-water sources by category, for 2015

13. Median values for public supply withdrawal per capita use rates, in gallons per person per day, determined using total withdrawals divided by population served, normalized by region and year, for the compilations from 1985 through 2015

14. Interquartile ranges for public supply withdrawal per capita use rates determined using total withdrawals divided by population served, normalized by region and year, for the compilations from 1985 through 2015

15. Median values for public supply delivery per capita use rates, in gallons per person per day, determined using public supply deliveries divided by population served, normalized by region and year, for the compilations from 1985 through 2015

16. Interquartile ranges for public supply delivery per capita use rates determined using public supply deliveries divided by population served, normalized by region and year, for the compilations from 1985 through 2015

17. Median values for self-supplied domestic population, in thousands of people, normalized by region and year, for the compilations from 1985 through 2015

18. Interquartile ranges for self-supplied domestic population, in thousands of people, normalized by region and year, for the compilations from 1985 through 2015

19. Median values for self-supplied domestic per capita use rates, in gallons per person per day, determined using self-supplied withdrawals divided by self-supplied domestic population, normalized by region and year, for the compilations from 1985 through 2015

20. Interquartile ranges for self-supplied domestic per capita use rates, determined using self-supplied withdrawals divided by self-supplied domestic population, normalized by region and year, for the compilations from 1985 through 2015 
21. Median values for irrigation application rates, in acre-feet per acre, determined using irrigation withdrawals divided by irrigated acres, normalized by region and year, for the compilations from 1985 through 2015 .

22. Interquartile ranges for irrigation application rates determined using irrigation withdrawals divided by irrigated acres, normalized by region and year, for the compilations from 1985 through 2015

23. Median values for thermoelectric power rates, in gallons per megawatt hour, determined using thermoelectric withdrawals divided by power generated, normalized by region and year, for the compilations from 2005 through 2015

24. Interquartile ranges for thermoelectric power rates determined using thermoelectric withdrawals divided by power generated, normalized by region and year, for the compilations from 2005 through 2015

\section{Conversion Factors}

U.S. customary units to International System of Units

\begin{tabular}{|c|c|c|}
\hline Multiply & By & To obtain \\
\hline \multicolumn{3}{|c|}{ Area } \\
\hline acre & 4,047 & square meter $\left(\mathrm{m}^{2}\right)$ \\
\hline acre & 0.4047 & hectare (ha) \\
\hline acre & 0.004047 & square kilometer $\left(\mathrm{km}^{2}\right)$ \\
\hline \multicolumn{3}{|c|}{ Volume } \\
\hline gallon (gal) & 3.785 & liter $(\mathrm{L})$ \\
\hline gallon (gal) & 0.003785 & cubic meter $\left(\mathrm{m}^{3}\right)$ \\
\hline gallon (gal) & 3.785 & cubic decimeter $\left(\mathrm{dm}^{3}\right)$ \\
\hline million gallons (Mgal) & 3,785 & cubic meter $\left(\mathrm{m}^{3}\right)$ \\
\hline cubic foot $\left(\mathrm{ft}^{3}\right)$ & 0.02832 & cubic meter $\left(\mathrm{m}^{3}\right)$ \\
\hline acre-foot (acre-ft) & 1,233 & cubic meter $\left(\mathrm{m}^{3}\right)$ \\
\hline acre-foot (acre-ft) & 0.001233 & cubic hectometer $\left(\mathrm{hm}^{3}\right)$ \\
\hline \multicolumn{3}{|c|}{ Flow rate } \\
\hline gallon per day (gal/d) & 0.003785 & cubic meter per day $\left(\mathrm{m}^{3} / \mathrm{d}\right)$ \\
\hline million gallons per day (Mgal/d) & 0.04381 & cubic meter per second $\left(\mathrm{m}^{3} / \mathrm{s}\right)$ \\
\hline \multicolumn{3}{|c|}{ Energy } \\
\hline megawatt (MW) & $8.6 \times 10^{8}$ & calories per hour $(\mathrm{cal} / \mathrm{h})$ \\
\hline megawatt hour (MWh) & $3.6 \times 10^{9}$ & joule $(\mathrm{J})$ \\
\hline megawatt hour (MWh) & $3.4 \times 10^{6}$ & British thermal unit (Btu) \\
\hline
\end{tabular}




\section{Abbreviations}

$\begin{array}{ll}\text { AWUDS } & \text { Aggregate Water-Use Data System } \\ \text { DOE } & \text { U.S. Department of Energy } \\ \text { EIA } & \text { U.S. Energy Information Administration } \\ \text { IQR } & \text { interquartile range } \\ \text { NWUP } & \text { National Water-Use Program } \\ \text { USDA } & \text { U.S. Department of Agriculture } \\ \text { USGS } & \text { U.S. Geological Survey }\end{array}$





\title{
Factors Affecting Uncertainty of Public Supply, Self-Supplied Domestic, Irrigation, and Thermoelectric Water-Use Data, 1985-2015-Evaluation of Information Sources, Estimation Methods, and Data Variability
}

\author{
By Carol L. Luukkonen, Kenneth Belitz, Samantha L. Sullivan, and Pierre Sargent
}

\section{Abstract}

The U.S. Geological Survey (USGS) Water-Use Program is responsible for compiling and disseminating the Nation's water-use data. Working in cooperation with local, State, and Federal agencies, the USGS has collected and published national water-use estimates every 5 years, beginning in 1950 . These water-use data may vary because of actual changes in water use, because of changes in estimation methods, or because of errors. Comparison and interpretation of these data is difficult without first determining the factors that contribute to data variability. This report describes factors that may affect data quality and documents ways to investigate the variability of public supply, self-supplied domestic, irrigation, and thermoelectric water-use data for the 1985-2015 compilations.

The USGS produces national water-use estimates for various categories of water use for every county in the United States. Knowledge about the sources of data for county estimates is important because factors such as estimation methodology and reporting affect data uncertainty Determination of meaningful patterns and trends in the data are contingent on the use of consistent methodology throughout the period of interest. With the many ways that water-use data have been collected, assembled, and estimated, multiple factors likely contribute to data uncertainty, Data used to produce these estimates may be furnished from agencies that collect information from entities who report water use; gaps in reported data are typically estimated to achieve a comprehensive county estimate. For example, public supply and thermoelectric category data are based primarily on furnished site-specific data; whereas crop irrigation is often furnished or estimated at the county scale. Public supply deliveries for domestic use and self-supplied domestic withdrawals are most often estimated by USGS personnel using per capita use rate coefficients. Irrigation may be estimated using crop water requirements, application rates, or other soil water balance methods when furnished reported data are not available.
Rates, percentages, medians, and interquartile ranges were used to investigate variability in the water-use data among States, regions, and years. The purposes of these evaluations were to (1) identify extreme values that may reflect changes in information sources, estimation methods, or errors; (2) indicate areas of variable or consistent values that are unexpected; and (3) indicate areas where values change because of local climate or other factors. Where factors are identified that contribute to data variability, such as a change in methodology, additional work could determine uncertainty because of these factors.

These evaluations identified the availability of information that is needed to address data limitations. Factors such as estimation methodology affect data quality. Some updates to method codes assigned in 2015 and assignment of method codes to earlier compilation datasets for all categories would provide much needed metadata for users of the data. Improvements in data documentation describing sources of information and estimation methods and additional metadata information from agencies and entities that furnish water-use data, would enable a more complete understanding and depiction of water-use patterns and trends. Additional metadata are needed for users of the data to better understand the water-use data and interpret changes in water use across the United States and with time.

\section{Introduction}

Water-use information is essential to accurately understand past and current usage and how future water demands will be met while maintaining adequate water quality and quantities for human and ecosystem needs. Evaluation of trends in total water use for the Nation among geographic areas, categories of use, and water sources with time is important for water resource assessments. The U.S. Geological Survey (USGS) is dedicated to providing reliable scientific information that accurately describes current and historical conditions and enables a better understanding of the Earth's 
water resources. Compiling and disseminating the Nation's water-use data is the responsibility of the USGS National Water-Use Program (NWUP). Working in cooperation with local, State, and Federal agencies, the USGS has collected and published national water-use estimates every 5 years, beginning in 1950 through 2015. These annual reports produced every 5 years are referred to as "compilations." The 65 -year span represents the longest, most comprehensive compilation of water-use data by a Federal agency in the United States.

The Aggregate Water-Use Data System (AWUDS) is the database management system that has been used to enter, store, and analyze State water-use data aggregated by county starting with the 1985 compilation. AWUDS is part of the USGS National Water Information System (U.S. Geological Survey, 2021) and contains data for public supply, self-supplied domestic, irrigation, thermoelectric, industrial, commercial, hydroelectric, mining, livestock, and aquaculture water-use categories. Data for some of these categories are not available for all compilation years because of changes in mandatory reporting requirements with time. Public supply, irrigation, and thermoelectric accounted for 90 percent of the water withdrawals for the eight categories reported in 2015 (Dieter and others, 2018). Therefore, AWUDS county data for these water-use categories are the focus of this study. For some evaluations, self-supplied domestic water use also was included to present a more complete picture of residential water-use patterns.

The county water-use data reported for each compilation by the USGS NWUP were derived from many sources, depending on the category of use and the information available. In each State, USGS water-use specialists compile available furnished reported water-use data for individual water users from State, Federal, and local agencies or directly from facilities. Data from State agencies may be variable from State to State and with time. Where reported data are unavailable, estimation is used to fill in the gaps to achieve a complete county estimate. USGS water-use specialists implement multiple approaches and generally rely on coefficients or other data-driven model approaches that may vary temporally and spatially. For each compilation year, a primary focus is to obtain reliable water-use information for the largest water users in each category of use, so that to the extent possible, county-wide estimates are based on reported rather than estimated data.

Multiple USGS efforts have been in place to improve consistency in approaches to data estimation. For example, throughout the course of these compilations, the USGS NWUP has provided national datasets to State water-use specialists, developed models, and worked with State agencies to initiate or expand on reporting programs. Datasets of national scope furnished to State water-use specialists have included total county populations from the U.S. Census; model derived water-use estimates for the livestock, aquaculture, and mining categories (Lovelace, 2009a, 2009b, 2009c); and power generation and withdrawals reported by thermoelectric plants to the U.S. Department of Energy (DOE), U.S. Energy Information
Administration (EIA). For the 2010 and 2015 compilations, model estimates for thermoelectric water withdrawals and consumptive use for about 1,100 facilities throughout the United States were developed by Diehl and others (2013) and Diehl and Harris (2014) and were provided to USGS wateruse specialists. To estimate irrigation consumptive use for the 2015 compilation, estimates of evapotranspiration (Senay and others, 2013) were provided for each State.

The Science and Engineering to Comprehensively Understand and Responsibly Enhance Water Act provides financial assistance to State agencies with stipulations that the funding be used to support activities related to water-use data collection and methods research at the State level. As part of this act, the USGS Water-Use Data and Research program provides financial assistance to improve the availability, quality, compatibility, and delivery of water-use data that are collected or estimated by State agencies with primacy over water management and permitting. These Water-Use Data Research projects will improve the quality of reported and estimated data for compilation and water-use efforts.

For the previous compilations from 1985 through 2015, water-use data, information sources, and estimation methods differ with time for county, State, and national estimates. Sources of variability might include (1) actual water-use changes, (2) changes in methodology, and (3) errors. Actual changes in water use can result from changes in factors that affect water-use amounts. For example, irrigated crops may require additional water applications during times of low precipitation compared to times with normal or above average precipitation. Legal decisions, local restrictions, economic trends, and population driven effects also may affect water-use amounts. Water suppliers may extend their service areas or change their mix of water sources from predominantly groundwater to a surface-water source or vice versa. The transfer of water from one service area to another could result in larger water withdrawal rates where the water is withdrawn and lower withdrawal rates where the water is used. Likewise, differences in facility operations, water conservation measures, or improved technologies could contribute to differences in water use among various spatial scales and with time.

Water-use amounts may vary in time and space because of changes in how data are furnished or estimated. Data that are furnished may be metered; may be estimated based on pump capacities, flow durations, or irrigation system transit times; or may be calculated using specified or unspecified methods. Meter or measurement accuracy, precision, or calibration details are rarely provided to the USGS with furnished data. Where reported data are unavailable, estimation methods may be consistently applied for some categories; for example, use of a per capita coefficient and population to determine domestic water use. However, methods and coefficients often differ from State to State and with time because of data availability, changes in USGS personnel, changes in reporting requirements, or other reasons. Determination of meaningful patterns and trends in the data are contingent on the use of consistent methodology throughout the period of interest. 
Water-use amounts also may vary from State to State and with time because of errors. Human errors may include transcription or transposition errors, incorrect reporting units, data omissions, and measurement errors. Water-use categories defined by States may differ from USGS category definitions, the spatial scale for reporting often differs, thresholds for reporting requirements and the number of resources that are dedicated to compliance may vary from State to State, and other reasons could contribute to errors or inconsistencies in water-use data. These types of errors may be more common for earlier compilation years because in more recent (2015) years data collection, storage, and delivery efforts have improved.

Variability in the water-use data among States and with time may reflect actual changes in water use because of climate, regional or socioeconomic differences, or other factors; however, the variability may not have any relation to actual changes in water use and may be due to changes in methodology. Other data may appear to be consistent but still may be inaccurate and not representative of actual water use. Therefore, comparison and interpretation of these data is difficult without first determining the factors that contribute to these unexpected patterns of variability and consistency. Understanding how the water-use estimates were collected, assembled, and estimated is needed to help define and identify the factors that affect data uncertainty and is needed before the uncertainty of these estimates can be quantified.

Water-use compilation documentation and 2015 method codes were investigated to determine available information on factors such as sources of data and estimation methods. The aggregated water-use data from the 1985-2015 compilations were investigated using rates and percentages to determine how to highlight areas of unexpected variability or consistency and potential values that warrant further investigation. The information in this study is needed to build the foundation for understanding sources of uncertainty in these water-use data. Uncertainty information is necessary to inform users about the limitations of the data, to indicate if a result is adequate for its intended purpose, and to ascertain if the data are consistent with other results. Subsequent work could build on this foundation by identifying the factors that contribute to potentially anomalous values and determine procedures to assign uncertainty to those factors affecting the quality of the water-use data.

\section{Purpose and Scope}

The purpose of this report is to investigate available information on factors that affect data quality and comparability in the water-use estimates for the 1985-2015 compilations. This report describes (1) sources of information for water-use data, (2) methods used for estimation when reported data are not available, and (3) specific characteristics of 2015 compilation water-use data. The purpose of this report also is to describe numerical measures that can be used to study variability in water-use estimates with time and space.

The following four water-use categories are evaluated for the compilations from 1985 through 2015: public supply, self-supplied domestic, irrigation, and thermoelectric power. Water-use information from the 5-year compilations for 1985, 1990, 1995, 2000, 2005, 2010, and 2015 are published in the following reports: Solley and others (1988, 1993, 1998); Hutson and others (2004); Kenny and others (2009); Maupin and others (2014); and Dieter and others (2018). County-level data from AWUDS for all published categories of use for these compilation years and used for these analyses are available in a USGS data release (Sullivan and others, 2021).

The scope of the report includes analysis of state and county-level data for the 5-year compilation datasets from 1985 through 2015 for the 50 States, Puerto Rico, and the U.S. Virgin Islands (hereafter referred to as "States" for brevity). Geographic locations are not shown on maps. These datasets represent 5-year snapshots of annual water use that is reported in million gallons per day by category of use. For this study, the term "county" is used to represent all State subdivisions, including, county, barrio, borough, parish, island, and municipio. For the purposes of this report, ranges of years may be used to describe several compilation years; for example, 1985-95 is written to mean the 5-year compilations for 1985,1990 , and 1995 and is not meant to include every year. The scope of this uncertainty assessment is limited by available documentation and data. This analysis focuses on data values for 1985-95; data values and documentation for 2000-10; and data values, documentation, and method codes for 2015 .

\section{Terminology Used in this Report}

A "Glossary" is at the end of this report and is available online at https://water.usgs.gov/watuse/wuglossary.html. Each water-use category consists of data elements that may or may not be required for a compilation year (table 1). The USGS NWUP provides tabulations of water-use data for each category data element. Since 1985 and before 2000 , several changes have been made to the mandatory and optional category data elements and to the definitions of various water-use categories. For example, reporting of fresh and saline withdrawals was mandatory for some years and optional for other years. Consumptive use reporting changed from an optional to a mandatory data element in 2015 for the public supply, irrigation, and thermoelectric categories. Terms and units depicting withdrawals and ancillary data for the 5-year compilations have not changed since 2000. Terminology describing category changes is available online at https://water.usgs.gov/watuse/WU-Category-Changes.html. 
Table 1. Mandatory and optional county water-use category data element reporting requirements, 1985-2015.

[Blue shading indicates mandatory (required), yellow shading indicates optional (not required), and gray shading indicates not reported. IR, irrigation; TE, thermoelectric; GW, groundwater; SW surface water]

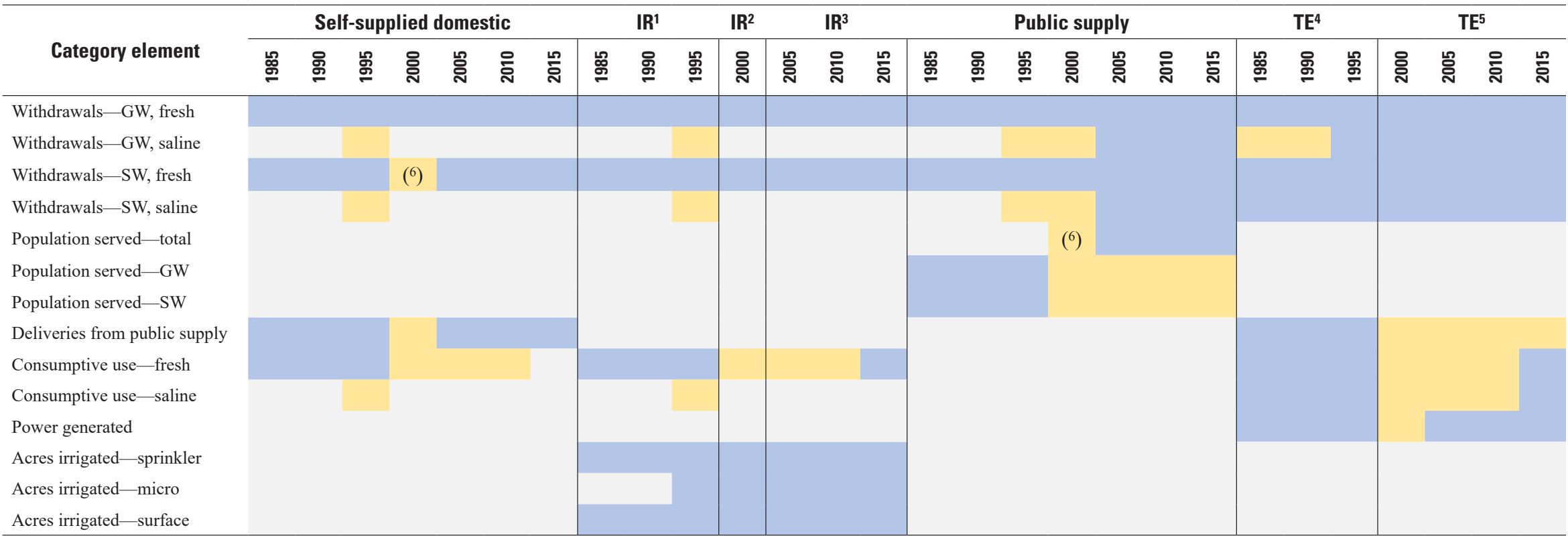

${ }^{1}$ Reporting of total irrigation only.

${ }^{2}$ Reporting of crop and golf course irrigation.

${ }^{3}$ Reporting of total irrigation, optional split by crop and golf course irrigation.

${ }^{4}$ Fossil fuel, geothermal, and nuclear thermoelectric categories.

${ }^{5}$ Once-through and closed-loop cooling thermoelectric categories.

${ }^{6}$ Reporting of State level totals only at the time of the compilation. 


\section{Approach}

The approach in this report is to focus evaluations on examination of similarities and differences in information sources, estimation methods, 2015 water-use data characteristics, and water-use data for 1985-2015. In this report, some water-use data elements were combined so that similar uses could be compared. For example, saline groundwater and surface water were generally a small component (less than 5 percent) of the public supply withdrawals for most States (except U.S. Virgin Islands and Florida); therefore, for most evaluations in this report, fresh and saline groundwater are combined and fresh and saline surface water are combined. For some evaluations in this report, public supply water withdrawals from groundwater and surface water were combined to represent total public supply withdrawals. Because of the reporting difference for the irrigation category (table 1), some evaluations focus specifically on crop irrigation. Other evaluations present information in the total, crop, and golf course categories separately. For the thermoelectric category, data are demarcated by fuel type from 1985 through 1995 and cooling system from 2000 through 2015.

For many comparisons within this report, States have been divided into 11 regions based on similarities in climate (seasonal temperature and precipitation patterns) and physiography (fig. 1.1). States within these regions are compared to evaluate variability in the water-use data. Comparisons are made using rates, percentages, medians, and interquartile ranges (IQRs). Rates of water use are expressed in terms of million gallons per day, acre-feet per acre, or gallons per megawatt hour and are defined in the "Glossary." Percentages are calculated for specific data elements. For example, the surface-water percentage was determined as the total surface-water withdrawals divided by the total water withdrawals for the category. The optional elements of reclaimed wastewater and public supply deliveries are included in the determination of consumptive use percentages; otherwise these percentages may be greater than 100 percent.

For each State, within a given year, the following two state-scale characteristic values were calculated for each water-use component using county data: (1) the median and (2) the IQR. The median is the middle value in a sorted list of county values for each State. The IQR describes the range or spread in county values and was determined as the difference between the upper (75th percentile) and the lower (25th percentile) quartiles. In turn, the state-scale characteristic values can be placed into the context of a region (fig. 1.1). For each region, within a given year, the following two characteristic values can be defined for a water-use component: (1) the median of the state-scale medians and (2) the median of the state-scale IQRs. These regional-scale characteristic median and IQR values were compared to highlight potentially anomalous values.

The results of these comparisons were used to determine if States are moving in similar directions from year to year. Outliers, or unusual patterns of water-use information, could be caused by a variety of reasons, some relating to actual changes in water use, such as a shift from groundwater to surface-water sources or drought conditions. However, changes in methods and errors could be causing these anomalous patterns. Multiple changes in estimation methods might result in lower confidence and increase uncertainty in the data, whereas initiation of a reporting program could indicate higher confidence in the data moving forward. Plotted values such as rates or percentages that have remained unchanged for all or part of the period since 1985 may warrant further inspection because this pattern might indicate that values, such as coefficients, may not have been updated. Graphical comparisons provide a means of qualitatively and quantitatively indicating areas of potential uncertainties by (1) identifying extreme values that may reflect changes in information sources, estimation methods, or errors; (2) indicating areas of variable or consistent values that are unexpected; (3) indicating areas where changes in values happen because of climate or other factors; and (4) demonstrating if visual evidence of uncertainty exists (for example, error in source data and methods) in the final published water-use estimates. These evaluations also are a first cut to identify factors that may contribute to water-use data uncertainty and identify protocols for additional work to assess data reliability and improve water-use data estimation.

\section{Methods of Analysis}

The water-use data for the four categories throughout the 7 compilation years are evaluated to assess data variability and consistency and potential factors affecting data uncertainty. This uncertainty assessment focuses on the information sources, estimation methods, 2015 water-use data characteristics, and variability in the 1985-2015 water-use data. To understand data quality, information regarding how the data were provided or estimated and information regarding variability in the water-use values were evaluated.

Water-use compilation documentation is most complete for 2015; however, some evaluations were done for the 2000-10 compilations when the primary information sources and estimation methods could be determined. Because a variety of methods may be used for each category element to produce data for the compilation, the method used to estimate most of the data element is referred to as the primary method in this report. The number of States relying on specific information sources and estimation methods were summarized.

Evaluations of the 2015 compilation included information about other characteristics, such as per capita use rates, that make up and potentially affect the quality of the water-use data. A per capita coefficient may have been determined for a State or county from a study within the current compilation year. On the other hand, a coefficient may have been carried forward from previous compilations and, thus, may need to be reviewed. Other characteristics that were used in the 
development of the water-use data also were evaluated (for example, the source of water and whether data were reported or estimated).

The report uses tables, graphs, and charts to illustrate the variability in the water-use data. These summaries and evaluations are as follows: (1) normalized data values to facilitate comparison among States (for example, public supply per capita use rates), (2) percentages (for example, percentage of groundwater or percentage of consumptive use for a category), and (3) median and IQR as indicators of the center of the distribution and the range in values. The medians and IQRs of the county values for each State were evaluated for patterns in the data values for a given State throughout time and for analysis of values comparing States with similar climates.

\section{Sources of Information and Estimation Methods}

This study evaluated primary sources of information and the methods used to estimate data to fill gaps when reported data were lacking or insufficient. Ancillary information sources reported as part of a census, such as the U.S. Department of Agriculture (USDA) Census of Agriculture reports, also were summarized. The following sections describe water-use data information sources and estimation methods, by category element and State, with the goal of investigating the consistency or inconsistency of sources and methods.

\section{Sources of Information and Methods Used to Estimate Water-Use Data by Category Element}

The primary information sources and estimation methods for the selected categories were summarized to describe the number of States relying on each source or method for the 2000-15 compilation years (tables $2-5$ ). Information from 1985 through 1995 is not included because little documentation exists for these earlier compilations. These tabulations provide an indicator of data quality through evaluation of the consistency of sources and methods. States using similar sources and methods would have more comparable data than States using sources and methods that differ. Similarly, using consistent sources and methods with time also improves data comparability; a count indicates the number of States that had used the same data sources for the past three or four compilations.

For public supply, information sources and estimation methods were tabulated for three elements for 2000-15withdrawals, population served, and deliveries for domestic use (table 2). The primary source of information for public supply withdrawals and population served was reports from State agencies that have primacy for ensuring and meeting safe drinking water regulations or primacy over water rights.
Many State agencies have public supply information that is consistent throughout the compilation years. For population served, information sources included U.S. Census data and the Safe Drinking Water Information System database. Public supply deliveries for domestic use were primarily estimated, although facilities in some States report this information. Data for withdrawals and service connections from public suppliers are often used to develop system-level domestic use coefficients. When estimates are needed for public supply deliveries for domestic use, methods include surveys of public supply sales information collected by facilities, calculations using coefficients for per capita use, estimates from a sampling of the public supply systems, and development of average delivery percentages to various customer categories. Estimation methods most often relied on data from previous compilations or were not fully described in documentation reports. USGS personnel in a few States consistently used the same method from 2005 through 2015.

For the self-supplied domestic category, information sources and estimation methods were tabulated for the water withdrawal data element for 2000-15 (table 2). The selfsupplied domestic population is automatically calculated in the AWUDS database as the total county population minus the publicly supplied population. Any errors in the determination of the publicly supplied population served or total county population will propagate to errors in the self-supplied domestic populations. Occasionally, the reported public supply population is greater than the total county population because of public supply facilities reporting populations that are served in neighboring counties. When this discrepancy arose, USGS personnel made adjustments during the compilation to the public supply population to account for only the population that is within the county, thereby avoiding having a negative self-supplied domestic population. Self-supplied domestic and public supply populations cumulatively do not exceed the total county population in the database. Self-supplied domestic water withdrawals are typically estimated by multiplying the self-supplied domestic population by a self-supplied domestic per capita use coefficient, but four to nine States report this value during these compilations (table 2). The self-supplied per capita coefficient may be based on the State's public supply per capita coefficient, on previous compilations, or on other sources.

For crop irrigation, information sources were tabulated for two elements - withdrawals and irrigated acres (table 3). During 2000-15, crop irrigation either was reported within the total irrigation category or was reported separately. Primary data sources for withdrawals were from State agencies or estimates by USGS personnel. Primary data sources for irrigated acres were from State agencies or from State or Federal USDA reports. State agency data were used consistently in 16 States in 2015 for withdrawals, and State agency or USDA sources were used consistently for irrigated acres from 2000 through 2015. Many of these data are collected annually by State agricultural agencies; however, some data are available for years other than a compilation year. For 
Table 2. Summary of primary source of data, by number of States, for the public supply and self-supplied domestic categories for the 2000, 2005, 2010, and 2015 water-use compilations.

[USGS, U.S. Geological Survey; SDWIS, Safe Drinking Water Information System; --, not determined]

\begin{tabular}{|c|c|c|c|c|c|c|}
\hline \multirow{2}{*}{ Source } & \multicolumn{4}{|c|}{ Compilation year } & \multicolumn{2}{|c|}{ Same method from } \\
\hline & 2000 & 2005 & 2010 & 2015 & $2000-15$ & $2005-15$ \\
\hline \multicolumn{7}{|c|}{ Public supply withdrawals } \\
\hline Survey/questionnaire responses as administered by State agencies & 8 & 7 & 3 & 3 & 0 & 0 \\
\hline USGS estimates & 6 & 3 & 2 & 5 & 1 & 1 \\
\hline \multicolumn{7}{|c|}{ Public supply population served } \\
\hline State agency/local agency reported data & 22 & 22 & 25 & 24 & 12 & 15 \\
\hline U.S. Census & 9 & 6 & 6 & 6 & 4 & 4 \\
\hline SDWIS & 8 & 11 & 11 & 15 & 5 & 9 \\
\hline USGS estimates & 6 & 6 & 8 & 5 & 1 & 1 \\
\hline Water-user reported data & -- & 10 & 7 & 10 & -- & 5 \\
\hline State agency reported or calculated data & -- & 8 & 12 & 16 & -- & 3 \\
\hline Other published data & -- & 3 & 5 & 3 & -- & 1 \\
\hline Survey as administered by State agencies & -- & 7 & 5 & 4 & -- & 3 \\
\hline Previous compilation & -- & 10 & 10 & 13 & -- & 2 \\
\hline Unknown & -- & 9 & 4 & 2 & -- & 0 \\
\hline USGS estimates using other methods & -- & 5 & 9 & 4 & -- & 0 \\
\hline \multicolumn{7}{|c|}{ Self-supplied domestic withdrawal per capita rates } \\
\hline
\end{tabular}

example, the USDA Census of Agriculture is produced in years ending in 2 and 7, and the USDA Farm and Ranch Irrigation Survey is produced in years ending in 3 and 8 . Some USGS personnel adjust irrigation data from non-compilation years using climate or other data to better represent the conditions during the compilation year.

Methods used by USGS personnel for estimating crop irrigation withdrawals varied depending on available information or selected estimation methods in each State (table 4). For the 2000-15 compilations, the primary method for estimating withdrawals involved using crop application rates or crop water requirements, or both. In 2015, model-based estimation methods such as the soil water balance or the evapotranspiration estimation spreadsheet provided by the NWUP (row 2 of table 4) were used more often than previous years. For additional information on USGS estimates of irrigation water use, Dickens and others (2011) published a report documenting methods used in the 2000 and 2005 compilations and Painter and others (2020) documented methods and inventoried irrigation information for the 2015 compilation. Areas with reported data may serve as sources of coefficients to estimate water use for crops or golf courses in nearby areas with no reported data. Irrigation estimation methods sometimes included adjustments for climate, system efficiencies, and conveyance losses. The irrigation system type may be based on local information or on State information reported in census of agricultural reports.

For thermoelectric water use, information sources and estimation methods were tabulated for two elements (withdrawals and power generation) for $2000-15$ with sources and 
Table 3. Summary of primary source of data, by number of States, for the irrigation category for the 2000, 2005, 2010, and 2015 water-use compilations.

[USGS, U.S. Geological Survey; USDA, U.S. Department of Agriculture]

\begin{tabular}{|c|c|c|c|c|c|c|}
\hline \multirow{2}{*}{ Source } & \multicolumn{4}{|c|}{ Compilation year } & \multicolumn{2}{|c|}{ Same method from } \\
\hline & 2000 & 2005 & 2010 & 2015 & 2000-15 & $2005-15$ \\
\hline \multicolumn{7}{|c|}{ Crop irrigation withdrawals } \\
\hline Extension Service & 2 & 2 & 1 & 0 & 0 & 0 \\
\hline USGS estimates & 30 & 30 & 28 & 28 & 23 & 24 \\
\hline No crop irrigation & 1 & 1 & 1 & 1 & 0 & 0 \\
\hline \multicolumn{7}{|c|}{ Crop irrigated acres } \\
\hline State agency & 10 & 10 & 15 & 16 & 8 & 9 \\
\hline Extension Service & 6 & 5 & 3 & 2 & 1 & 1 \\
\hline USDA (State or Federal office) & 32 & 33 & 28 & 28 & 21 & 23 \\
\hline
\end{tabular}

Table 4. Summary of primary methods used by the U.S. Geological Survey, by number of States, for estimating crop irrigation withdrawals for the $2000,2005,2010$, and 2015 water-use compilations.

[ET, evapotranspiration; CU, consumptive use; SWB, soil water balance]

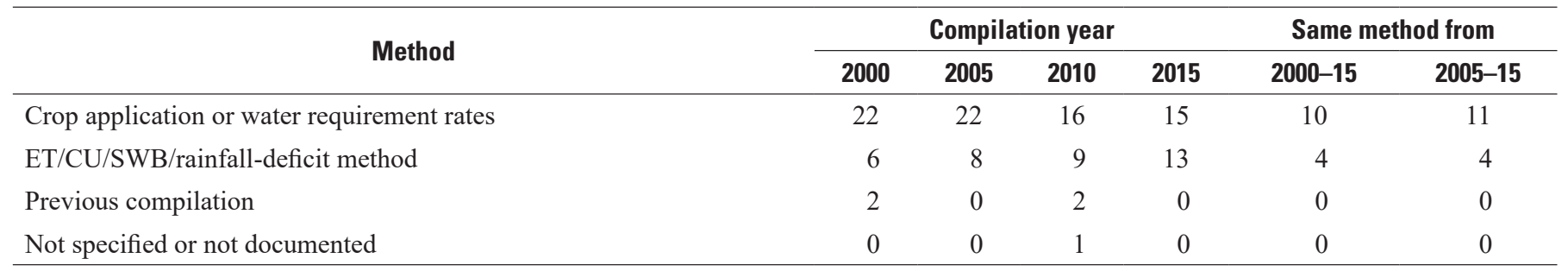

methods combined for once-through and closed-loop cooling system types (table 5). The primary sources for thermoelectric withdrawals were data from State agencies followed by NWUP EIA supplied data. The USGS NWUP provided the DOE-EIA water withdrawals, returns, consumptive use, and net electrical generation by thermoelectric plants to USGS personnel for use in compilations since 2000.

The DOE-EIA reporting requirements are based on power generation plant capacities. Plants with nameplate capacities, or maximum rated output, of 100 megawatts or more are required to report water withdrawals and consumptive use. Plants with nameplate capacities of 1 megawatt or more are required to report power generation amounts. The USGS NWUP provided model estimates for average daily water withdrawal and consumptive use for each U.S. thermoelectric plant with cooling system and generating capacities of 1 megawatt or more (Diehl and others, 2013; Diehl and Harris,
2014). These model estimates provide a source for withdrawal estimates for plants that are below the DOE-EIA reporting requirements. The primary source for power generation values were NWUP EIA for the compilations from 2005 through 2015 (table 5). Power generation was an optional data element for the 2000 compilation and was not summarized for this review. USGS personnel in 20 States used the same sources of thermoelectric withdrawal data for the 2005-15 compilations.

USGS personnel infrequently estimated the thermoelectric category elements because these data generally were reported to State or Federal agencies. When reported data were unavailable or incomplete, coefficients relating water use to power generation were developed and applied to estimate power generation from withdrawals (or to estimate withdrawals from power generation). Consumptive use, which was a mandatory thermoelectric category data element for the 1985 , 
1990, 1995, and 2015 compilations, was estimated from model results or rates based on available data or was determined for the fuel or cooling system types.

Overall public supply withdrawals are primarily based on reported data sources and these sources have been used consistently by most States in the past several compilations. Public supply populations served and irrigated crop acreage have more varied sources; however, the two sources used most frequently provide reported data. Public supply deliveries for domestic use and self-supplied domestic withdrawals have few States consistently using the same sources throughout the past several compilations. Crop irrigation withdrawals are frequently estimated, and estimates have consistently been based on crop water requirements throughout the past several compilations for some States. Thermoelectric withdrawals and power generation values are based primarily on reported data sources, but these sources have not been consistently used for the past several compilations. All these category elements are based generally on reported data; however, consistency of data sources is variable with time.

\section{Sources of Information and Methods Used to Estimate Water-Use Data by State}

Similarities and differences in water-use data sources and estimation methods among States can be used to help determine whether variability in water use is because of changes in water use, because of changes in methodology, or because of errors. A first step in this comparison is to identify where data have primarily been furnished and where data have primarily been estimated. Whether data are reported or estimated is an important factor affecting water-use data uncertainty. This evaluation investigated the primary sources of information; however, additional work would be needed to determine reporting percentages for secondary sources of information. Some documentation reports do not capture the total amount of reported versus estimated data for each category element. Therefore, for each State, the primary water-use data sources were classified into the following groups: (1) primarily reported, (2) primarily estimated, and (3) insufficiently documented. Reasons for classifying the data as insufficiently documented are unavailable or sparse documentation or difficulties with determining the primary sources and methods. These groupings may not adequately convey State reported data percentages because other data sources were not compiled. During the review process for each compilation, data values are reviewed; however, data quality would be difficult to determine and quantify where documentation is insufficient.

Table 5. Summary of primary source of data, by number of States, for the thermoelectric category for the 2000, 2005, 2010, and 2015 water-use compilations.

[USGS, U.S. Geological Survey; NWUP, National Water-Use Program; EIA, U.S. Energy Information Administration; --, not applicable]

\begin{tabular}{|c|c|c|c|c|c|c|}
\hline \multirow{2}{*}{ Source } & \multicolumn{4}{|c|}{ Compilation year } & \multicolumn{2}{|c|}{ Same method from } \\
\hline & 2000 & 2005 & 2010 & 2015 & $2000-15$ & $2005-15$ \\
\hline \multicolumn{7}{|c|}{ Thermoelectric withdrawals } \\
\hline USGS & 4 & 6 & 2 & 1 & 0 & 1 \\
\hline Facility & 11 & 9 & 6 & 7 & 4 & 5 \\
\hline State Agency & 25 & 22 & 23 & 20 & 10 & 12 \\
\hline NWUP, USGS & 0 & 0 & 8 & 5 & 0 & 0 \\
\hline NWUP, EIA & 3 & 9 & 12 & 17 & 0 & 2 \\
\hline EIA & 6 & 5 & 0 & 2 & 0 & 0 \\
\hline Unknown & 2 & 1 & 1 & 0 & 0 & 0 \\
\hline None & 1 & 0 & 0 & 0 & 0 & 0 \\
\hline \multicolumn{7}{|c|}{ Thermoelectric power generation } \\
\hline USGS & -- & 1 & 1 & 0 & 0 & 0 \\
\hline Facility & -- & 8 & 8 & 6 & 0 & 3 \\
\hline State agency & -- & 5 & 4 & 3 & 0 & 2 \\
\hline NWUP, EIA & -- & 19 & 32 & 38 & 0 & 16 \\
\hline EIA & -- & 12 & 6 & 5 & 0 & 4 \\
\hline Unknown & -- & 7 & 1 & 0 & 0 & 0 \\
\hline
\end{tabular}


Public supply withdrawals, population served, and deliveries for domestic use are presented in table 6. Public supply deliveries for domestic uses were not required for the 2000 compilation. The primary source of information for withdrawals and population served was furnished reported data, whereas public supply deliveries for domestic use were typically estimated. Based on primary data sources, public supply withdrawals were reported in about 82 to 94 percent of States with the percentage increasing from 2000 through 2010 and decreasing in the 2015 compilation. Public supply populations were reported in about 67 to 77 percent of States with percentages generally increasing from the 2000 through the 2015 compilations. Public supply deliveries had the highest reporting percentage of 33 percent in 2005; reporting percentages declined in 2010 and increased to about 27 percent for the 2015 compilation based on primary data sources. For public supply deliveries, the number of States with insufficient documentation declined from 2005 through 2015. These percentages would likely vary with additional analyses investigating secondary sources of information used by States to estimate public supply water use.

Crop irrigation withdrawals and irrigated acres for the 2000-15 compilation years are presented in table 7. Crop irrigation withdrawals are about evenly divided between States where reported data are available and States where withdrawals were estimated. On the other hand, irrigated acreages are reported in all but seven States. Based on primary data sources, irrigation withdrawals were reported in about 42 percent of States in 2000 and this reporting frequency increased to about 46 percent in the 2015 compilation. Irrigated acreages are more frequently reported with about 90 to 94 percent of States having a primary data source of reported acreage with reporting frequencies slightly lower in 2010 and 2015 than in 2000 and 2005.

Thermoelectric withdrawals and power generation for the once-through and closed-loop cooling system types for the 2000-15 compilations are presented in table 8 . Thermoelectric withdrawals and power generation are primarily reported. Based on primary data sources, thermoelectric withdrawals were reported in about 87 to 88 percent of States from 2005 through 2015, except for a lower reporting frequency of 79 percent in 2010. Based on primary data sources, thermoelectric power generation was reported data in about 85 percent of States in 2005, and this reporting frequency increased to 100 percent in the 2015 compilation.

\section{Characterization of Information Relevant to the Water-Use Data Elements for the 2015 Compilation}

Information that was used by USGS personnel to develop water use reported for the 2015 compilation was evaluated during this study. This information included (1) method code assignments; (2) whether data were reported or estimated; (3) the spatial scale of reporting or estimation of water-use data; (4) how the source of water, whether groundwater or surface water, was determined; (5) the primary year of source information; and (6) the primary year for coefficients used for estimation. Most of these evaluations were accomplished using method codes or available documentation. To limit the number of maps and to make the tables manageable, similar data elements were frequently combined for characterization. Maps were used to show data by county, and tables were used to summarize numbers of States.

\section{Water-Use Program Method Codes}

To provide users with more information about the data, USGS personnel developed and assigned method codes to each water-use data element for each county. The method codes helped to better describe provenance of the data used in the 2015 compilation. Codes were developed for the following: (1) class, which describes whether data elements were reported as areal aggregated or site specific values or as estimated values; (2) source, which identifies the entity providing furnished or estimated data; (3) type, which provides information about the source of data or estimation method; and (4) subtype, which provides additional information about reported data or when estimates were based on coefficients (table 9). For each mandatory data element, multiple method codes were allowed and were listed in order of relevancy.

As part of this study, water-use method codes were summarized for selected 2015 categories (table 10). For these summaries, method codes reported for mandatory category elements were combined. Only 46 method code combinations (out of slightly more than 300 allowable combinations of the 4-letter code) were used to describe data reporting and estimation methods for these categories. The public supply category had the most unique code combinations. The method code representing site-specific data from a State agency that are not readily available for public use, SSDU, is one of the top three codes used most frequently for all categories except crop irrigation. The method code representing site-specific data that are publicly available from Federal agencies, SFBU, is the most frequently used code for both thermoelectric categories. Coefficients for consumptive use rates are used most consistently for the crop and golf course categories. For the total irrigation category, USGS personnel used modeling methods, EGMM, most often. The most frequently used method codes starting with $\mathrm{E}$ are all followed by a $\mathrm{G}$ as the second letter indicating that USGS personnel estimated the data. Finally, frequently used method codes starting with S (for site-specific reported data) are followed by an S representing a State agency or an F representing a Federal agency.

Method codes address estimation methods and sources of data that were used to estimate water-use data elements, such as population, irrigated acres, and power generated. Data source, whether reported or estimated, is an important 
Table 6. Primary sources of information for the public supply withdrawal, population served, and deliveries for domestic use data elements by State, grouped into three categories for the 2000, 2005, 2010, and 2015 compilations.

[No shading indicates not mandatory for 2000; light-gray shading indicates primarily reported; medium-gray shading indicates primarily estimated; dark-gray shading indicates insufficiently documented]

\begin{tabular}{|c|c|c|c|c|c|c|c|c|c|c|c|c|}
\hline \multirow{2}{*}{ State } & \multicolumn{4}{|c|}{ Withdrawals } & \multicolumn{4}{|c|}{ Population served } & \multicolumn{4}{|c|}{$\begin{array}{l}\text { Public supply deliveries for domes- } \\
\text { tic uses }\end{array}$} \\
\hline & 2000 & 2005 & 2010 & 2015 & 2000 & 2005 & 2010 & 2015 & 2000 & 2005 & 2010 & 2015 \\
\hline \multicolumn{13}{|l|}{ Alabama } \\
\hline \multicolumn{13}{|l|}{ Alaska } \\
\hline \multicolumn{13}{|l|}{ Arizona } \\
\hline \multicolumn{13}{|l|}{ Arkansas } \\
\hline \multicolumn{13}{|l|}{ California } \\
\hline \multicolumn{13}{|l|}{ Colorado } \\
\hline \multicolumn{13}{|l|}{ Connecticut } \\
\hline \multicolumn{13}{|l|}{ Delaware } \\
\hline \multicolumn{13}{|l|}{ Florida } \\
\hline \multicolumn{13}{|l|}{ Georgia } \\
\hline \multicolumn{13}{|l|}{ Hawaii } \\
\hline \multicolumn{13}{|l|}{ Idaho } \\
\hline \multicolumn{13}{|l|}{ Illinois } \\
\hline \multicolumn{13}{|l|}{ Indiana } \\
\hline \multicolumn{13}{|l|}{ Iowa } \\
\hline \multicolumn{13}{|l|}{ Kansas } \\
\hline \multicolumn{13}{|l|}{ Kentucky } \\
\hline \multicolumn{13}{|l|}{ Louisiana } \\
\hline Maine & & & & & & & & & & & & \\
\hline Maryland & & & & & & & & & & & & \\
\hline Massachusetts & & & & & & & & & & & & \\
\hline Michigan & & & & & & & & & & & & \\
\hline Minnesota & & & & & & & & & & & & \\
\hline Mississippi & & & & & & & & & & & & \\
\hline Missouri & & & & & & & & & & & & \\
\hline Montana & & & & & & & & & & & & \\
\hline Nebraska & & & & & & & & & & & & \\
\hline Nevada & & & & & & & & & & & & \\
\hline New Hampshire & & & & & & & & & & & & \\
\hline New Jersey & & & & & & & & & & & & \\
\hline New Mexico & & & & & & & & & & & & \\
\hline New York & & & & & & & & & & & & \\
\hline North Carolina & & & & & & & & & & & & \\
\hline North Dakota & & & & & & & & & & & & \\
\hline Ohio & & & & & & & & & & & & \\
\hline Oklahoma & & & & & & & & & & & & \\
\hline Oregon & & & & & & & & & & & & \\
\hline Pennsylvania & & & & & & & & & & & & \\
\hline Rhode Island & & & & & & & & & & & & \\
\hline South Carolina & & & & & & & & & & & & \\
\hline
\end{tabular}


Table 6. Primary sources of information for the public supply withdrawal, population served, and deliveries for domestic use data elements by State, grouped into three categories for the 2000, 2005, 2010, and 2015 compilations. - Continued

[No shading indicates not mandatory for 2000; light-gray shading indicates primarily reported; medium-gray shading indicates primarily estimated; dark-gray shading indicates insufficiently documented]

\begin{tabular}{|c|c|c|c|c|c|c|c|c|c|c|c|c|}
\hline \multirow[t]{2}{*}{ State } & \multicolumn{4}{|c|}{ Withdrawals } & \multicolumn{4}{|c|}{ Population served } & \multicolumn{4}{|c|}{$\begin{array}{l}\text { Public supply deliveries for domes- } \\
\text { tic uses }\end{array}$} \\
\hline & 2000 & 2005 & 2010 & 2015 & 2000 & 2005 & 2010 & 2015 & 2000 & 2005 & 2010 & 2015 \\
\hline \multicolumn{13}{|l|}{ South Dakota } \\
\hline \multicolumn{13}{|l|}{ Tennessee } \\
\hline \multicolumn{13}{|l|}{ Texas } \\
\hline \multicolumn{13}{|l|}{ Utah } \\
\hline \multicolumn{13}{|l|}{ Vermont } \\
\hline \multicolumn{13}{|l|}{ Virginia } \\
\hline \multicolumn{13}{|l|}{ Washington } \\
\hline \multicolumn{13}{|l|}{ West Virginia } \\
\hline \multicolumn{13}{|l|}{ Wisconsin } \\
\hline \multicolumn{13}{|l|}{ Wyoming } \\
\hline \multicolumn{13}{|l|}{ Puerto Rico } \\
\hline U.S. Virgin Islands & & & & & & & & & & & & \\
\hline
\end{tabular}

factor affecting data uncertainty. Water-use data for public supply and thermoelectric are based on reported data sources for most States, whereas irrigation water use is frequently estimated. This information provides an important indicator of data quality; however, method codes do not address withdrawal accuracy and more information is needed to adequately quantify uncertainty. For example, an indication of the percentage of the data that are covered by each method code would enable determinations of whether most data have been reported or estimated. Reported data for a category and county may account for 60 percent of the facilities, and these facilities may represent 90 percent of the total withdrawal amounts. In evaluating data coverage and quality within a category, the water-use volumes are important to consider in addition to the number of facilities. Similarly, additional information about how water withdrawal volumes are determined by the reporting entity is needed to quantify uncertainty.

\section{Reported and Estimated Water-Use Data}

The 2015 water-use method codes were used during this study to identify where data were reported or were estimated by county, which is an important factor in describing data uncertainty. With the addition of method codes, data reporting or estimation can be investigated at the county scale and used to determine where methods have been consistent or inconsistently used. In addition, the 2015 method codes specified the spatial scale by which the data were furnished, whether by site (S) or as an areal aggregate (A); spatial scale is not indicated by the method codes when data were estimated (E). Areal aggregated data were generally provided by county, but may be provided for State or other regional, multicounty areas.

The first letter of the method code or codes as reported in the 2015 compilation by county for specified water-use categories is shown in figures $1-5,6 A-B$, and $7 A-B$. In some counties, two method codes were applied to each county in these figures. For example, a county with a method code indicating data provided as site-specific data followed by a code or codes indicating data were estimated would be coded as $\mathrm{S}$, E. In this example, although county data may be available for the larger public suppliers, data may need to be estimated for smaller systems. Likewise, a county with a code indicating data were provided as an areal aggregate followed by two codes also indicating that estimated data pertain to the value would be coded as A, E. When one or more codes start with the same letter, the county is coded with the letter of the first code. For simplicity, method codes representing withdrawals from fresh groundwater sources are shown in figures 1,4 , and $6 A-B$. In most cases, coding was similar between groundwater and surface-water sources. For irrigated acres, only coding for the sprinkler irrigation type is shown because this is the primary method used in the United States in 2015.

The first letter of the method codes that apply to public supply groundwater withdrawals is shown in figure 1. Reported site-specific data are available as the primary source of data for most States throughout the United States (light and dark green); with most of these States relying solely on reported data (dark green). For a few States, USGS personnel relied on an estimation method for this data element (red and maroon). Indiana is the only State with the primary source 
Table 7. Classification of the primary sources of information for the crop irrigation withdrawals and irrigated acre data elements by State, for the $2000,2005,2010$, and 2015 compilations.

[No shading indicates no data estimated; light-gray shading indicates primarily reported; medium-gray shading indicates primarily estimated; dark-gray shading indicates insufficiently documented]




Table 7. Classification of the primary sources of information for the crop irrigation withdrawals and irrigated acre data elements by State, for the 2000, 2005, 2010, and 2015 compilations. - Continued

[No shading indicates no data estimated; light-gray shading indicates primarily reported; medium-gray shading indicates primarily estimated; dark-gray shading indicates insufficiently documented]

\begin{tabular}{|c|c|c|c|c|c|c|c|c|}
\hline \multirow{2}{*}{ State } & \multicolumn{4}{|c|}{ Withdrawals } & \multicolumn{3}{|c|}{ Irrigated acres } & \multirow[b]{2}{*}{2015} \\
\hline & 2000 & 2005 & 2010 & 2015 & 2000 & 2005 & 2010 & \\
\hline \multicolumn{9}{|l|}{ South Dakota } \\
\hline \multicolumn{9}{|l|}{ Tennessee } \\
\hline \multicolumn{9}{|l|}{ Texas } \\
\hline \multicolumn{9}{|l|}{ Utah } \\
\hline \multicolumn{9}{|l|}{ Vermont } \\
\hline \multicolumn{9}{|l|}{ Virginia } \\
\hline \multicolumn{9}{|l|}{ Washington } \\
\hline \multicolumn{9}{|l|}{ West Virginia } \\
\hline \multicolumn{9}{|l|}{ Wisconsin } \\
\hline \multicolumn{9}{|l|}{ Wyoming } \\
\hline \multicolumn{9}{|l|}{ Puerto Rico } \\
\hline U.S. Virgin Islands & & & & & & & & \\
\hline
\end{tabular}

being areal aggregated data from the State agency. For the four States where USGS personnel indicated estimation as the primary method, some site-specific furnished data also were available to supplement or be used as a basis for these estimates (fig. 1).

The first letter of the method codes for the public supply population served data element is shown in figure 2. Figure 2 reflects data where States reported total population served or reported population served by groundwater sources (see table 1.1 for State level listing of public supply population served reporting decisions). For a few States, USGS personnel based the population served values on areal aggregated data (1 State) or on estimates (11 States), whereas personnel in most States relied on some reported data as the primary method (fig. 2).

The first letter of the method codes for the public supply domestic delivery data element is shown in figure 3. For most States, USGS personnel primarily used estimated values for domestic deliveries; however, for eight States, USGS personnel also used site-specific reported data. Texas is the only State where USGS personnel used furnished aggregated domestic delivery data from a State agency. For a few States, USGS personnel relied primarily on site-specific furnished data for domestic delivery (five States) with some data also being estimated (seven States) (fig. 3).

The first letter of the method codes for the irrigation groundwater withdrawal data element is shown in figure 4. These codes reflect methods for either the total irrigation category or for only crop irrigation for those States that reported crop and golf course uses separately (see table 1.1 for State level listing of irrigation category reporting decisions). Furnished aggregated irrigation withdrawal data are available from some State or Federal agencies (four States).

For the rest of the United States, USGS personnel either received furnished site-specific data or relied on estimation methods to determine withdrawals. For most States that had furnished data, USGS personnel also used some estimation to supplement water-use values. Likewise, for most States that USGS personnel relied on estimation methods, some reported irrigation withdrawal data also were available (fig. 4).

The first letter of the method codes for irrigated acres using sprinklers for either the total irrigation or crop irrigation categories is shown in figure 5. For the sprinkler data element, which includes irrigated acreage, only 10 States have reporting programs that include site-specific irrigated system type acreage information; therefore, for most States, USGS personnel used areal aggregated data reported primarily in Census of Agriculture reports or estimated this information. For many States, estimation was used along with reported data sources.

The first letter of the method codes for thermoelectric groundwater withdrawals is shown in figures $6 A-B$. For most States, for once-through and closed-loop cooling system plants, USGS personnel relied on furnished sitespecific data for withdrawals and for only a few States, relied on estimation methods. Many States have sources of reported data; however, in some States, USGS personnel also needed to supplement the reported data with estimated data for this category data element. For only a few States (for example, California and Tennessee), USGS personnel used estimation as the primary source of thermoelectric withdrawal data (fig. $6 A-B$ ), and most of these estimates are derived from the USGS thermoelectric model (Diehl and Harris, 2014). 
Table 8. Classification of the primary sources of information for the thermoelectric withdrawals and power generation data elements by State, for the $2000,2005,2010$, and 2015 compilations.

[No shading indicates optional data element in 2000 compilation; light-gray shading indicates primarily reported; medium-gray shading indicates primarily estimated; dark-gray shading indicates insufficiently documented]

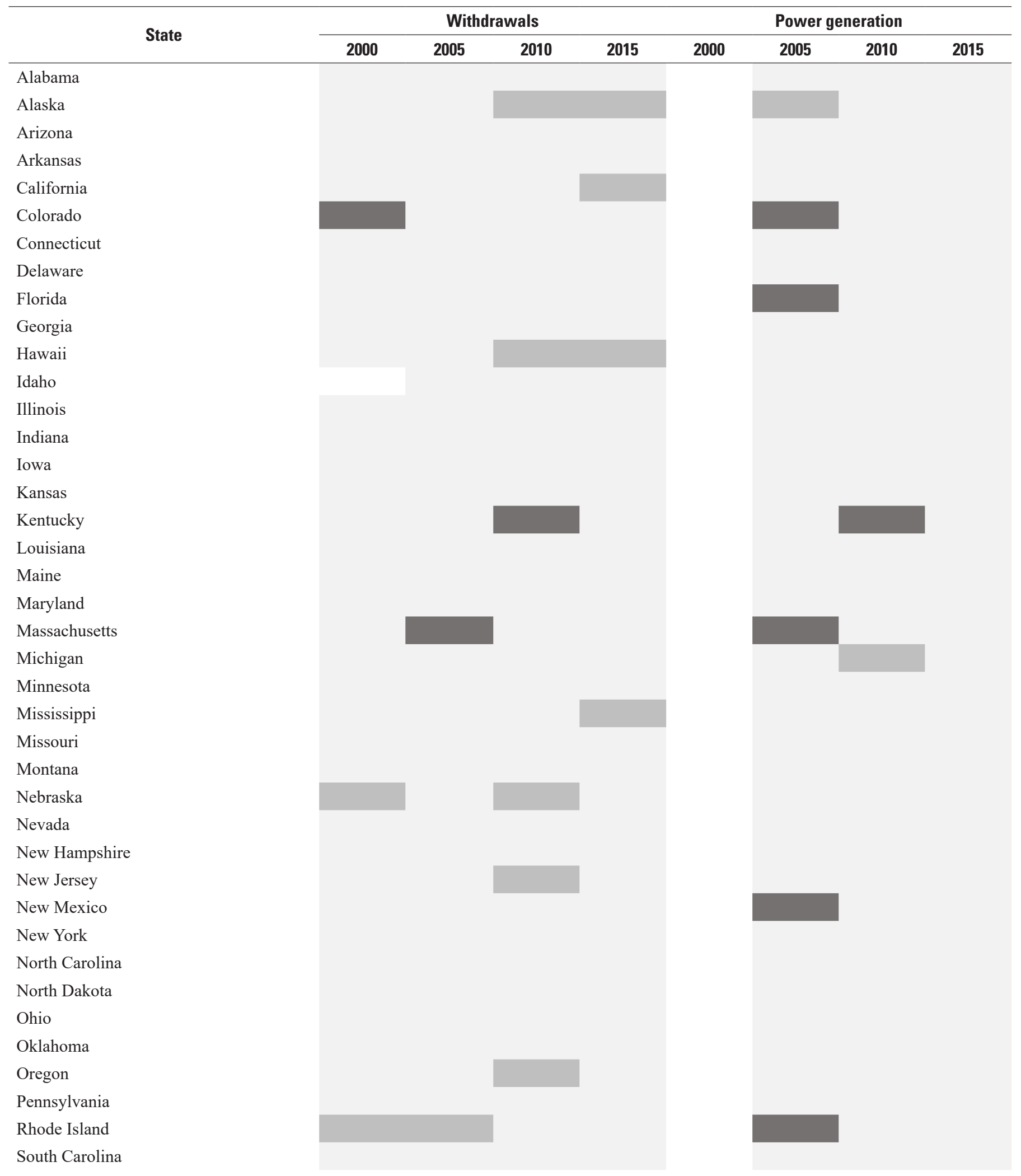


Table 8. Classification of the primary sources of information for the thermoelectric withdrawals and power generation data elements by State, for the 2000, 2005, 2010, and 2015 compilations.-Continued

[No shading indicates optional data element in 2000 compilation; light-gray shading indicates primarily reported; medium-gray shading indicates primarily estimated; dark-gray shading indicates insufficiently documented]

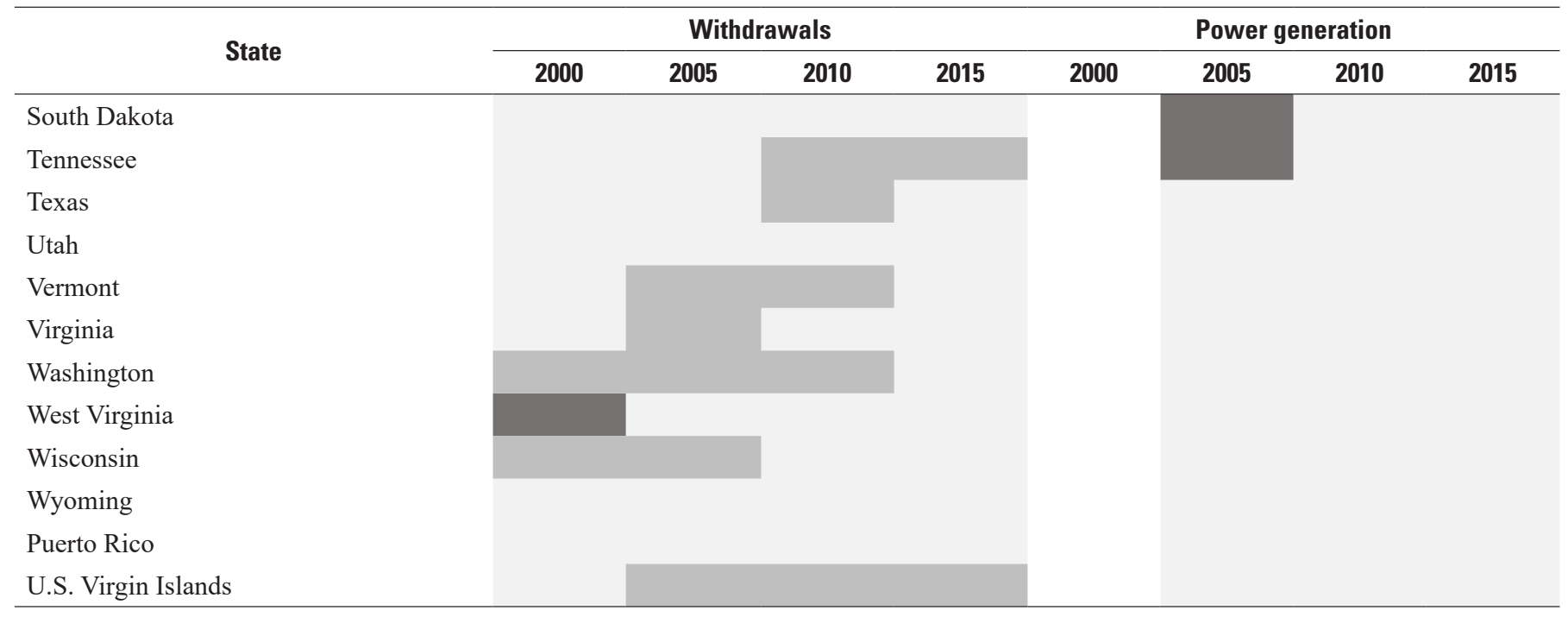

The first letter of the method codes for the thermoelectric power generation data element is shown in figures $7 A-B$. For only a few States for both cooling system types, USGS personnel relied on estimation methods to determine power generation amounts. For most States, USGS personnel relied solely on reported site-specific data for this data element and needed to use some estimation to supplement the reported data values in only a few States (fig. $7 A-B$ ). USGS personnel estimated power generation using production coefficients in West Virginia and using the thermoelectric model (Diehl and Harris, 2014) in Hawaii.

\section{Spatial Scale of Reported or Estimated Water-Use Data}

Water-use data may be provided or estimated at different spatial scales. Spatial scale is another factor potentially affecting data uncertainty because of the amount of extra processing that may be required for areal aggregated data. Areal aggregated data may need to be disaggregated to enable reporting at the county scale in the compilation. Areal aggregated values may encompass all counties in a State and not reflect local differences. The spatial scale of the furnished or estimated data was evaluated using the 2015 water-use program method codes and documentation. For the purposes of this report when describing spatial reporting scales, the following definitions apply: facility is meant to include site-specific data reported or estimated by site, by facility, and by well or intake; county is meant to include State subdivisions; region is meant to include an area encompassing multiple counties; and State is meant to indicate a value or rate that is the same for all parts of the
State. For some categories in 2015, such as public supply, golf course irrigation, and thermoelectric, withdrawal data are most commonly site specific, whereas data reporting for crop irrigation are more commonly available at the county level (table 11). Irrigation type and consumptive use for crop and golf course irrigation were often determined using the same percentages for each county or for the whole State.

\section{Apportionment of Source of Water Between Groundwater and Surface Water}

For most States, reported information from agencies for public supply and thermoelectric use includes the source of water (groundwater or surface water) (table 12). Self-supplied domestic withdrawals generally are assumed to be from groundwater. The source of water also is often reported for crop and golf course irrigation. Where the source of water is not reported, the same percentage of groundwater to surface water from previous compilations for crop irrigation may be carried forward to the next compilation summary. Some USGS personnel will contact local agencies to verify these percentages or make updates where needed. Other sources may be used, such as local reports, field verification, water rights or surface-water diversion analysis, or the percentages from another category with reported data. In a few cases for these categories, not enough information was available to determine how the source of water was determined. 
Table 9. Table of method codes that provide information on the class, source, and types of data.

[NGO, nongovernmental organization]

\begin{tabular}{|c|c|c|}
\hline Code & Short name & Definition \\
\hline \multicolumn{3}{|r|}{ Class } \\
\hline $\mathrm{S}$ & Reported site-specific & Value was reported at the source/facility/user level. \\
\hline $\mathrm{E}$ & Estimated & Value was estimated, generally by the U.S. Geological Survey. \\
\hline $\mathrm{N}$ & Unknown & Value was derived with unknown methods (historical values only). \\
\hline G & U.S. Geological Survey & U.S. Geological Survey. \\
\hline $\mathrm{F}$ & Federal agency & From another Federal agency (not the U.S. Geological Survey). \\
\hline $\mathrm{S}$ & State agency & From a State agency. \\
\hline $\mathrm{U}$ & Water user & From a water user directly. \\
\hline $\mathrm{L}$ & Other government agency & From another governmental agency. \\
\hline $\mathrm{C}$ & Coefficient & Value was estimated using coefficients. \\
\hline $\mathrm{T}$ & Capacity or flow rate & Value was estimated from plant or pump capacity, flow or discharge rate. \\
\hline M & Model & Value was estimated using a model. \\
\hline $\mathrm{P}$ & Permit & Value was a permitted use or water right allowed use. \\
\hline G & Geospatial analysis & Value was derived using geospatial analysis. \\
\hline A & Disaggregated & Value was derived from a different set of aggregated values. \\
\hline $\mathrm{B}$ & Publicly available resource & Published in a report, website, or made available online to the public as a dataset. \\
\hline $\mathrm{D}$ & Restricted-access dataset & Dataset/database that is not readily available to the public or at all. \\
\hline M & Modified & Reported value was modified by U.S. Geological Survey from the provided values. \\
\hline $\mathrm{C}$ & Per capita rate & Per capita use coefficient, includes human and animal. \\
\hline A & Application rate & Application rate coefficient. \\
\hline $\mathrm{P}$ & Power consumption rate & Power consumption coefficient. \\
\hline $\mathrm{D}$ & Production rate & Coefficient per unit of product. \\
\hline $\mathrm{V}$ & Consumptive use rate & Consumptive use coefficient. \\
\hline $\mathrm{F}$ & Facility characteristic & $\begin{array}{l}\text { Coefficient for some characteristic of the water-use facility (for example, pond acreage, number } \\
\text { of tanks, and count of employees). }\end{array}$ \\
\hline Z & Not applicable & Subtype is not applicable because the class is unknown. \\
\hline
\end{tabular}


Table 10. Summary of the most frequently used 2015 method codes by category.

\begin{tabular}{|c|c|c|c|c|c|c|c|}
\hline \multirow[b]{2}{*}{ Category } & \multirow{2}{*}{$\begin{array}{l}\text { Number of unique } \\
\text { code combina- } \\
\text { tions used }\end{array}$} & \multicolumn{6}{|c|}{ Codes most frequently used } \\
\hline & & Code & $\begin{array}{c}\text { Number of } \\
\text { States }\end{array}$ & Code & $\begin{array}{c}\text { Number of } \\
\text { States }\end{array}$ & Code & $\begin{array}{c}\text { Number of } \\
\text { States }\end{array}$ \\
\hline Total irrigation & 26 & EGMM & 8 & SSDU & 7 & EGCA & 7 \\
\hline Crop irrigation & 36 & EGCV & 25 & AFBU & 19 & EGHU & 17 \\
\hline Thermoelectric_closed loop & 26 & SFBU & 47 & EGMU & 25 & SSDU & 20 \\
\hline
\end{tabular}

\section{Date of Source Information}

Water-use data may be reported or estimated for the current compilation year or may rely primarily on previous compilations or other sources before the compilation year. Source-year data used for the 2015 compilation were evaluated using available documentation. This information is not captured in the method coding but is important to understand to interpret and quantify data quality. Data that are not current for the compilation year may not adequately represent wateruse rates or trends.

Public supply withdrawals and populations served for 2015 were primarily based on 2015 information (fig. 8). When 2015 data were unavailable, sources included data from previous compilations or from published information from prior years. Crop irrigation withdrawals, consumptive use, irrigated acres, and irrigation type data elements are primarily based on source data from 2010 through 2015 (fig. 8). Other sources for withdrawals, irrigation type, and irrigated acres included information from previous compilations or were based on USDA reports that are not concurrent with compilation years. Source years for consumptive use were often not specified. Golf course irrigated acres sometimes were based on previous compilations. Thermoelectric withdrawal, consumptive use, and power generation data elements for the 2015 compilation most often were based on 2015 data (fig. 8). Thermoelectric withdrawals sometimes were based on information in published reports or from previous compilations.

\section{Coefficients Used for Water-Use Data Estimation}

Coefficients provide a means to estimate water use when reported data are not available and are used most frequently for public supply deliveries for domestic use and self-supplied domestic withdrawals (fig. 9). How coefficients are selected or calculated affect data quality and uncertainty. In some areas, the only available source of coefficients may be outdated or not directly related to the geographic area being considered. Typically for public supply, total withdrawals are reported or estimated. From this total, the deliveries for domestic use are estimated using a coefficient for the percentage of total withdrawals delivered for domestic use or based on per capita use rate for the number of people served by each public water system. The self-supplied domestic population is typically multiplied by a per capita use rate coefficient to determine withdrawal amounts. Many States use reported data to determine the coefficients that are needed to estimate data based on the assumption that self-supplied and publicly supplied per capita rates in an area are the same.

Public supply deliveries for domestic use are evaluated for the 3 most recent compilation years and self-supplied domestic withdrawals for 4 years (fig. 9). Coefficients for public supply deliveries for domestic use generally were calculated using reported data from each compilation year; however, a few States relied on the same source for all three compilations. The number of years that were used to determine coefficients for self-supplied domestic withdrawals were based on a much larger range in years throughout the compilations from 2000 through 2015. Data quality and uncertainty may be adversely affected with compilation data being estimated using coefficients based on noncurrent year information. Per capita water usage varies with time in response to many factors, such as water efficient appliances and fixtures, local conservation measures, and climate, so using data from earlier years may introduce error into the estimated values. 


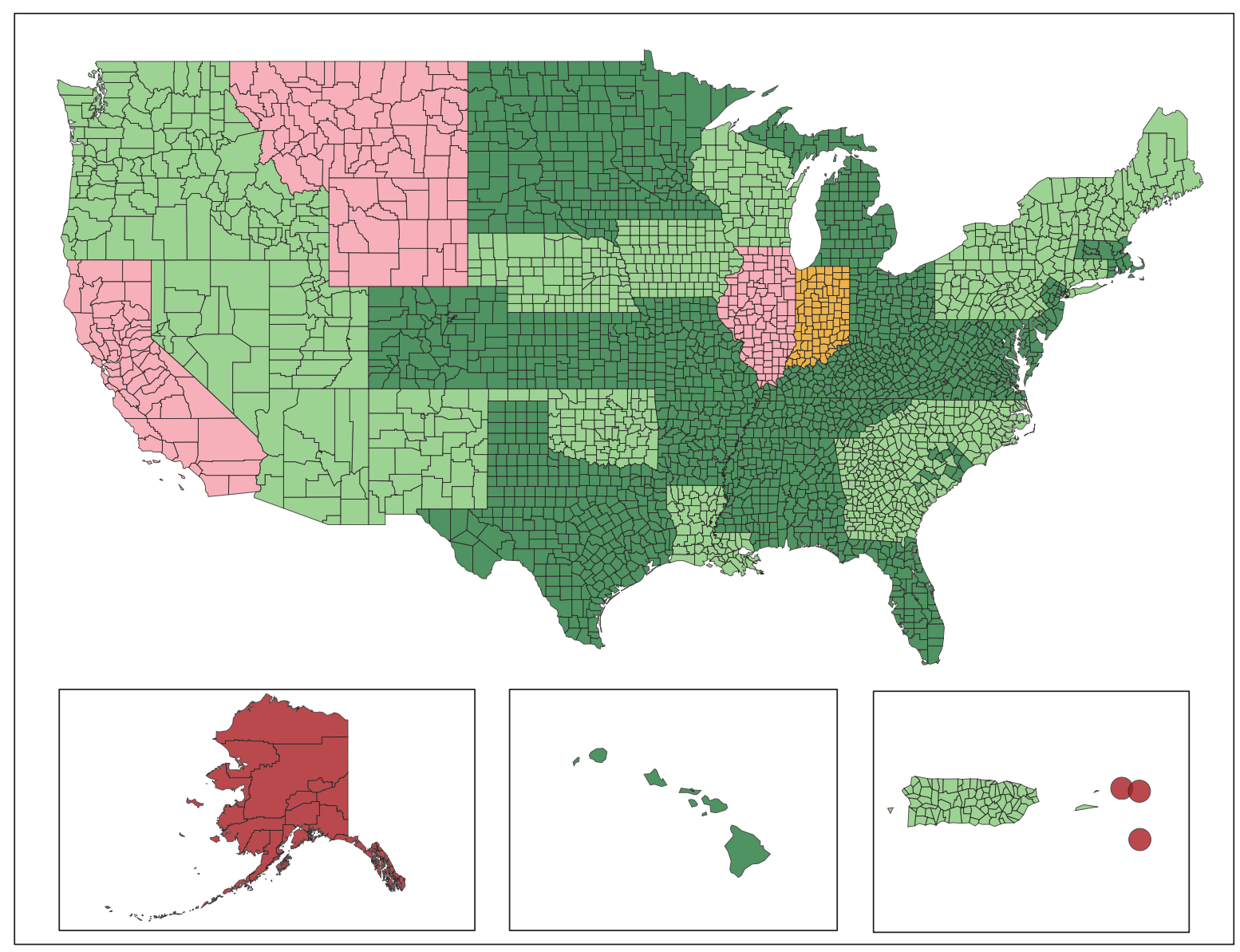

\section{EXPLANATION}

[Noncontiguous U.S. States and territories not to scale]

Areal aggregated data (method code A)

Estimated data (method code E)

Estimated, site-specific data (method codes E, S)

Site-specific data (method code S

Site-specific, estimated data (method codes S, E)

Figure 1. Map showing public supply groundwater withdrawal method codes, by county, for the 2015 compilation indicating whether values are site-specific, areal aggregated, estimated, or a combination. 


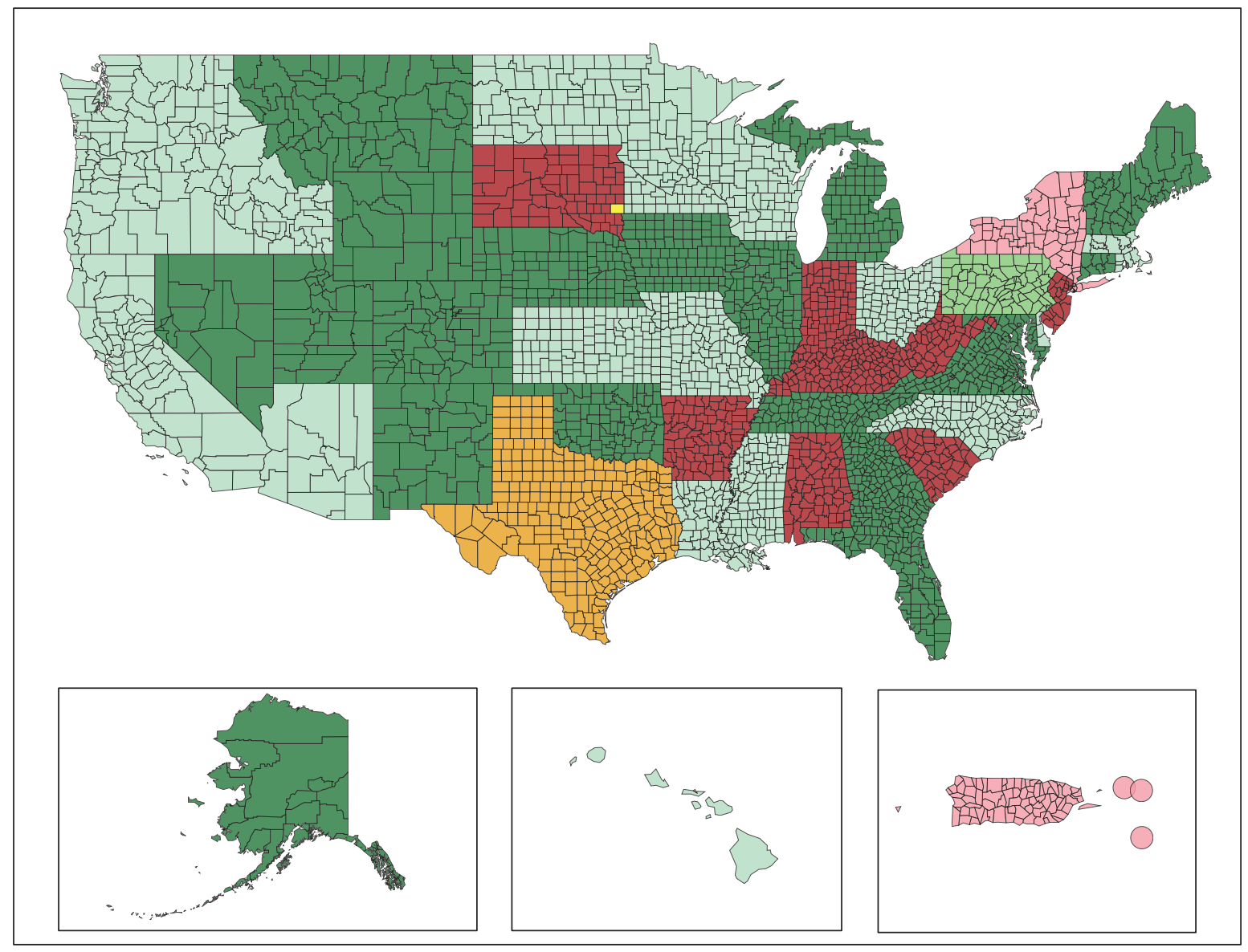

EXPLANATION

[Noncontiguous U.S. States and territories not to scale]

Areal aggregated data (method code A)

Areal aggregated, site-specific data

(method codes A, S)

Estimated data (method code E)

Estimated, site-specific data (method codes E, S)

Site-specific data (method code S)

Site-specific, areal aggregated, estimated data (method codes S, A, E)

Site-specific, estimated data (method codes S, E)

Map data @ OpenStreetMap contributors, available under the Open Database License (http://www.openstreetmap.org/copyright)

Figure 2. Map showing public supply population served method codes, by county, for the 2015 compilation indicating whether values are site-specific, areal aggregated, estimated, or a combination. 




\section{EXPLANATION}

[Noncontiguous U.S. States and territories not to scale]

Areal aggregated data (method code A)

Estimated data (method code E)

Estimated, areal aggregated data (method $\left.\operatorname{codes} \mathrm{E}_{1} \mathrm{~A}\right)$

Estimated, site-specific data (method codes E, S)

Site-specific data (method code S)

Site-specific, estimated data (method codes S, E)

Figure 3. Map showing public supply domestic delivery method codes, by county, for the 2015 compilation indicating whether values are site-specific, areal aggregated, estimated, or a combination. 


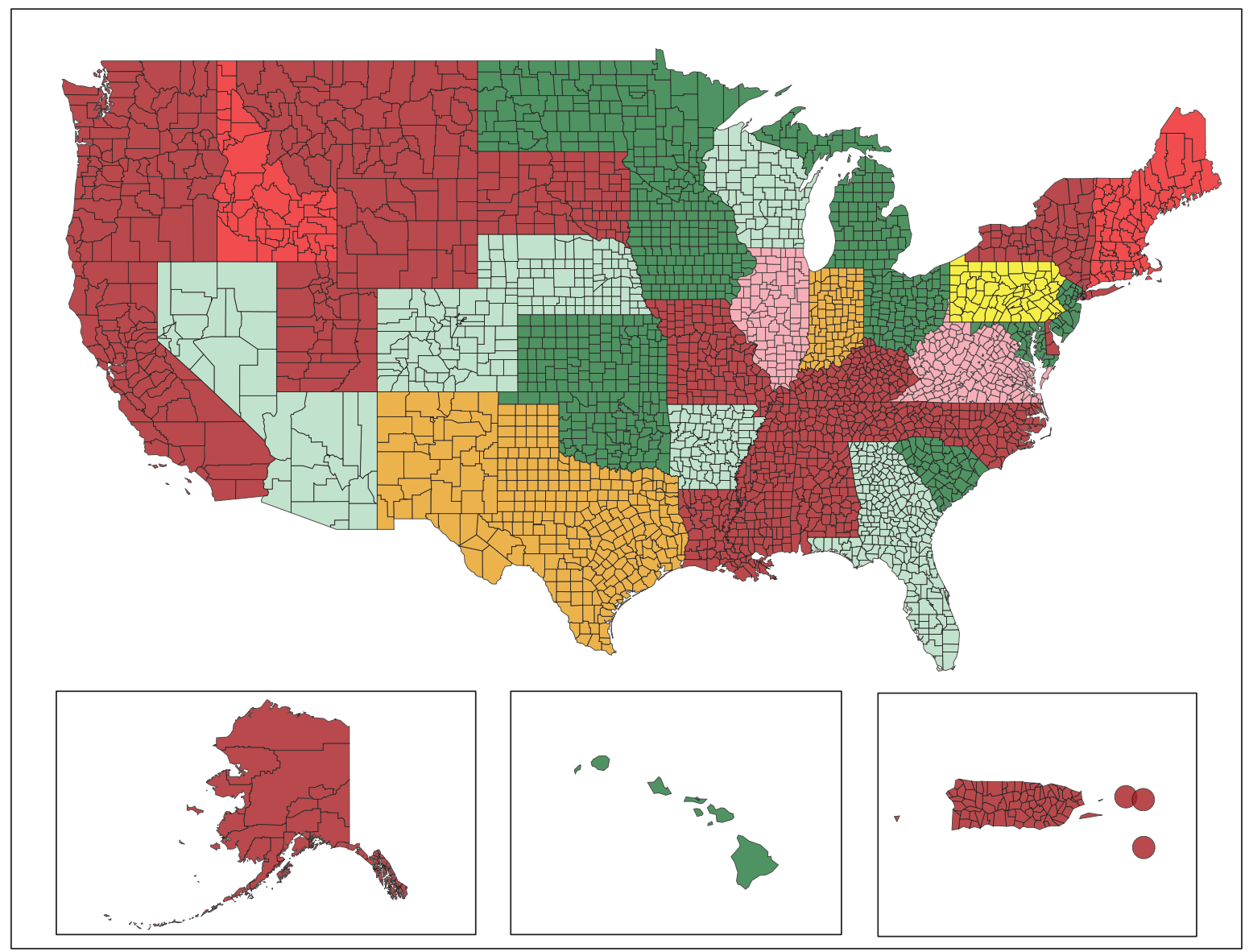

EXPLANATION

[Noncontiguous U.S. States and territories not to scale]

Areal aggregated data (method code A)

Areal aggregated, estimated data (method $\operatorname{codes} A, E)$

Estimated data (method code E)

Estimated, areal aggregated data (method $\operatorname{codes} E, A)$

Estimated, site-specific data (method codes E, S)

Site-specific data (method code S)

Site-specific, estimated data (method codes S, E)

Map data @ OpenStreetMap contributors, available under the Open Database License (http://www.openstreetmap.org/copyright)

Figure 4. Map showing irrigation groundwater withdrawal method codes, by county, for the 2015 compilation indicating whether values are site-specific, areal aggregated, estimated, or a combination. 




\section{EXPLANATION}

[Noncontiguous U.S. States and territories not to scale]

Areal aggregated data (method code A)

Areal aggregated, estimated data (method codes A, E)

Estimated data (method code E)

Estimated, site-specific data (method codes E, S)

Site-specific data (method code S)

Site-specific, areal aggregated data

(method codes S, A)

Site-specific, areal aggregated, estimated data (method codes S, A, E)

Site-specific, estimated data (method codes S, E)

Map data (c) OpenStreetMap contributors, available under the Open Database License (http://www.openstreetmap.org/copyright)

Figure 5. Map showing irrigated acres by sprinkler method codes, by county, for the 2015 compilation indicating whether values are site-specific, areal aggregated, estimated, or a combination. 


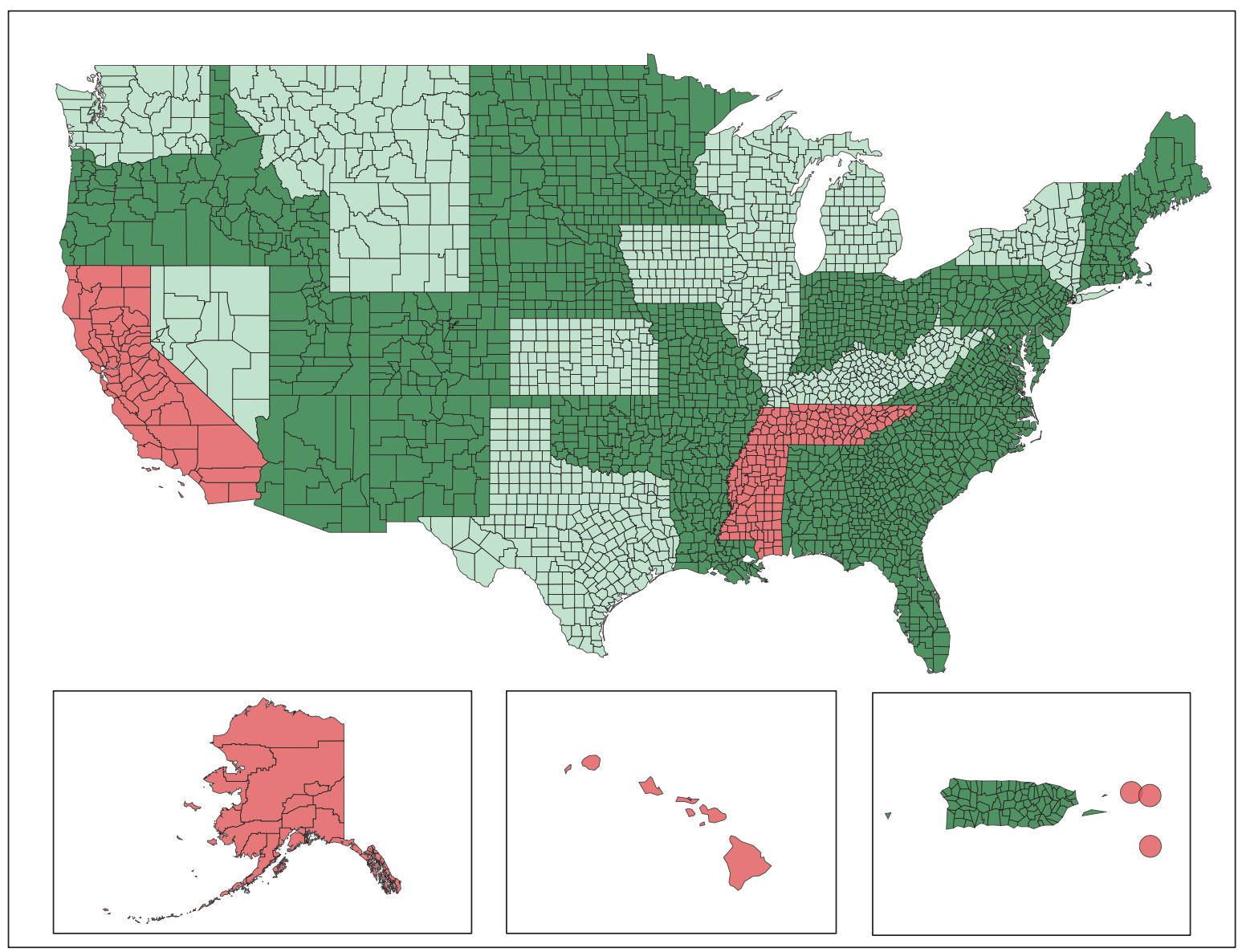

\section{EXPLANATION}

[Noncontiguous U.S. States and territories not to scale]

Estimated data (method code $\mathrm{E}$

Site-specific data (method code S)

Site-specific, estimated data (method codes S, E)

Map data @ OpenStreetMap contributors, available under the Open Database License (http://www.openstreetmap.org/copyright)

Figure 6. Map showing thermoelectric groundwater withdrawal method codes, by county, for the 2015 compilation indicating whether values are site-specific, estimated, or a combination. $A$, once-through cooling system and $B$, closed-loop cooling system. 


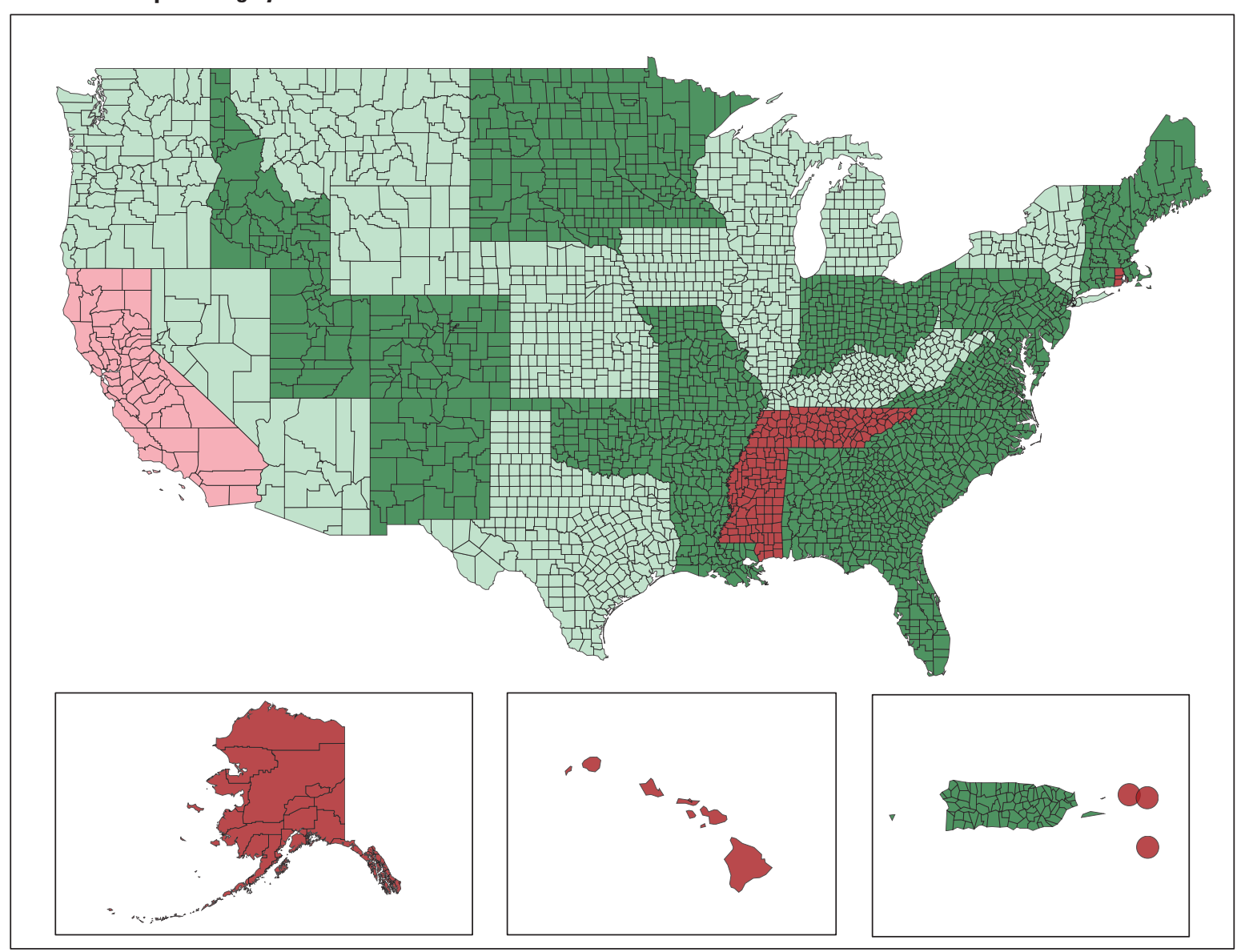

\section{EXPLANATION}

[Noncontiguous U.S. States and territories not to scale]

Estimated data (method code E)

Estimated, site-specific data (method codes E, S)

Site-specific data (method code S)

Site-specific, estimated data (method codes S, E)

Figure 6. Map showing thermoelectric groundwater withdrawal method codes, by county, for the 2015 compilation indicating whether values are site-specific, estimated, or a combination. $A$, once-through cooling system and $B$, closed-loop cooling system.-Continued 


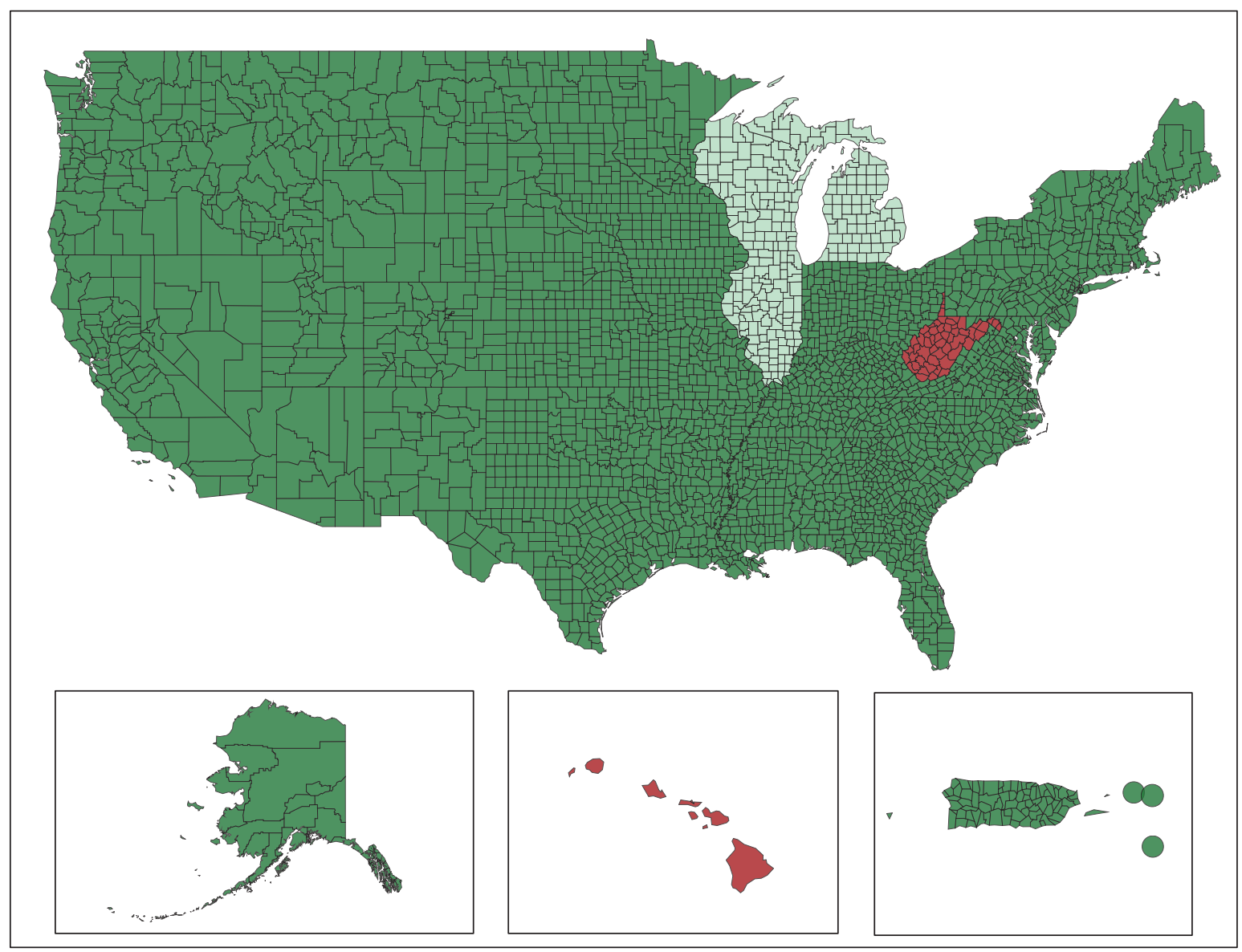

\section{EXPLANATION}

[Noncontiguous U.S. States and territories not to scale]

\section{Estimated data (method code E)}

Site-specific data (method code S)

Site-specific, estimated data (method codes S, E)

Map data () OpenStreetMap contributors, available under the Open Database License (http://www.openstreetmap.org/copyright)

Figure 7. Map showing thermoelectric power generation method codes, by county, for the 2015 compilation indicating whether values are site-specific, estimated, or a combination. $A$, once-through cooling system and $B$, closed-loop cooling system. 


\section{B. Closed-loop cooling system}

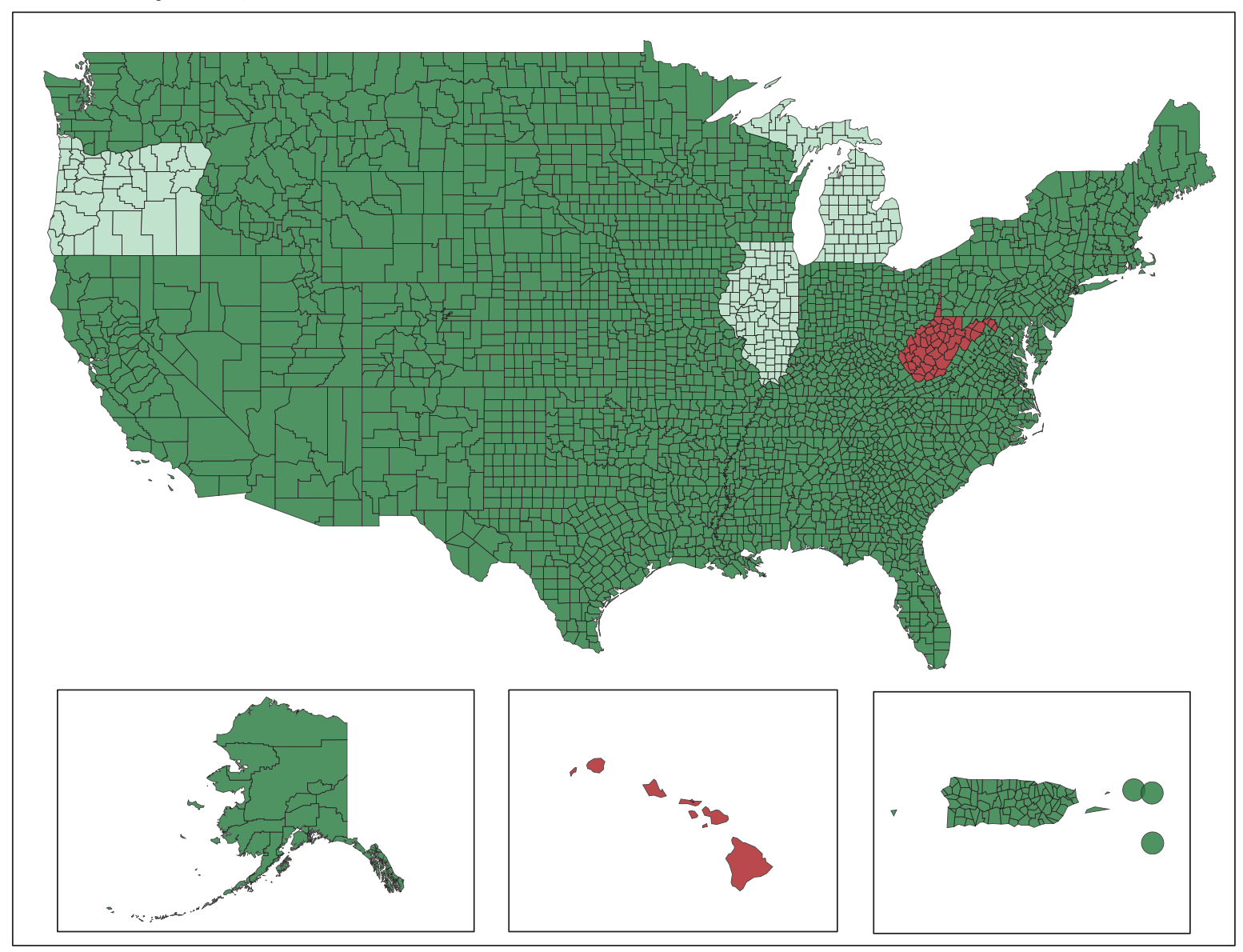

\section{EXPLANATION}

[Noncontiguous U.S. States and territories not to scale]

Estimated data (method code E)

Site-specific data (method code S)

Site-specific, estimated data (method codes S, E)

Figure 7. Map showing thermoelectric power generation method codes, by county, for the 2015 compilation indicating whether values are site-specific, estimated, or a combination. $A$, once-through cooling system and $B$, closed-loop cooling system.-Continued 


\section{Assessment of the Variability of Water-Use Data Values by State and Category}

Water-use data quality and variability can be evaluated through analysis of data values with time and comparison to neighboring States with similar characteristics. State-scale values were evaluated using radar charts where values for each compilation year are connected by lines and where States within each region have the same color. County-scale values were evaluated using dot plots displaying the medians and IQRs. These evaluations are used to identify water-use data that warrant closer examination and States (and years) that are potentially anomalous. The purpose of these comparisons was to look for State values that differ in pattern than values from previous years and differ in pattern for neighboring States in each compilation year. The purpose for these comparisons is not necessarily to identify trends but to identify values that do not follow apparent patterns and, thus, may have more uncertainty associated with the water-use values. To determine the reasons for each potentially anomalous value is beyond the scope of this assessment.

\section{Public Supply}

Rates and percentages for metrics related to the public supply category are shown in figures 10-15. Public supply delivery per capita use rates (fig. 10) generally indicate a pattern of higher rates in western States as compared to eastern States. Rates in 2015 generally were lower than earlier compilation years for most regions, except the Other region (fig. 10). Rates appear to be anomalously low in 2015 for South Dakota and Connecticut, and anomalously high in 1985 for Idaho and Utah. In the Pacific West and Southwest State regions, per capita rates are more variable, whereas in the Central and most of the Southeast Coast States, per capita rates are more consistent from year to year. In the Midwest region, 2015 stands out with lower per capita rates from the other years for some States in that region (fig. 10). Further analysis would be needed to evaluate whether variation in per capita use rates is because of water transfers, different methodology, or other reasons.

Percentage of public supply withdrawals from surface water shown in figure 11 is consistent for most States with time. Some States have a compilation year with anomalous values; for example, California and South Dakota in 1985, Vermont in 1990, and Connecticut in 2010. States within the same region often have variable percentages.

The percentage of each State's population served by public supply is shown in figure 12. For most States and regions, the percentage served by public supply has increased from 1985 through 2015. Some States show consistent percentages, such as Florida, whereas others, such as Arkansas and South Dakota, have much variability throughout the years, but still generally show the pattern of increases with time. Within regions, values varied among States, with the exception that values were similar in 2015 for States in the Southern Plains.

The percentage of public supply withdrawals delivered for domestic uses is shown in figure 13 and indicates much variability and the absence of spatial or temporal patterns between years and States. Some States have 1 year with values that are much above other compilation years, including Louisiana, Minnesota, Iowa, Indiana, West Virginia, Maine, and the U.S. Virgin Islands. Values in Montana and Texas have been consistent with time.

The medians and IQRs for county public supply withdrawal and delivery per capita rates for compilation years grouped by State are shown in figures 14-15. Within each region, the median and IQR generally are similar for counties in eastern States and dissimilar for counties in western States. Western States generally have higher values and exhibit a wider range in values than States in the eastern United States. From year to year for a State and within a region, some outliers are apparent and warrant further investigation. For example, the 1985 IQR and median for counties in Pennsylvania are larger than other values within that region. For some years, the IQR of counties is close to zero, which might be an artifact of use of a uniform per capita estimation rate for the State. Because public supply deliveries to domestic users were not required for the 2000 compilation, most States did not provide these data.

\section{Self-Supplied Domestic}

Self-supplied domestic per capita use rates are shown in figures 16-17. State-scale self-supplied domestic per capita use rates generally are within a somewhat narrow range for most years and State regions, except for some apparently anomalous values for Hawaii, Idaho, Nevada, Arizona, Nebraska, and Florida. Rates for 2015 generally are consistent among most State regions, except for the Other, Pacific West, Southwest, and the Southeast Coast regions. Domestic per capita rates in the Northern Plains have been consistent throughout the compilations from 1985 through 2015.

The medians and IQRs for county self-supplied domestic populations are shown in figure 17. Self-supplied domestic population median values are variable throughout years and among States in the New England, Mid-Atlantic, and Pacific West regions, whereas median values are consistent for States in the Gulf Coast, Plains, and Northern Rockies regions. Median population values for Connecticut are different from neighboring States, and the 2015 IQR is much higher than earlier years and other States in the same region. Values for some States generally are consistent throughout the compilation years but may vary from other States in the same region.

The medians and IQRs for self-supplied domestic per capita use rates for counties within each State for each region are shown in figure 18. The self-supplied domestic IQR plot 
Table 11. Summary of the number of States by category, element, and primary reporting scale, for 2015.

[NA, not available; --, no data]

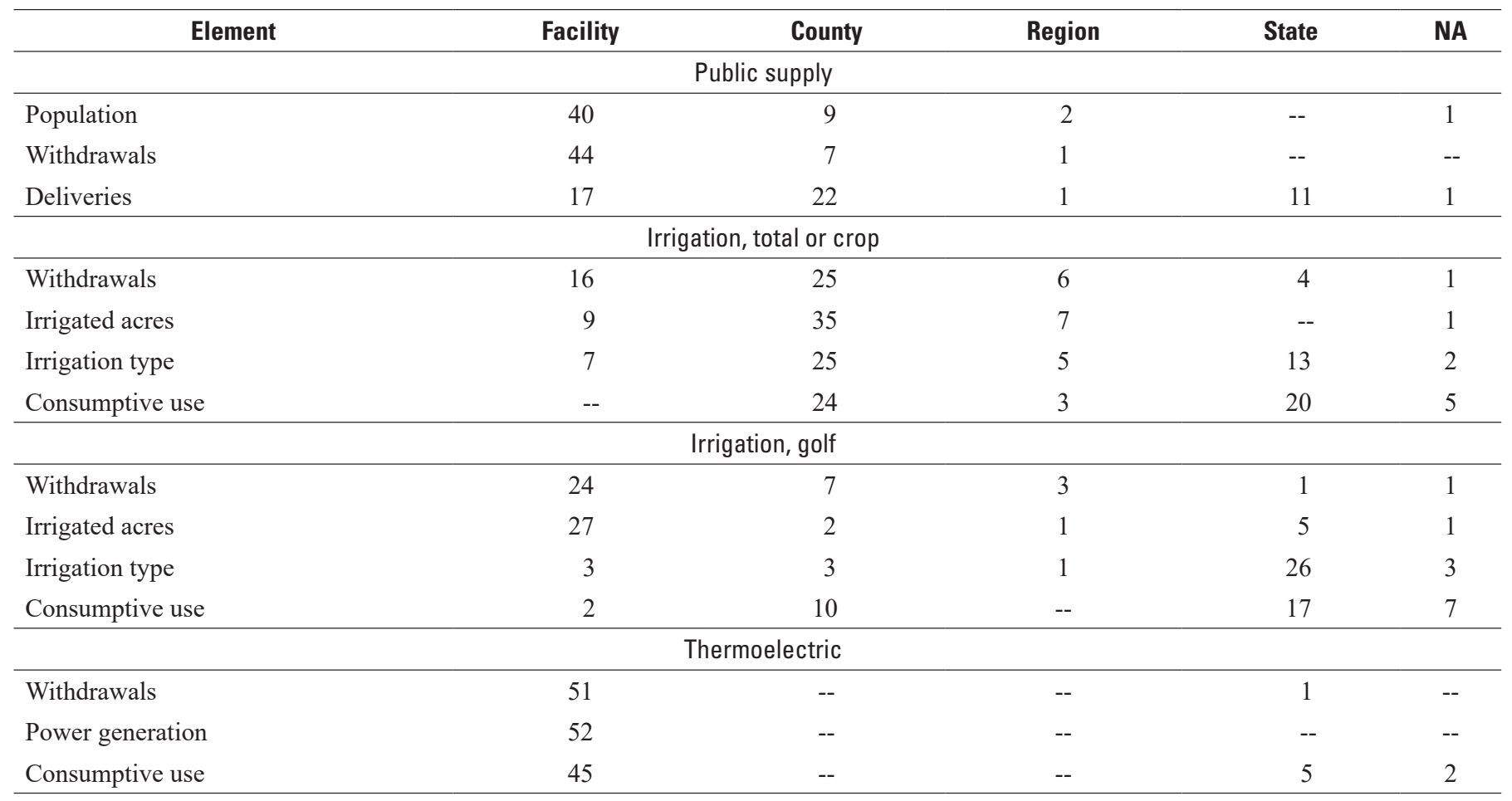

Table 12. Summary of information, by numbers of States, on groundwater and surface-water sources by category, for 2015 .

[GW, groundwater; --, no data]

\begin{tabular}{|c|c|c|c|c|c|c|}
\hline Category & Reported & $\begin{array}{l}\text { Based on } \\
\text { previous } \\
\text { compilation }\end{array}$ & $\begin{array}{c}\text { Multiple sources } \\
\text { of information }\end{array}$ & $\begin{array}{c}\text { Assumed } \\
\text { source of } \\
\text { water }\end{array}$ & $\begin{array}{l}\text { Assumed to } \\
\text { be GW source } \\
\text { only }\end{array}$ & Unknown/ none \\
\hline Public supply & 49 & 1 & -- & -- & -- & 2 \\
\hline Self-supplied domestic & 2 & 3 & 4 & 33 & 6 & 4 \\
\hline Irrigation, crop & 25 & 18 & 6 & 1 & -- & 2 \\
\hline
\end{tabular}

shows a similar trend as the public supply per capita rate IQR with lower values in the eastern United States as compared to the western States, except for California and the U.S. Virgin Islands rates in 2005 and Idaho and Hawaii in 1985 (fig. 18B). The self-supplied domestic median per capita rates are consistent throughout the United States (fig. 18A). Many States use the same per capita rate to estimate domestic self-supplied withdrawals from one compilation to the next in the absence of reported data. In the New England States, 2015 per capita rates were based on reported data, whereas for earlier compilations, some of these States used rates from previously published data. In the Southeast Coast, Southwest, and
Other regions some median values stand out as being much larger than for other years and for other States in the region (fig. 18A).

\section{Irrigation}

Irrigation rates and percentages are shown in figures 19-21. These figures include application rates by State for the compilations from 2000 through 2015 described separately for States that report golf course irrigation, crop irrigation, and total irrigation (fig. $19 A-C$, respectively). Values plotted below the $\mathrm{x}$-axis indicate a compilation year where data were not reported for that category element. 

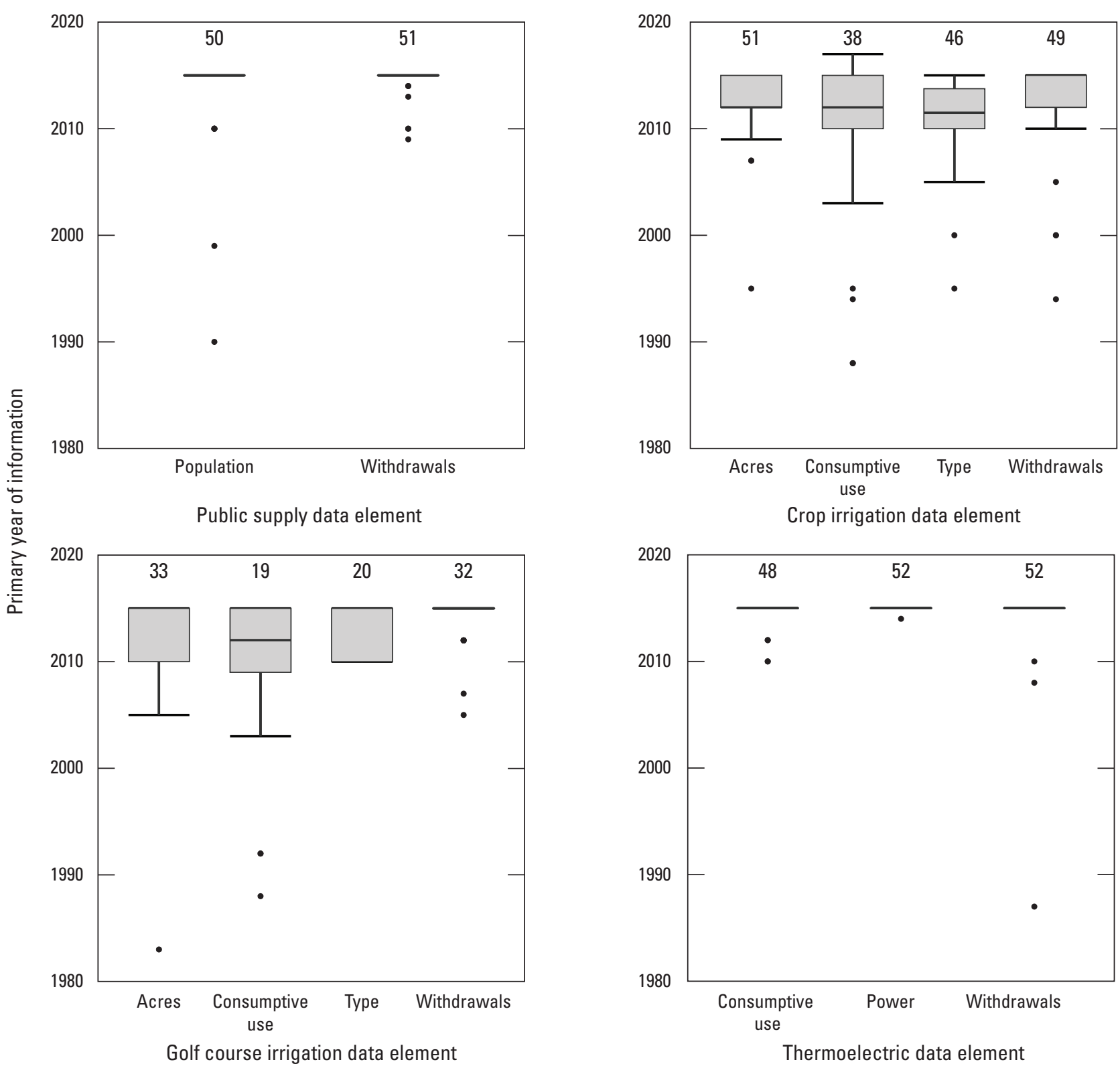

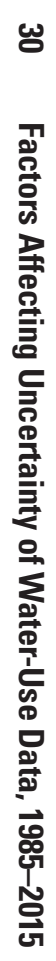

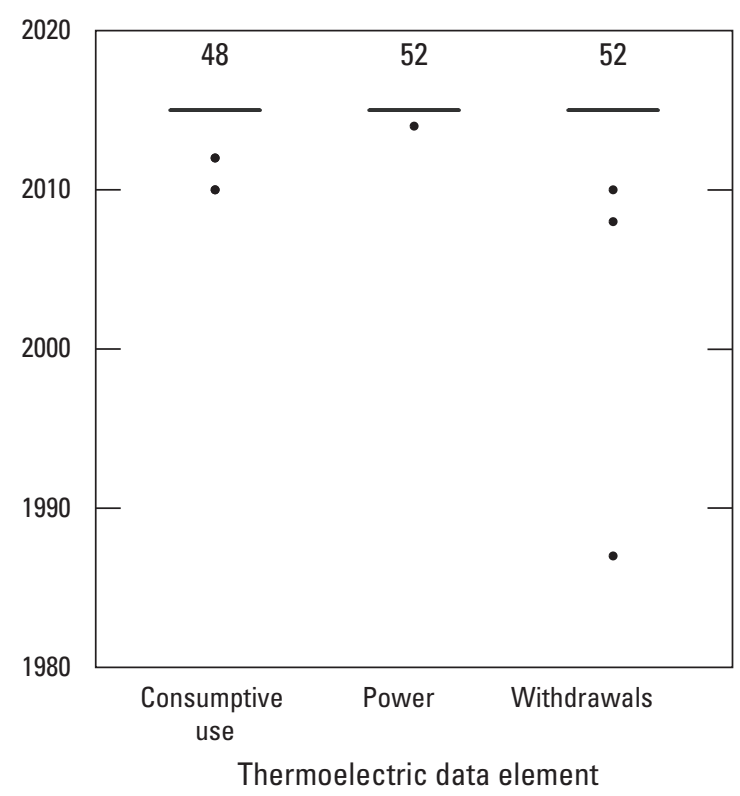

50 Number of values



Figure 8. Boxplots showing the primary year of information sources used for public supply, irrigation, and thermoelectric values for the 2015 compilation. 
This situation arises because USGS personnel may report crop and golf course irrigation separately for some years and may report total irrigation for other years (see table 1.1 for State level listing of irrigation category reporting decisions). Irrigation application rates generally are more consistent for golf course irrigation than for crop or total irrigation and are lower for States in the eastern United States than in the western United States. Irrigated acreage for crops was reported mostly in 2015, whereas irrigated acreage for golf courses was estimated mostly in 2015. Conversely, golf course withdrawals were reported in most States in 2015, and crop withdrawals were estimated in most States in 2015. Some exceptions are apparent with rates for Massachusetts being anomalous for some years for golf course and crop irrigation. Crop application rates within the Southeast Coast, Southwest, and Pacific West State regions are more variable than for other State regions. Total application rates within the Gulf Coast and Southwest regions are more variable among States than for other regions. Further analysis would be needed to evaluate whether variation in application rates is because of water transfers, different methodology, climate, or other reasons.

Consumptive uses for combined crop and golf courses and total irrigation are shown in figures $20 A-B$, respectively. Irrigation was not reported for the U.S. Virgin Islands in 2015; therefore, consumptive use in figure $20 A$ is zero. Some States, such as Missouri, Montana, Wyoming, and North Dakota, have relatively low rates, which warrant more investigation. For some States, consumptive use is estimated as 100 percent, which seems unrealistic because operational requirements are usually such that not all water withdrawals are available for use by crops. For example, irrigation requirements may be set for some crops regardless of local precipitation amounts or soil moisture contents.

The medians and IQRs for total and combined crop and golf course irrigation application rates within each county for each region are shown in figures $21 A-B$, respectively. Irrigation application rate IQRs for Massachusetts seem large compared to neighboring States in the New England region. Crop application rate IQRs in the Southeast Coast, Southwest, and Pacific West are more variable from year to year than other regions. Median application rates for crop, golf course, and total irrigation are higher and generally more variable in the western United States than in the eastern United States.

\section{Thermoelectric}

Thermoelectric category rates and percentages, reported separately by cooling system type by State for the compilations from 2005 through 2015, are shown in figures 22-24. Thermoelectric rates for once-through cooling system plants are relatively consistent among States in the Midwest and Central regions, but variable in some other regions. Some States, such as Hawaii, California, Oklahoma, Louisiana, and Rhode Island had values in 2005 that were different from values in other years. Several States have no reported oncethrough thermoelectric plants, which are indicated with a rate of zero on the chart (fig. 22A). These zero values provide little information about uncertainty because the zero value may be due to no reported or estimated data or may be because specific water-use information is limited or unavailable.

Thermoelectric power rates for closed-loop cooling system plants seem anomalously high for Louisiana, Kentucky, Tennessee, Connecticut, and New Jersey in 2005, for Minnesota in 2010, and for Kansas in 2015 (fig. 22B). Rates for 2015 are relatively low compared to other years for most States where maybe only a few counties have thermoelectric plants. Because of higher rates in earlier years for some of these States, additional investigation is needed to determine if reporting or methodologies differed, if plants have closed or changed cooling system types, or if other potential reasons may explain these differences in thermoelectric power rates.

Consumptive use associated with thermoelectric water use for 2015 is shown in figures $23 A-B$, where anomalously high values for once-through cooling are apparent for the U.S. Virgin Islands, Puerto Rico, and Minnesota (fig. 23A). The U.S. Virgin Islands does not have any closed-loop cooling plants and, thus, reported a zero consumptive use value. Other States with lower than expected consumptive use rates include Nevada, Kansas, Texas, Louisiana, Alabama, Minnesota, and Michigan. A few States with rates close to 100 percent also may warrant further investigation. Many States have apparently consistent consumptive use rates and may indicate reliance on the USGS thermoelectric model work (Diehl and others, 2013), which provided insight into reasonable rates based on plant cooling system types.

Some complexities that may result in apparently anomalous values may be facility reporting in the incorrect cooling system type, complex plants with both types, geothermal plants that are more difficult to interpret, reliance on State reported data that may have different consumptive use definitions, or estimation methods based on previous compilation percentages. Some plants may have both cooling system types, so withdrawals and consumptive use may all be assigned to one type if the information was insufficient to assign data to each type. Zero values were reported for States with either no once-through cooling system plants or a system configuration such as a complex-cooled plant with wet/dry tower combos that has no once-through cooling.

The medians and IQRs for thermoelectric rates using combined values for once-through and closed-loop cooling system type data elements are shown in figures $24 \mathrm{~A}-B$, respectively. Power rates were determined for the compilations from 2005 through 2015 because power generation values were not required in 2000, and before 2000, water use for thermoelectric was compiled by fuel type. 


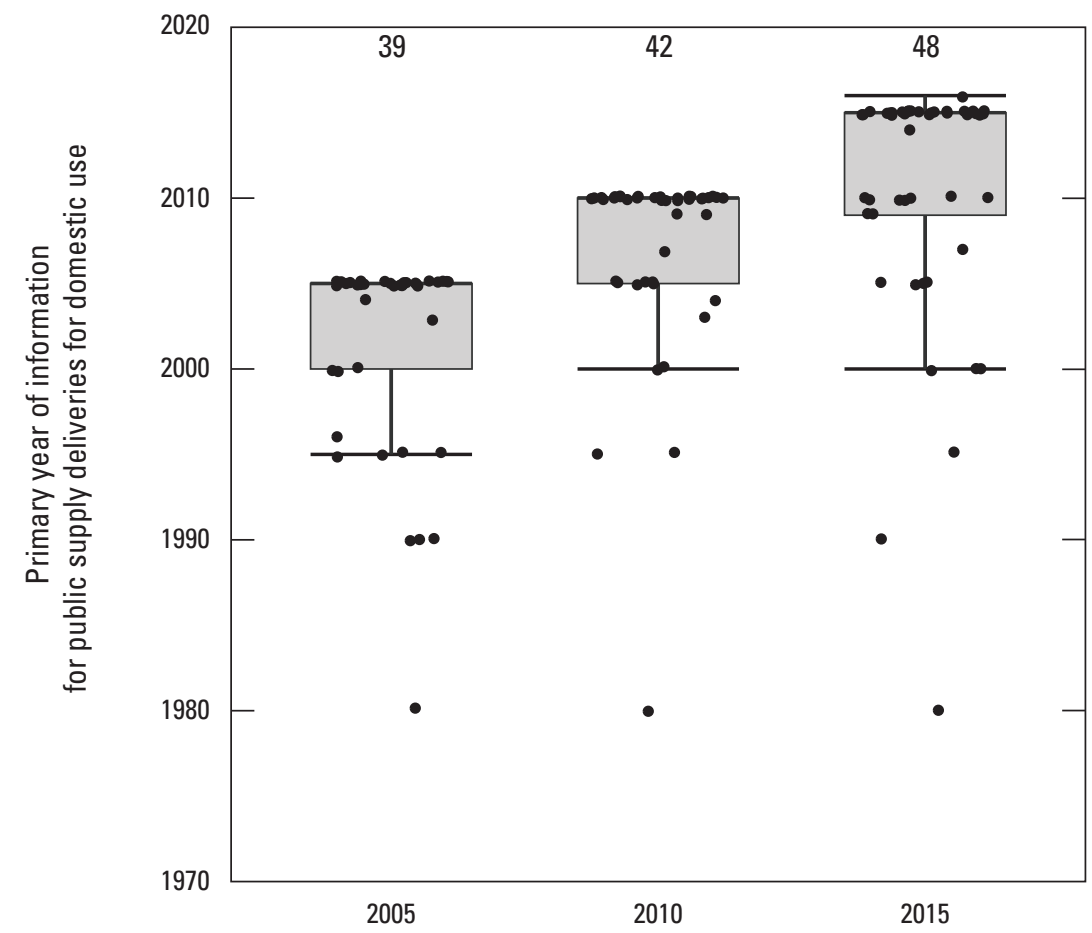

\section{EXPLANATION}
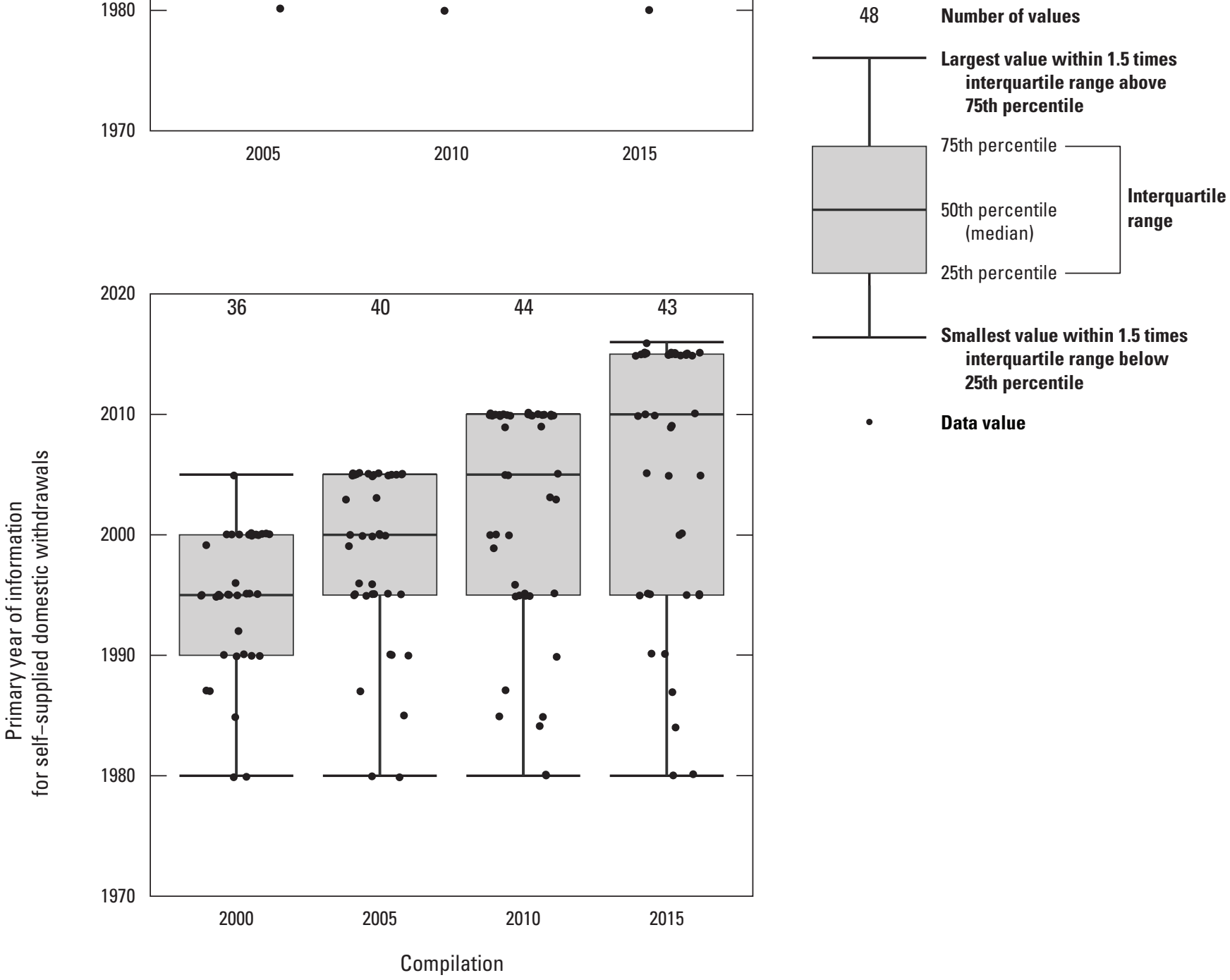

Figure 9. Boxplots showing the primary years U.S. Geological Survey personnel used for determining coefficients for estimating the data. 


\section{Assessment of the Variability of Water-Use Data by Region and Compilation Year}

This section describes variability for the public supply, self-supplied domestic, irrigation, and thermoelectric water use for data summarized by regions. This evaluation of variability is used to help provide insight into uncertainty and data reliability and is accomplished using State and regional scale characteristic medians and IQR values. The presumption is that variability among States within regions is expected to be less than variation among States in different regions because climate and environmental factors related to water use are expected to be fairly consistent within regions. Variability, or unexplained uncertainty within regions, could be further investigated to understand whether differences in reported water use are real or an artifact of differences in method of estimation or reporting.

\section{Water-Use Variability-Approach}

The information provided in tables 13-24 describes water-use component variability, and each table consists of three sections. The regional-scale characteristic medians and IQRs for each of the 11 regions are provided in the upper third of each table. Medians and IQRs normalized by region are provided in the middle third of each table, and medians and IQRs normalized by year are provided in the lower third. The values normalized by region are obtained by computing the median value for a region (along a row) and then dividing each regional-scale characteristic value by that median (for the row). The values normalized by year are obtained by computing the median value for a year (along a column) and then dividing each regional-scale characteristic value by that median (for the column). Normalizing by regions (middle third) highlights years that stand out for each region as anomalous. Normalizing by years (bottom third) highlights regions that stand out for each compilation year. Further investigation might include comparisons of these values with figures depicting medians and IQRs of county values for each State (for example, figs. 14-15). Some potentially anomalous values may be due to a few State or county values. Other anomalous values may relate to actual changes in water use because of regional socioeconomic or climatic differences.

The normalized values are shaded based upon the magnitude of the value (tables 13-24). If a normalized value is greater than 2.00 , then the value is defined as high and is shaded blue. If the normalized value is less than 0.50 , the value is defined as low and is shaded green. The selection of the thresholds was subjective - different thresholds could have been selected. Color in a table is an indicator of variability. If the data indicate several high and low values, then that water-use component is defined as relatively variable. If the data indicate few or no high or low values, then that water-use component is defined as relatively constant. The presence or absence of variability can be expected or unexpected. If the presence or absence of variability in a water-use component is unexpected, then those data may require additional evaluation.

\section{Water-Use Variability-Application}

Tables 13-24 can be examined for "patterns" of variability. For example, when the data are normalized by region, do any of the regions include a large number of years with high or low values? Are any of the years persistently high or low among the regions? Alternatively, when the data are normalized by year, are any of the regions high or low? Is the region expected to be high or low? Is that region persistently high or low throughout many years? In the paragraphs that follow, the tables for the water-use components are examined for instances or patterns of variability. The examination is intended to be exploratory and generally does not go beyond identifying regions and years with anomalous water use compared to other regions and years. Additional work would be needed to investigate the patterns and the factors explaining these anomalous values.

Regional-scale characteristic medians and IQRs for public supply withdrawal per capita rates are listed in tables 13-14, respectively. The normalized median and IQR values, with three exceptions, are within the chosen thresholds. The three exceptions are high values for the Northern Rockies during 1985-95 and could be evaluated with values for public supply water deliveries. Further investigation would ask the following questions: (1) why were the median and IQR county values much higher in the Northern Rockies than other regions in these 3 early compilation years, and (2) why were the median and IQR county values for the Northern Rockies high in only these 3 early compilation years and not in subsequent years? Was there a real change in public supply deliveries to domestic users on a per capita basis between 1995 and 2000 in the Northern Rockies or does the change reflect that a different method was used? With identification of this variability, subsequent analyses would be needed to investigate where the anomalous values relate to errors, changes in methodology, or actual changes in water use.

Regional-scale characteristic medians and IQRs for public supply delivery per capita rates are listed in tables 15-16, respectively. The public supply delivery per capita rates indicate more variability than the public supply withdrawal per capita rates. Public supply withdrawals are reported in most States; however, public supply deliveries for domestic use are typically estimated rather than reported for the compilation. Inspection of the tables indicates 3 shaded values for withdrawal rates (tables 13-14) and 52 shaded values for delivery rates (tables 15-16). The median values normalized by compilation year are consistently high for the Northern Rockies (4 of 6 years) and are high for 1990 in the Southwest and Pacific West (table 15). The following question arises: are the high 


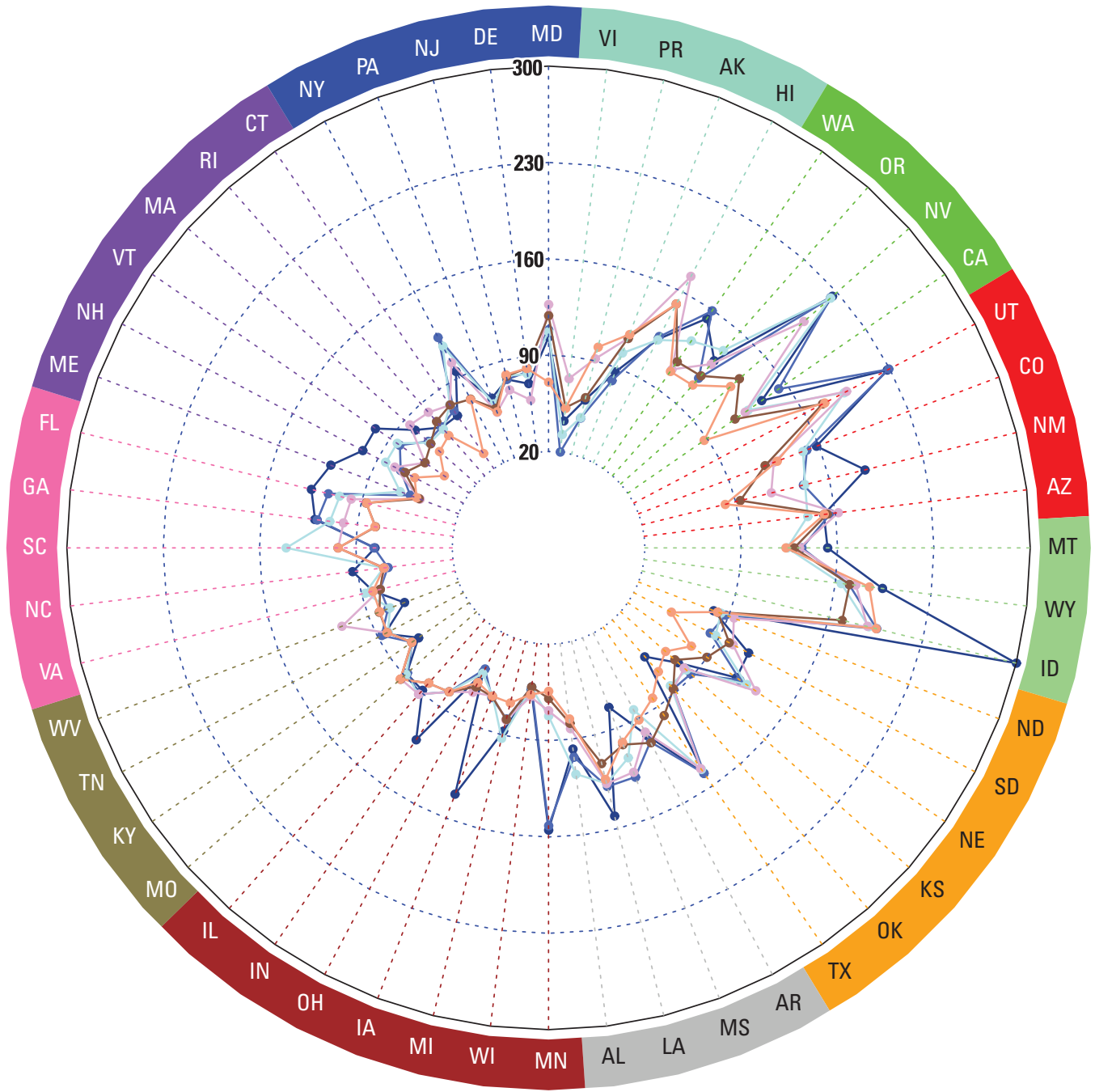

\section{EXPLANATION}

[State name abbreviations are U.S. Postal Service abbreviations]

Figure 10. Public supply delivery per capita rates, by State, for 1985-2015.

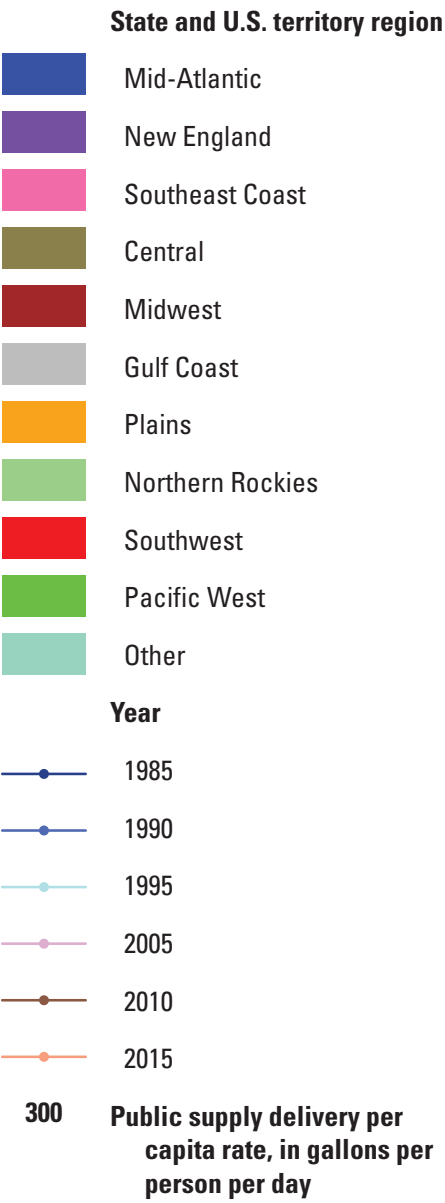




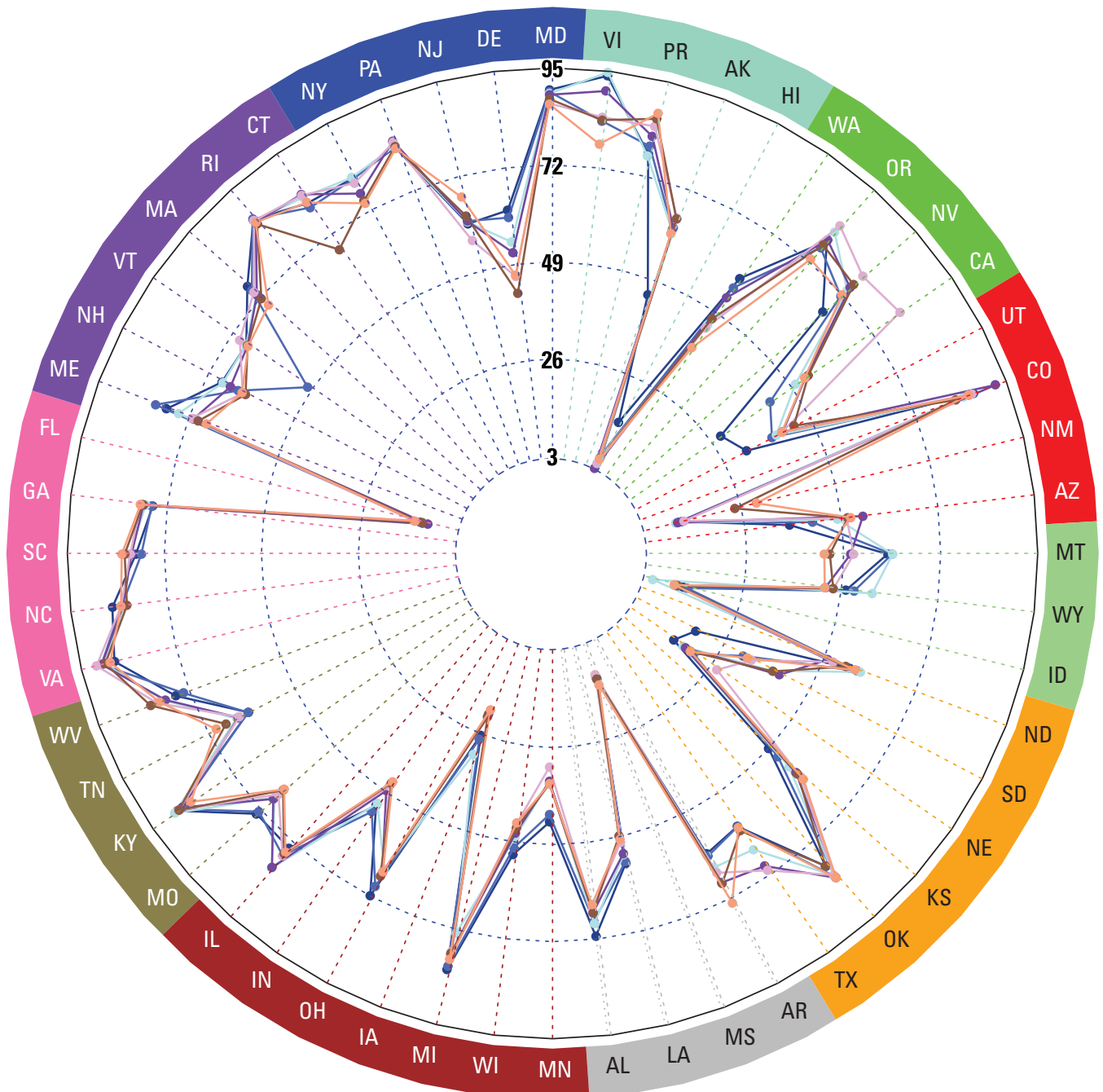

EXPLANATION

[State name abbreviations are U.S. Postal Service abbreviations]

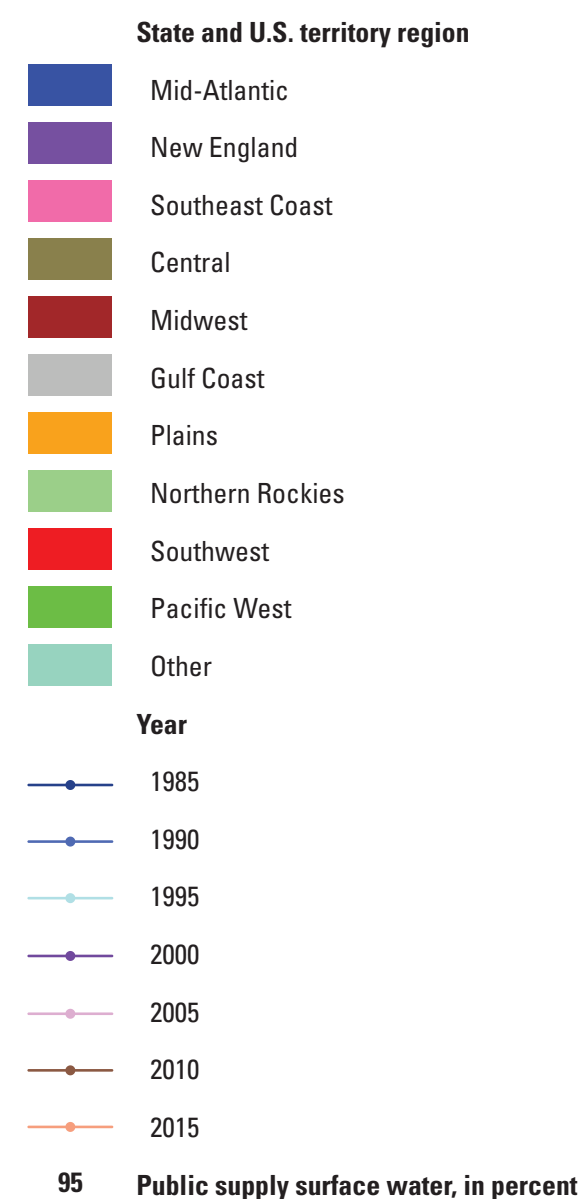

Figure 11. Public supply surface-water percentages, by State, for 1985-2015. 


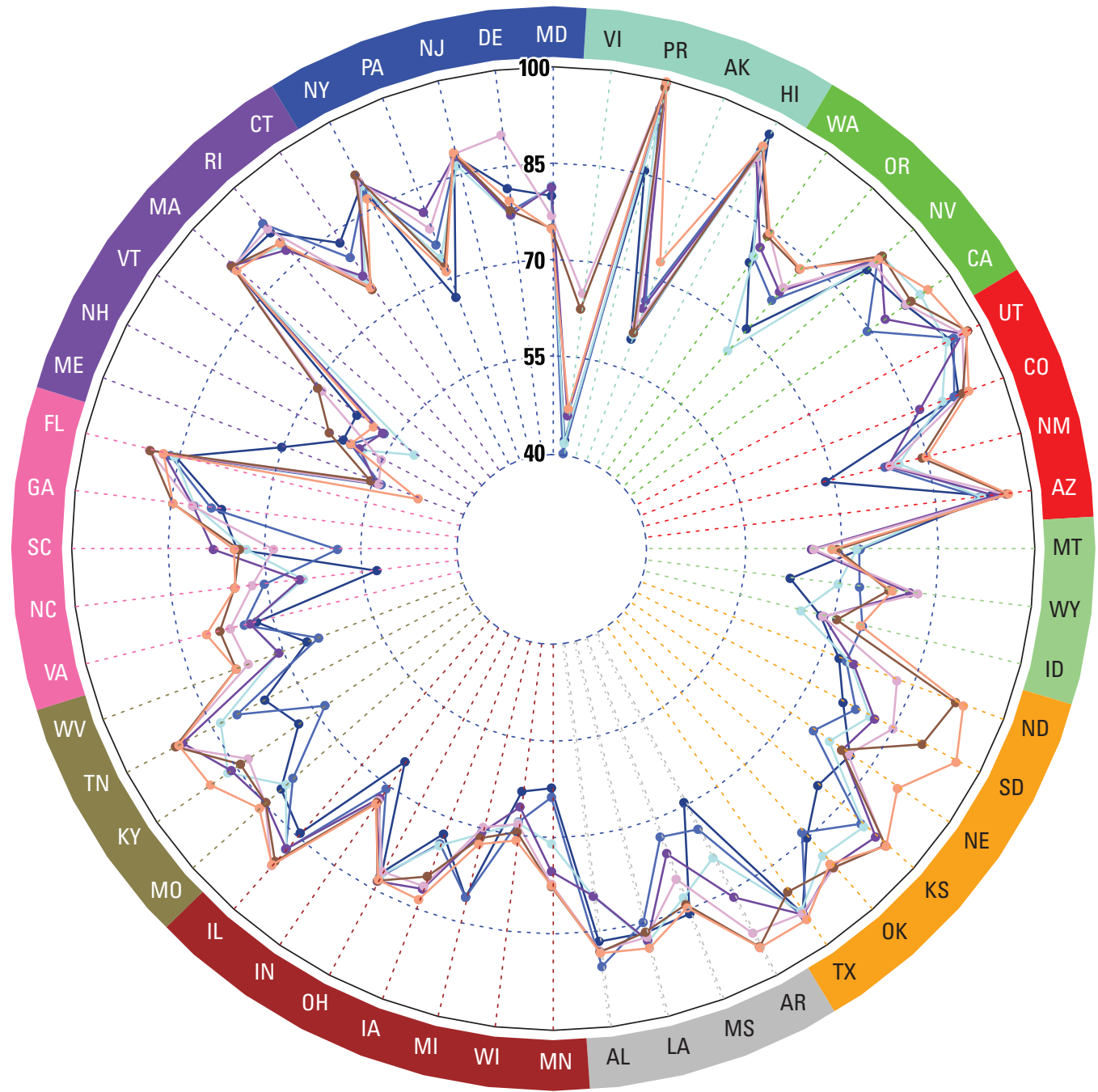

EXPLANATION

[State name abbreviations are U.S. Postal Service abbreviations]

Figure 12. Percentage of total State population on public supply for 1985-2015.

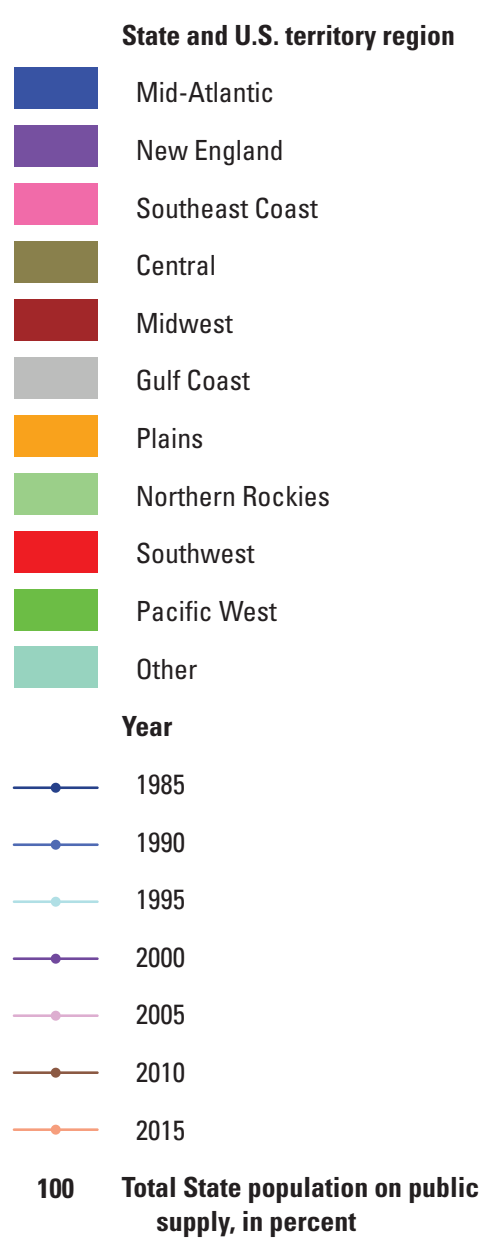




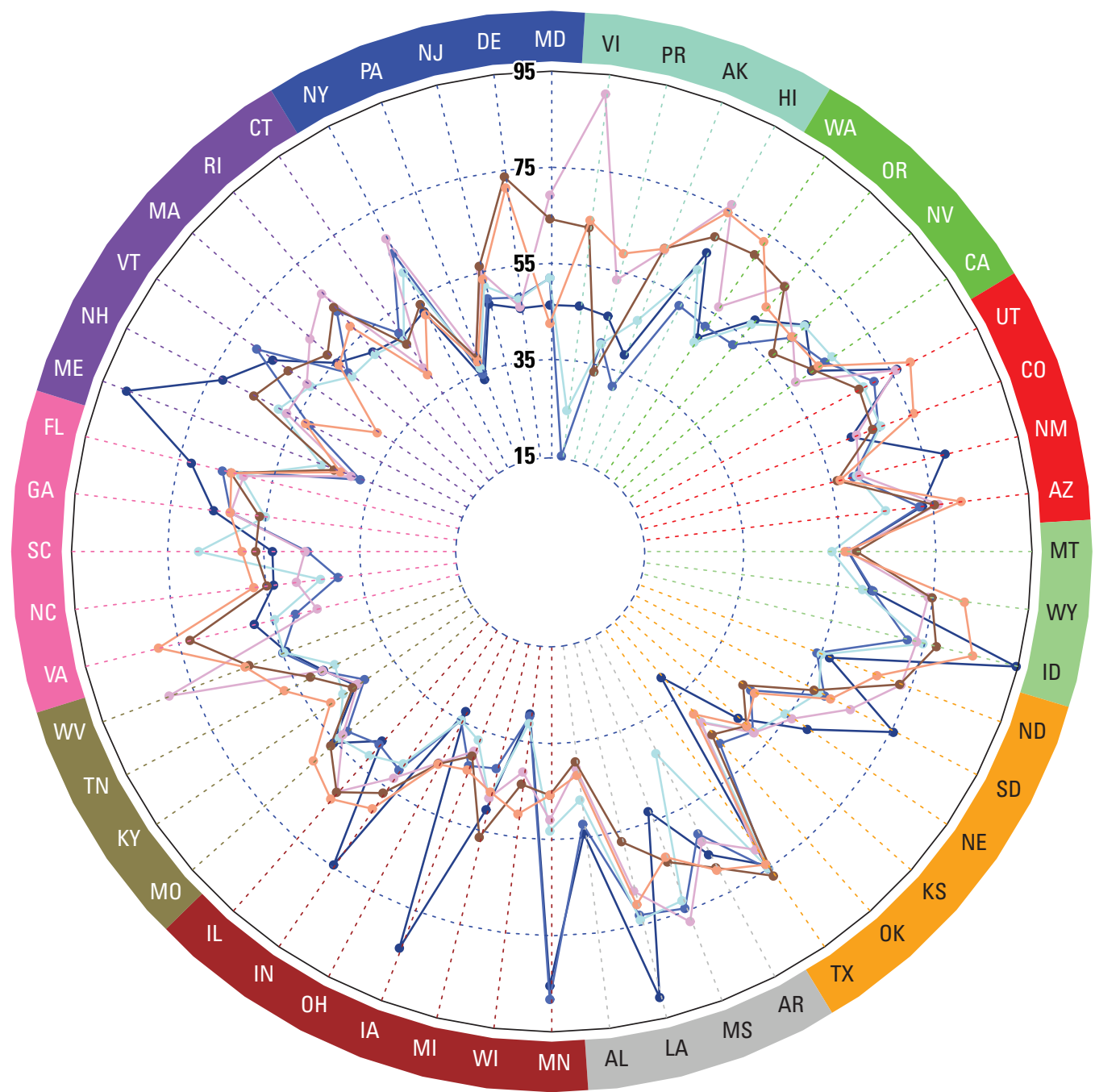

\section{EXPLANATION}

[State name abbreviations are U.S. Postal Service abbreviations]

\section{State and U.S. territory region}

Mid-Atlantic

New England

Southeast Coast

Central

Midwest

Gulf Coast

Plains

Northern Rockies

Southwest

Pacific West

Other

Year

$\longrightarrow \quad 1985$

$\longrightarrow \quad 1990$

1995

2005

2010

2015

95

Total public supply withdrawals

delivered for domestic use, in percent 


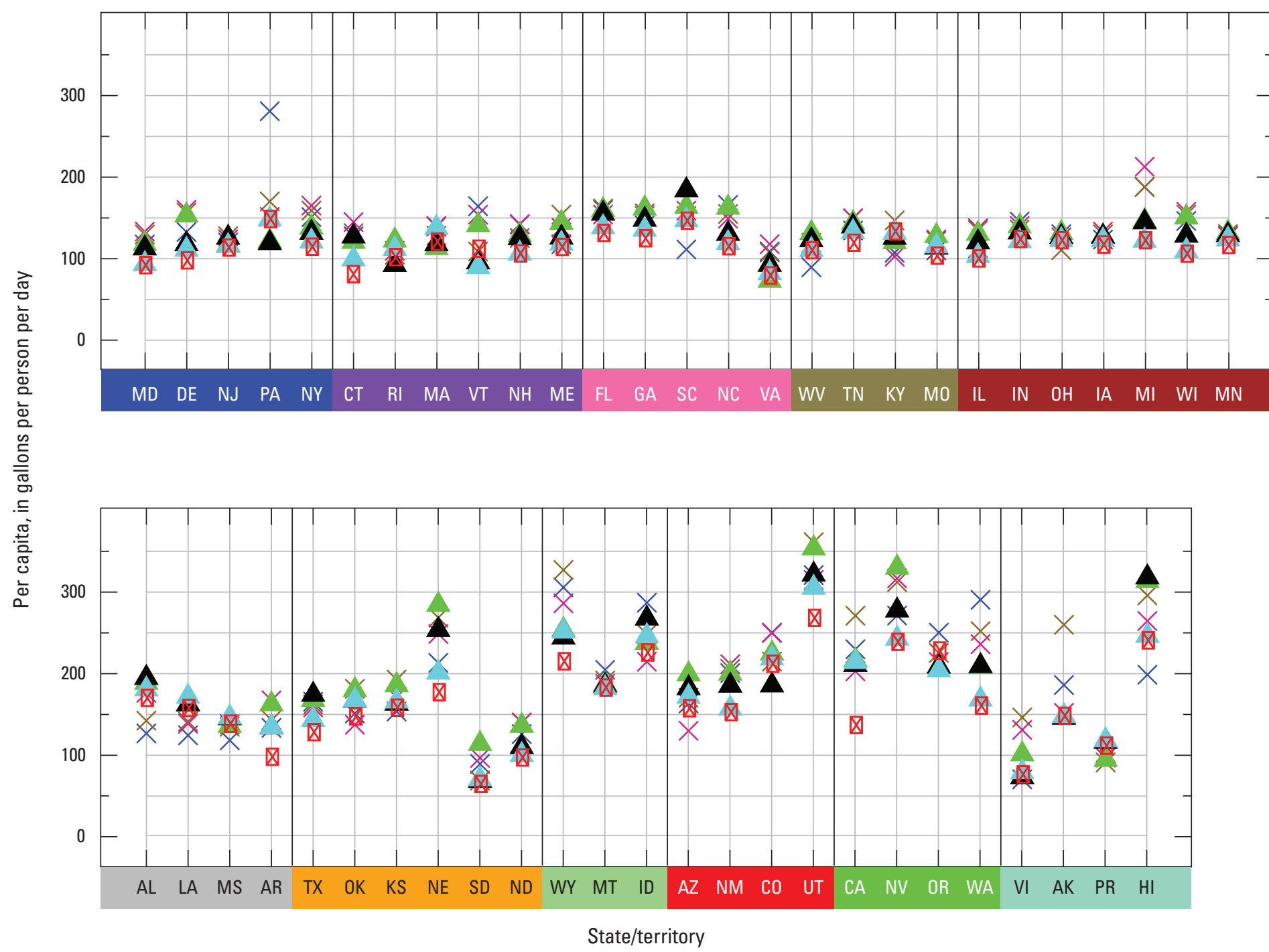

\section{EXPLANATION}

[State name abbreviations are

U.S. Postal Service abbreviations

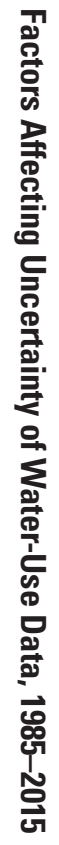
region

Mid-Atlantic

New England

Southeast Coast

Central

Midwest

Gulf Coast

Plains

Northern Rockies

Southwest

Pacific West

Other

Year

X 1985

X 1990

X 1995

- 2000

- 2005

- 2010

囚 2015

Figure 14. County public supply withdrawal per capita rate for 1985-2015. $A$, medians and $B$, interquartile ranges. 
$B$. Interquartile ranges

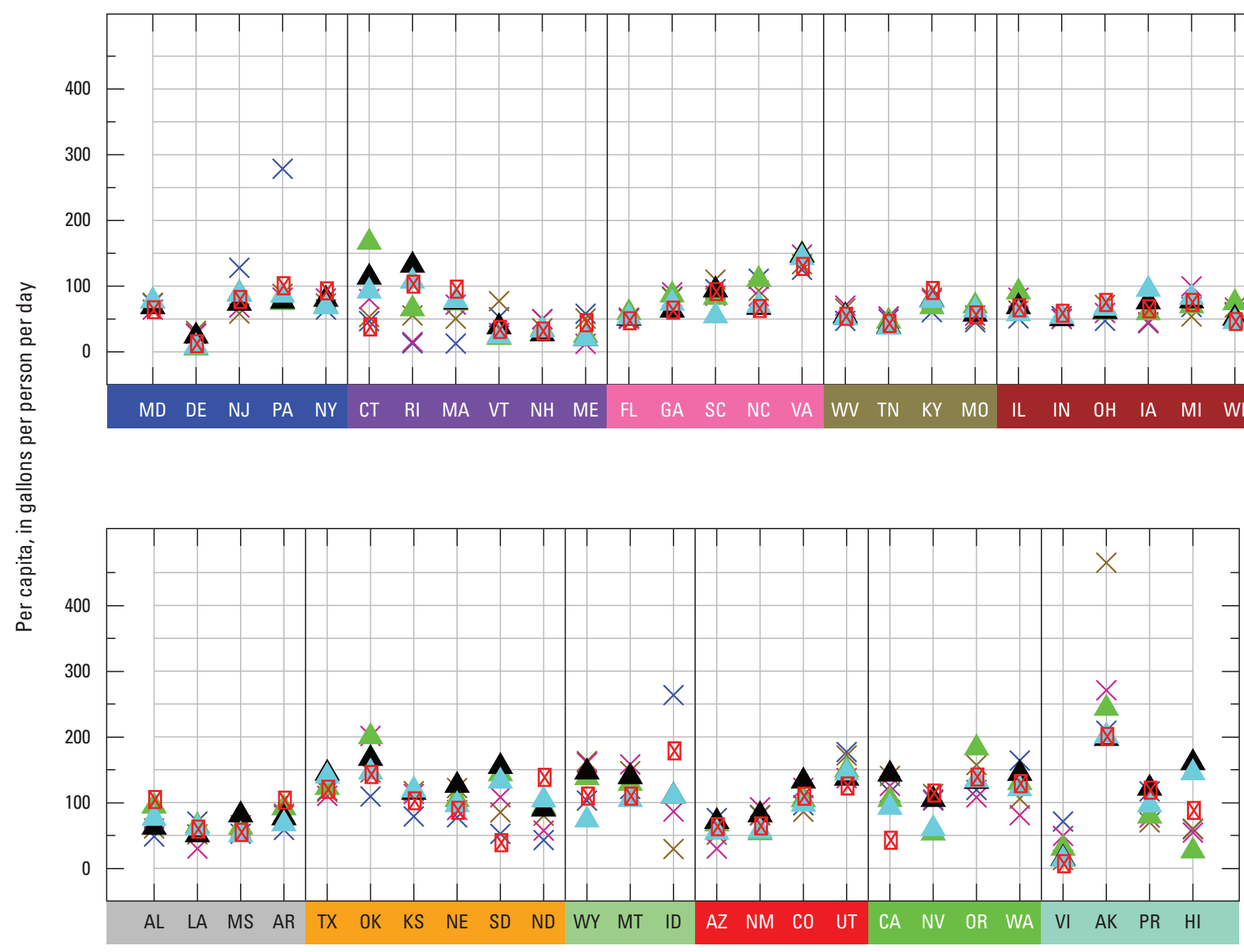

State/territory

\section{EXPLANATION}

[State name abbreviations are

U.S. Postal Service abbreviations]

State and U.S. territory

region

Mid-Atlantic

New England

Southeast Coast

Central

Midwest

Gulf Coast

Plains

Northern Rockies

Southwest

Pacific West

Other

Year

$\times \quad 1985$

X 1990

$\times \quad 1995$

$\triangle \quad 2000$

A 2005

A 2010

\ 2015

Figure 14. County public supply withdrawal per capita rate for 1985-2015. $A$, medians and $B$, interquartile ranges.-Continued 


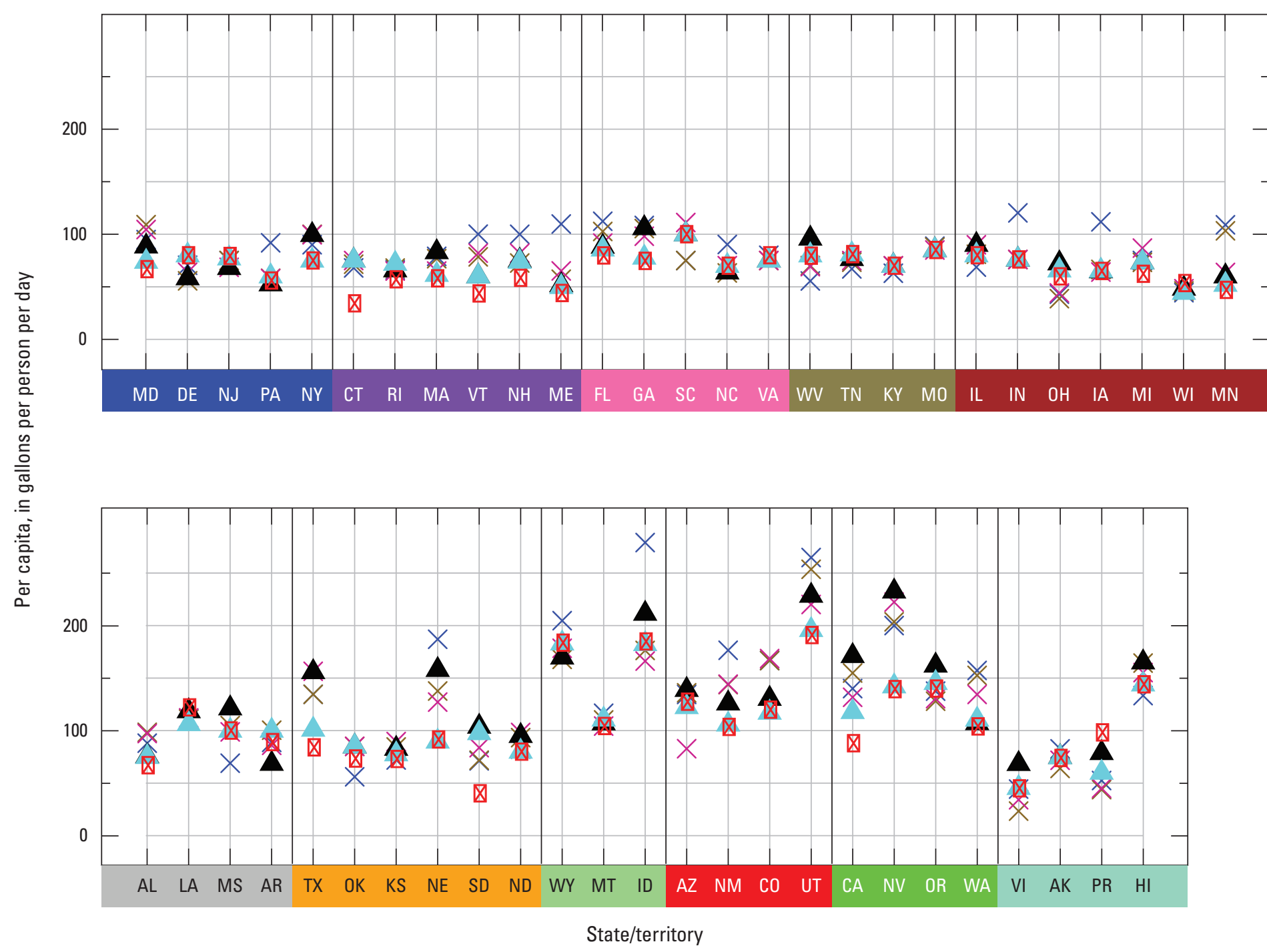

EXPLANATION

[State name abbreviations are

U.S. Postal Service abbreviations

State and U.S. territor

region

Mid-Atlantic

New England

Southeast Coast

Central

Midwest

Gulf Coast

Plains

Northern Rockies

Southwest

Pacific West

Other

Year

X 1985

X 1990

X 1995

- 2005

- 2010

囚 2015

Figure 15. County public supply delivery per capita rate for 1985-2015. $A$, medians and $B$, interquartile ranges. 
B. Interquartile ranges

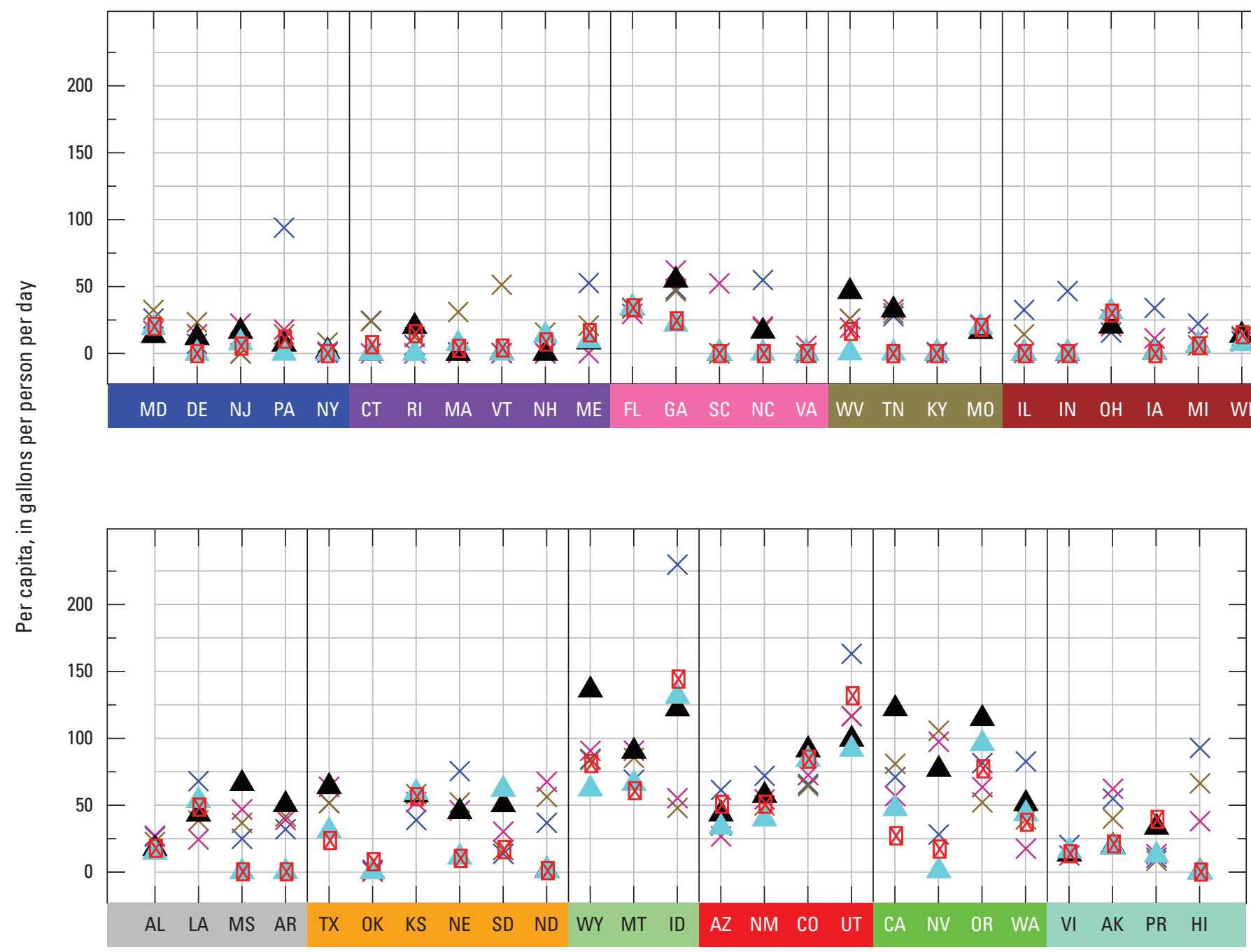

State/territory

\section{EXPLANATION}

[State name abbreviations are U.S. Postal Service abbreviations

\section{State and U.S. territory}

region

Mid-Atlantic

New England

Southeast Coast

Central

Midwest

Gulf Coast

Plains

Northern Rockies

Southwest

Pacific West

Other

Year

X 1985

$\times \quad 1990$

$\times \quad 1995$

- 2005

2010

囚 2015

Figure 15. County public supply delivery per capita rate for 1985-2015. $A$, medians and $B$, interquartile ranges.-Continued 


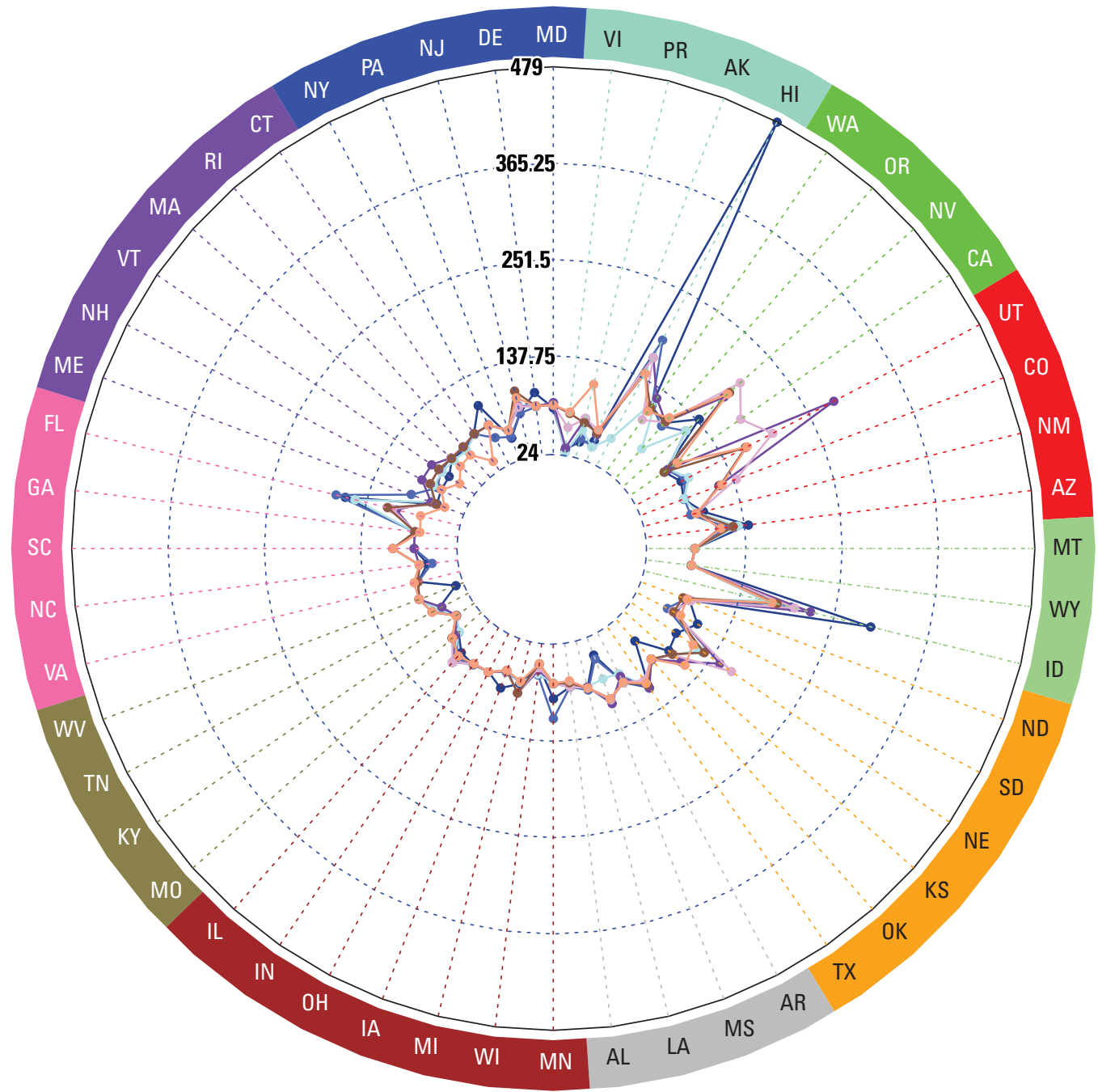

EXPLANATION

[State name abbreviations are U.S. Postal Service abbreviations]

Figure 16. Self-supplied domestic per capita rates, by State, for 1985-2015. 
A. Medians
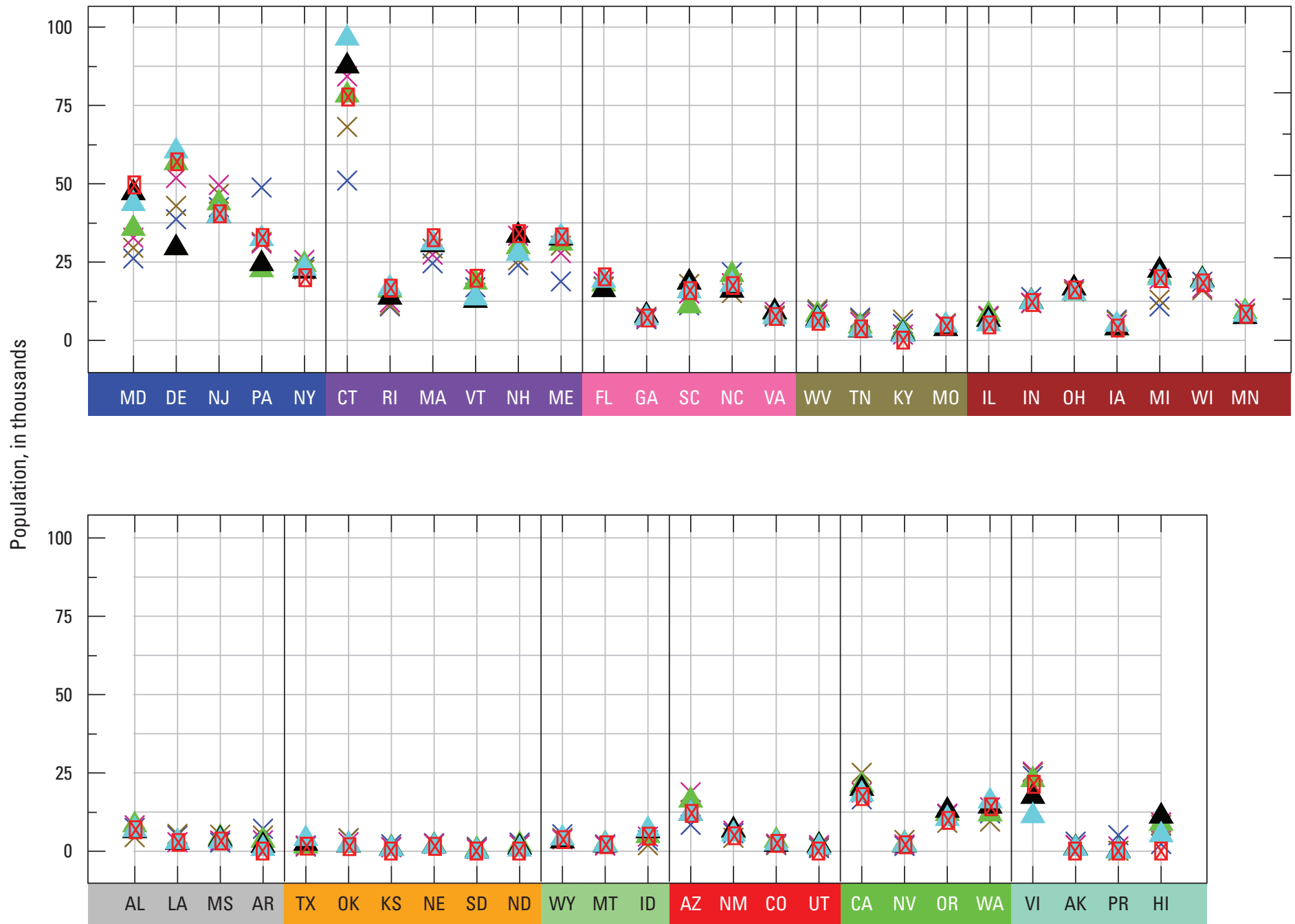

State/territory

Figure 17. County self-supplied domestic population for 1985-2015. $A$, medians and $B$, interquartile ranges.

\section{EXPLANATION}

[State name abbreviations are

U.S. Postal Service abbreviations]

State and U.S. territory

region

Mid-Atlantic

New England

Southeast Coast

Central

Midwest

Gulf Coast

Plains

Northern Rockies

Southwest

Pacific West

Other

Year

X 1985

$\times \quad 1990$

X 1995

2000

- 2005

- 2010

冈 2015 


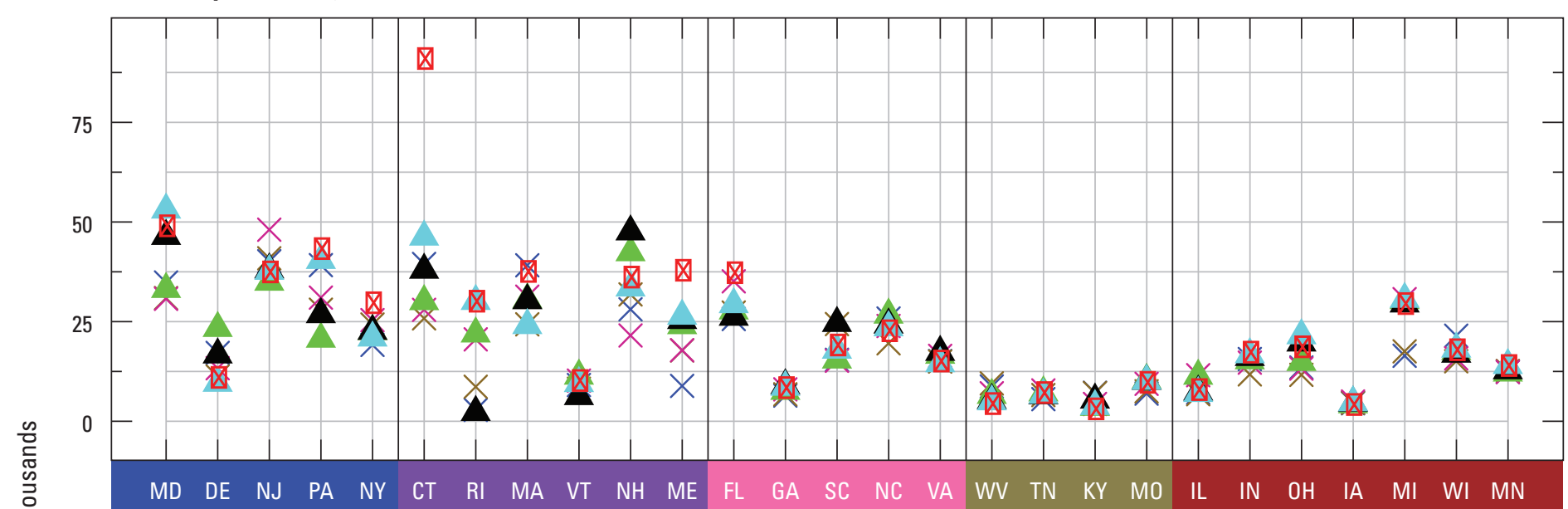

\section{EXPLANATION}

[State name abbreviations are

U.S. Postal Service abbreviations]

State and U.S. territory

region

Mid-Atlantic

New England

Southeast Coast

Central

Midwest

Gulf Coast

Plains

Northern Rockies

Southwest

Pacific West

50

50

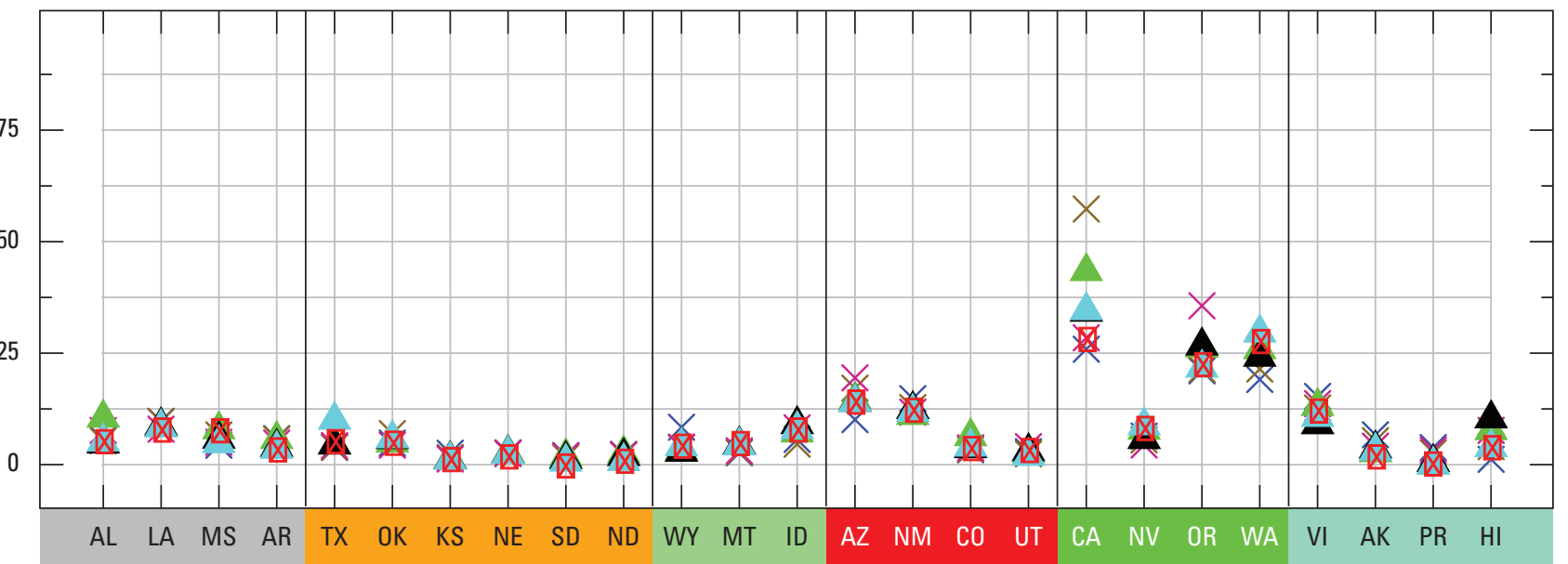

State/territory

Other

Year

$\times \quad 1985$

X 1990

X 1995

- 2000

- 2005

- 2010

叉 2015

Figure 17. County self-supplied domestic population for 1985-2015. $A$, medians and $B$, interquartile ranges.-Continued 
median values, particularly in the Northern Rockies, because of identifiable factors or because of assumptions or errors in the methods?

The table of normalized IQR values for public supply delivery per capita rates includes a relatively large number of high and low values (table 16). Some of this variability might reflect uncertainty. For example, the IQR values normalized by region are low for five of the regions in 2010 and four of the regions in 2015; the values are as low as 0.01 (table 16). The data for 2010 and 2015 may warrant additional evaluation. In addition, the IQRs values normalized by region include low and high years within the New England region (table 16).The data for New England might require additional evaluation. Some of the variability is systematic; for example, (1) the IQR values normalized by year are consistently high for the Northern Rockies, Southwest, and Pacific West; and (2) the IQR values normalized by year are consistently low for the Mid-Atlantic and New England (table 16). These systematic patterns might be due to identifiable factors, such as per capita rates that have remained relatively unchanged from compilation to compilation.

Comparison of the tables for public supply withdrawal and public supply delivery per capita rates also indicates the need for additional evaluation. If withdrawals are typically measured, and deliveries are typically estimated, then the differences may be related to assumptions or errors in the methods. On the other hand, differences may be related to public supply delivery types where urban systems may have large deliveries for multiple types of users, whereas more rural systems may only have deliveries to domestic users. States with counties having mostly rural systems would be expected to have less variation than States with a mix of urban and rural systems.

Regional-scale characteristic medians and IQRs for self-supplied domestic population are listed in tables 17-18, respectively. The median values normalized by region have one low value and no high values; the one low value is for the region labeled Other (table 17). The median values normalized by year have several high and low values, but those values are mostly systematic - the values are consistently high for five regions and consistently low for one region. However, the median values normalized by year have three values (all low) that are not systematic. There are three values, all low, that are not systematic - one each for the Northern Rockies, Southwest, and Other (table 17). The systemic and isolated anomalous values might require additional evaluation.

The IQR values for self-supplied domestic population (table 18) have patterns for values normalized by years that are comparable to those in the table of median values normalized by years (table 17). The IQR values normalized by region do not have high or low values (table 18). The regions that have consistently high and low IQR values normalized by year, except for the Midwest, (table 18) are the same regions that have consistently high and low median values normalized by year (table 17). Additional evaluation of the Midwest region might be warranted.
Regional-scale characteristic medians and IQRs for selfsupplied domestic per capita rates are listed in tables 19-20, respectively. The normalized median values include some high and low values, all of which are in the Other region (table 19). The States of Arkansas and Hawaii and territories of Puerto Rico and U.S. Virgin Islands, which are included in the Other region, are relatively different from each other and, therefore, the observed variability might not require additional evaluation.

The normalized IQR values for self-supplied domestic per capita use rates are relatively variable (table 20). The variability might be methodological, or it might be due to other identifiable factors. As an example of potential methodological concerns, consider the values normalized by region. The following four regions include normalized values that exceed the value of 4-Mid-Atlantic, New England, Central, and Gulf Coast (table 20). These values warrant additional evaluation. As an example of variability, consider the values normalized by year - the Mid-Atlantic, New England, Southeast Coast, and Midwest have values that are consistently low, and the Plains, Southwest, Pacific West, and the Other region have values that are consistently high (table 20). This variability is systematic and might be related to climate or other identifiable factors. These regional patterns might not require additional evaluation.

Regional-scale characteristic medians and IQRs for irrigation application rates are listed in tables 21-22, respectively. The median values normalized by region include values that are systematically low or high - all the low values are in 1985 and 1990, and the two high values are in 2005 and 2015 (table 21). Is the pattern in time related to climate or to methodology? A systematic pattern also can be seen in the median values normalized by year (table 21). The values for the Central (for 6 years) and Midwest (for 3 years) are consistently low, and the values for the Northern Rockies, Southwest, and Pacific West are consistently high (table 21). These regional patterns might not require additional evaluation.

The IQR values for irrigation application rates also are relatively variable. The IQR values normalized by region include high and low values in five of the regions and indicate no clear pattern (table 22). These values might need additional evaluation. The IQR values normalized by year do indicate systematic patterns - low values in cooler, wetter regions and high values in warmer, drier regions (table 22). These regional patterns might not require additional evaluation.

Regional-scale characteristic medians and IQRs for thermoelectric power rates are listed in tables 23 and 24, respectively. The median values normalized by region indicate variability that appears systematic - two high values in 2005 , two of the three low values in 2015, and no high or low values in 2010 (table 23). Are these patterns related to climate or other identifiable factors, or are these patterns related to assumptions or errors in methodology? The median values normalized by year are more variable. Some of the variability is systematic - higher values in cooler, wetter regions 


\section{A. Medians}

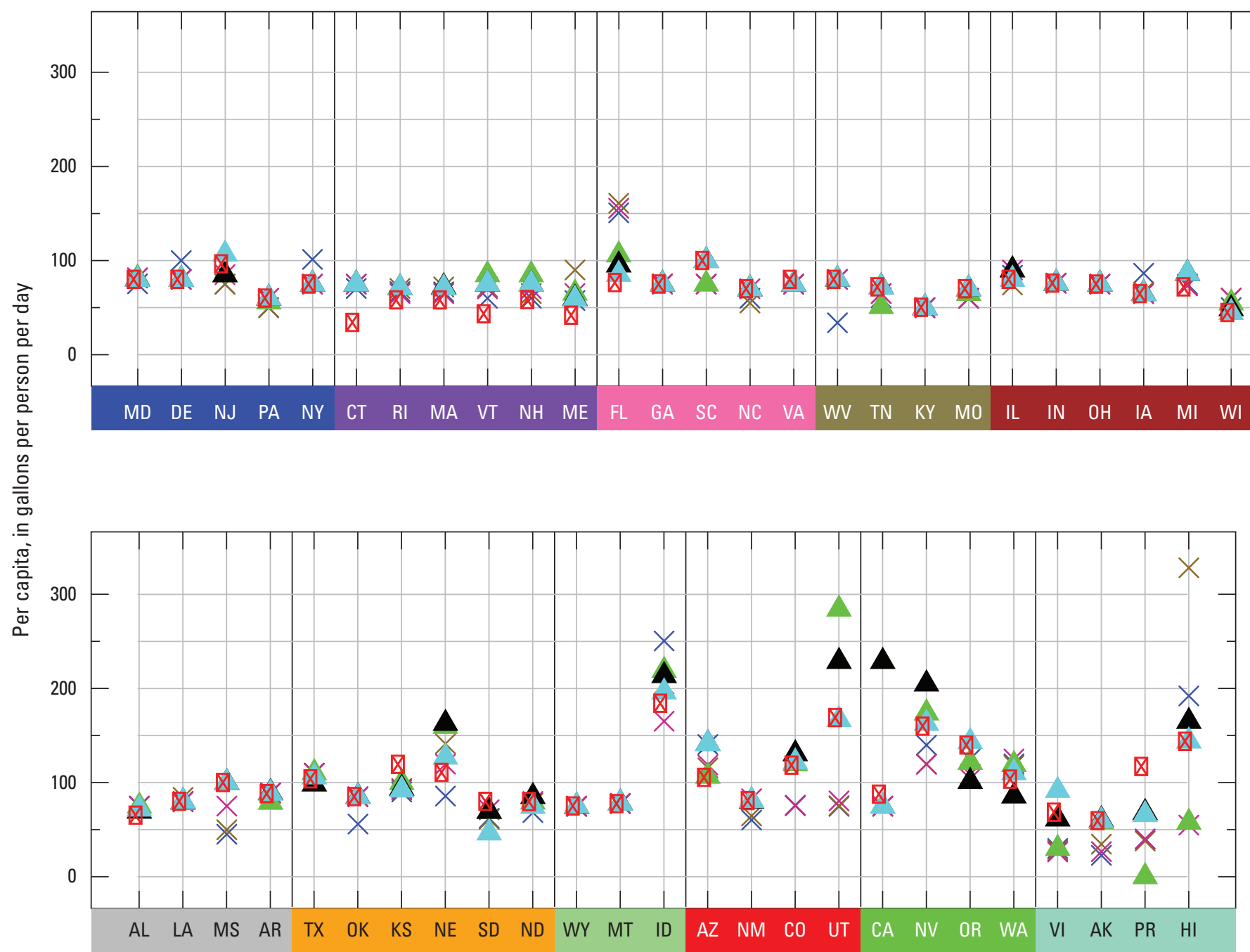

State/territory

2000

- 2005

- 2010

囚 2015

Figure 18. County domestic per capita rates for 1985-2015. $A$, medians and $B$, interquartile ranges. 
B. Interquartile ranges

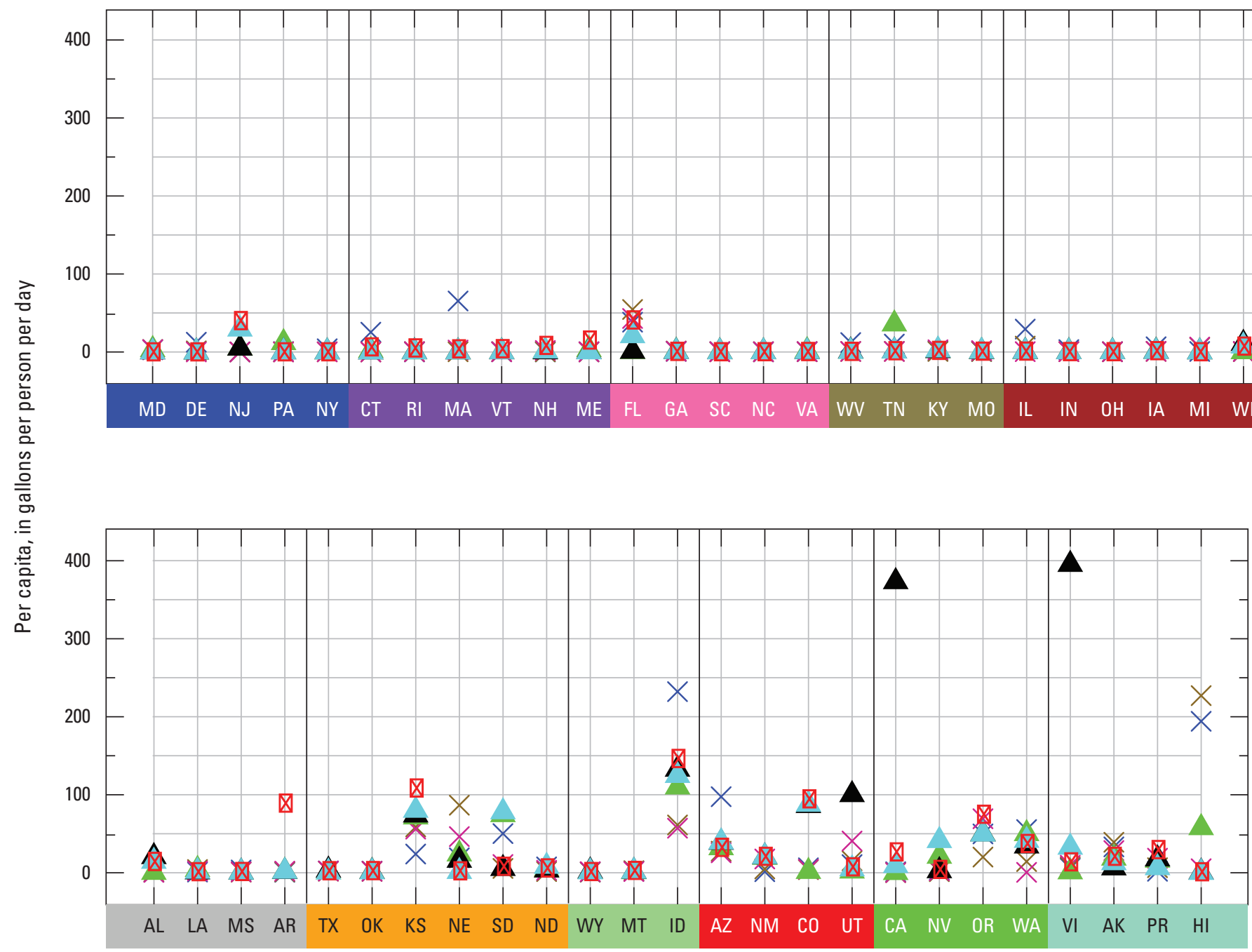

State/territory

\section{EXPLANATION}

[State name abbreviations are

U.S. Postal Service abbreviations]

State and U.S. territory region

Mid-Atlantic

New England

Southeast Coast

Central

Midwest

Gulf Coast

Plains

Northern Rockies

Southwest

Pacific West

Other

X 1985

X 1990

X 1995

- 2000

- 2005

- 2010

囚 2015

Figure 18. County domestic per capita rates for 1985-2015. $A$, medians and $B$, interquartile ranges. - Continued 


\section{A. Golf course irrigation}
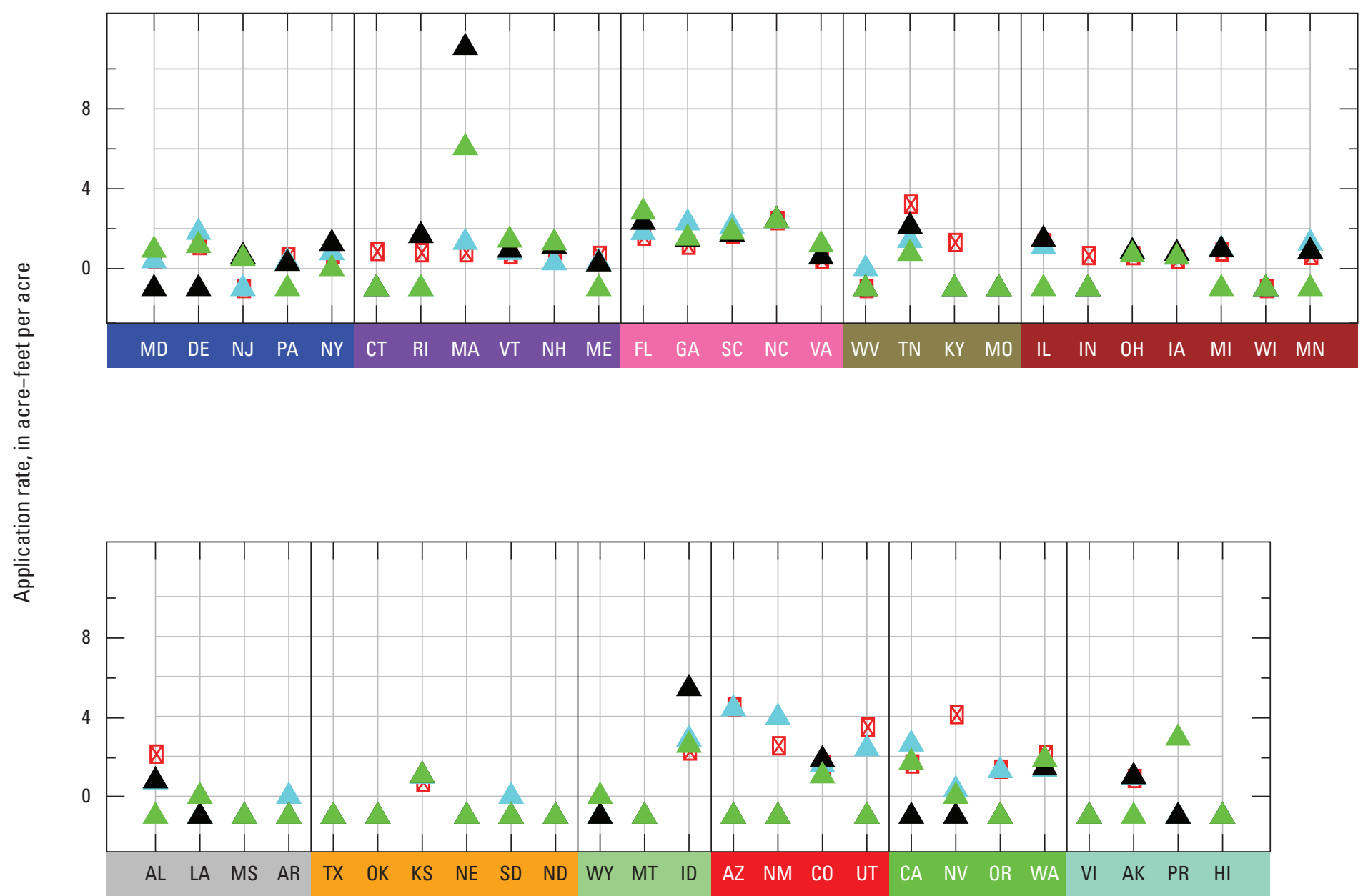

State/territory $\infty$

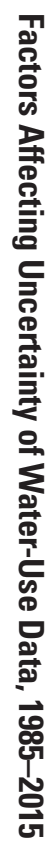

Pacific West

Other

Year

A 2000

A 2005

2010

囚 2015

Figure 19. Irrigation application rates, by State, for 2000-15. $A$, golf course irrigation, $B$, agricultural crop irrigation, and $C$, total irrigation. 
B. Agricultural crop irrigation

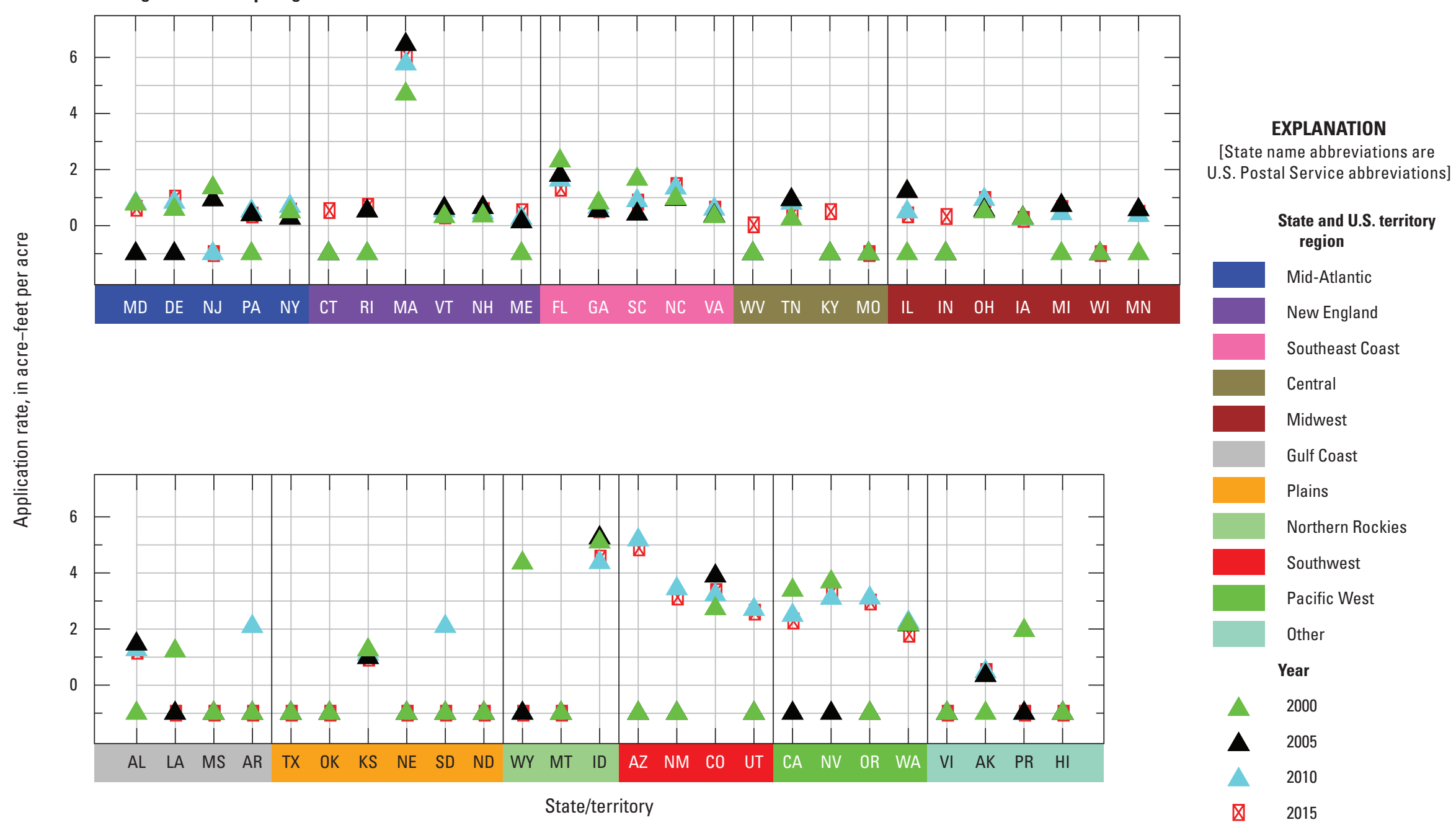

Figure 19. Irrigation application rates, by State, for 2000-15. $A$, golf course irrigation, $B$, agricultural crop irrigation, and $C$, total irrigation. -Continued 


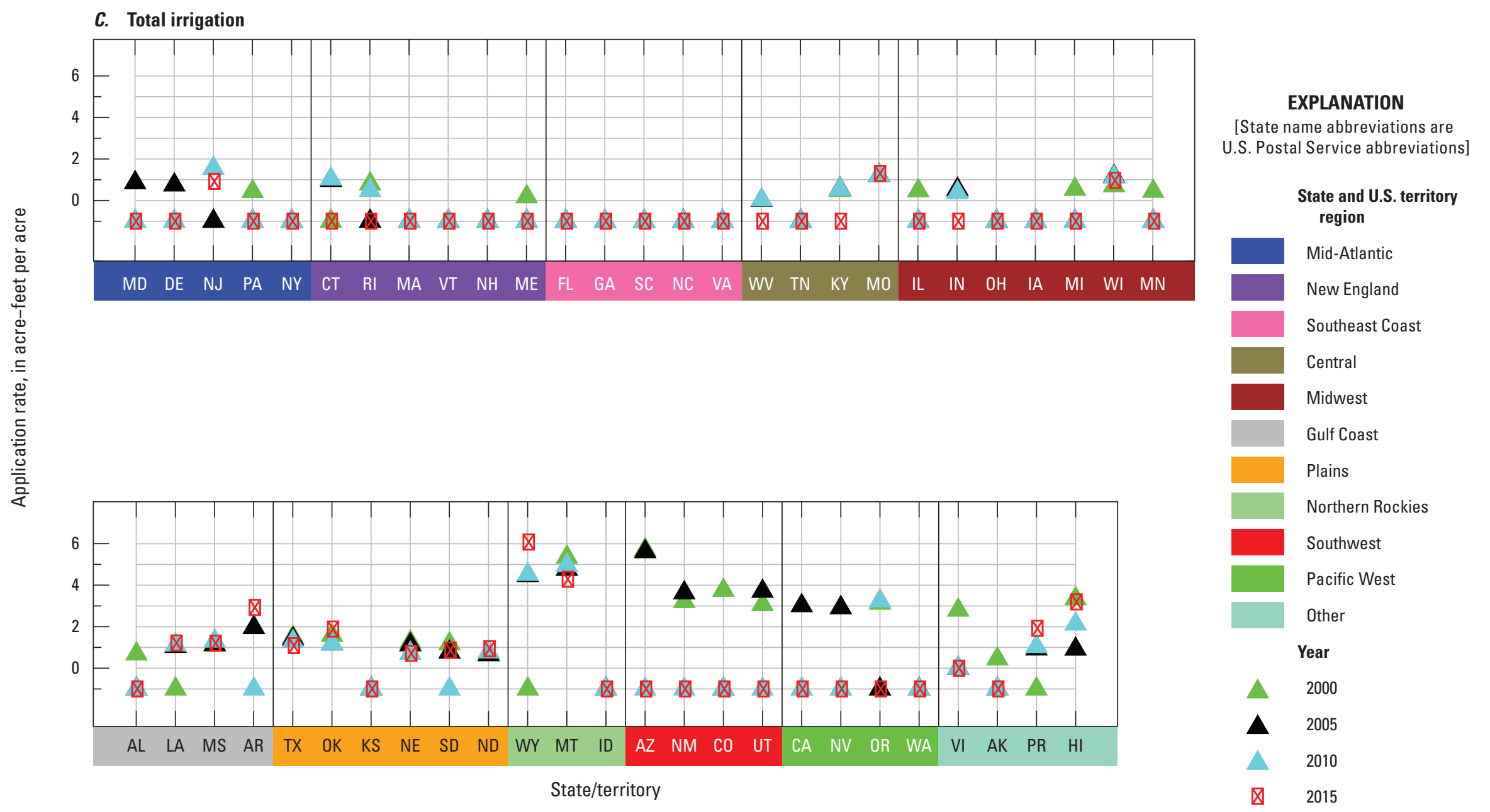

Figure 19. Irrigation application rates, by State, for 2000-15. $A$, golf course irrigation, $B$, agricultural crop irrigation, and $C$, total irrigation.-Continued 


\section{A. Combined crop and golf courses}

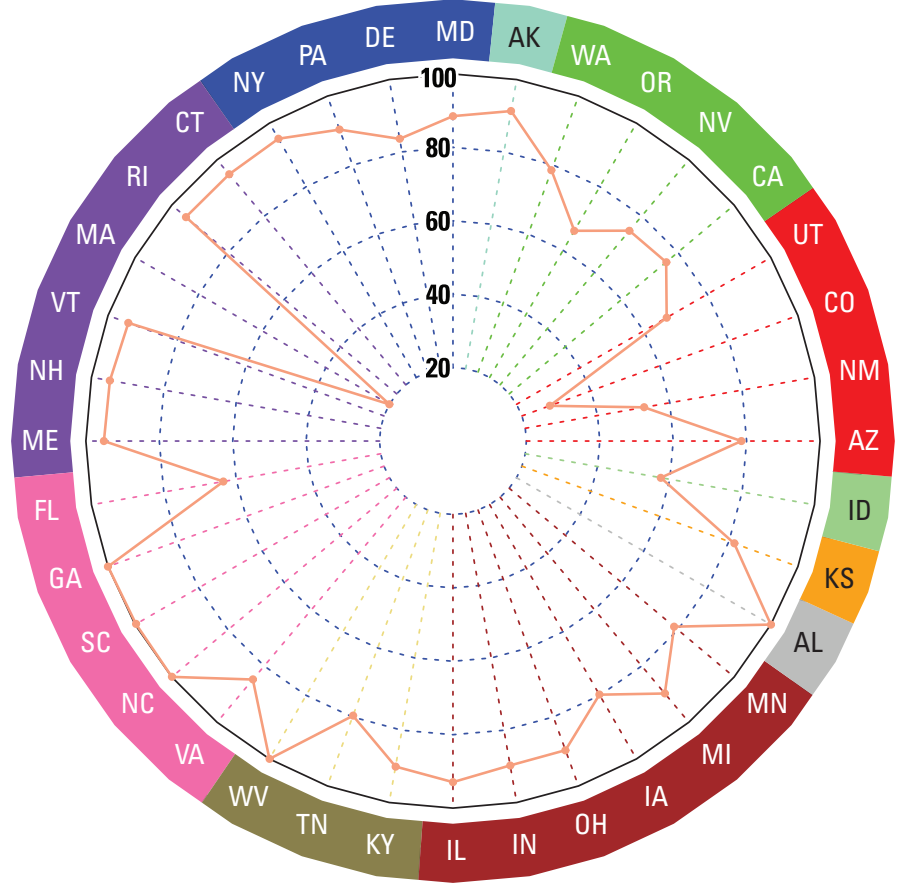

B. Total irrigation

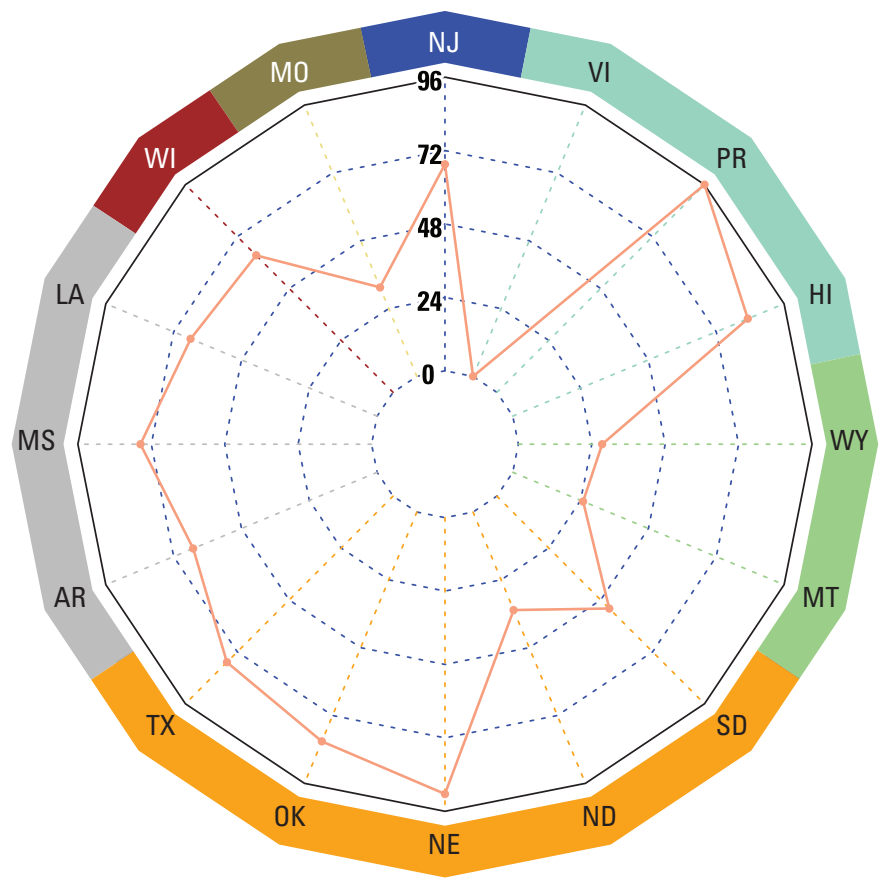

\section{EXPLANATION}

[State name abbreviations are U.S. Postal Service abbreviations]

\section{State and U.S. territory region}

Mid-Atlantic

New England

Southeast Coast

Central

Midwest

Gulf Coast

Plains

Northern Rockies

Southwest

Pacific West

Other

$\longrightarrow$ Consumptive use

100

Consumptive use, in percent

Figure 20. Consumptive use percentage, by State, for 2015. $A$, combined crop and golf courses and $B$, total irrigation. 


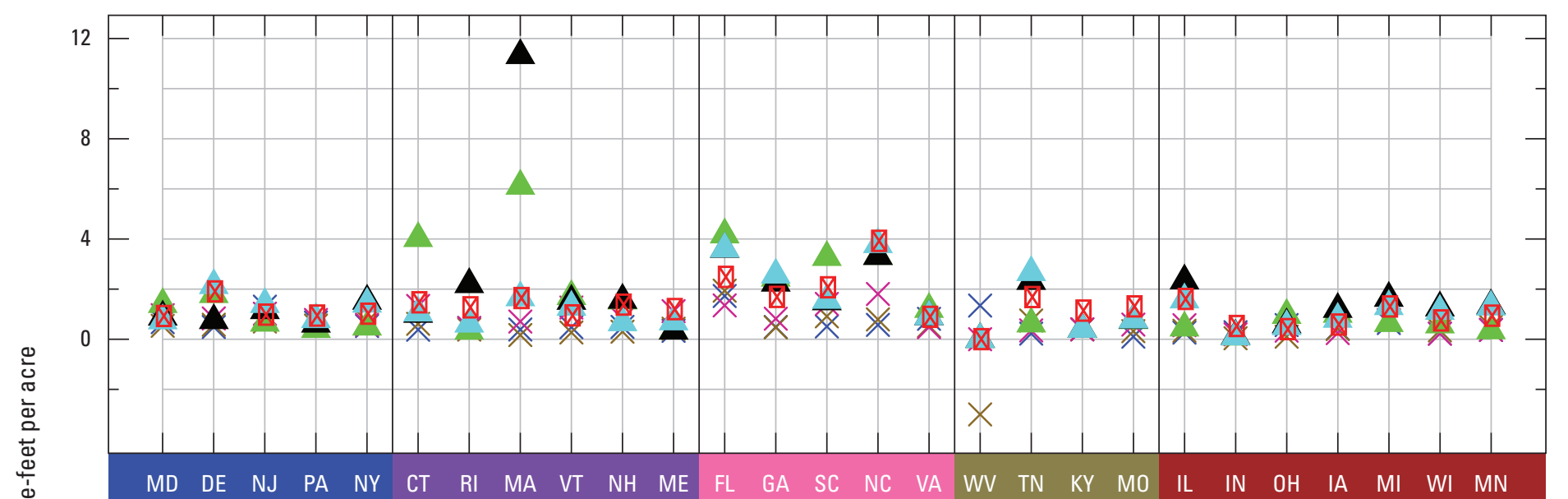

\section{EXPLANATION}

[State name abbreviations are

U.S. Postal Service abbreviations]

State and U.S. territory

region

Mid-Atlantic

New England

Southeast Coast

Central

Midwest

Gulf Coast

Plains

Northern Rockies

Southwest

Pacific West

Other

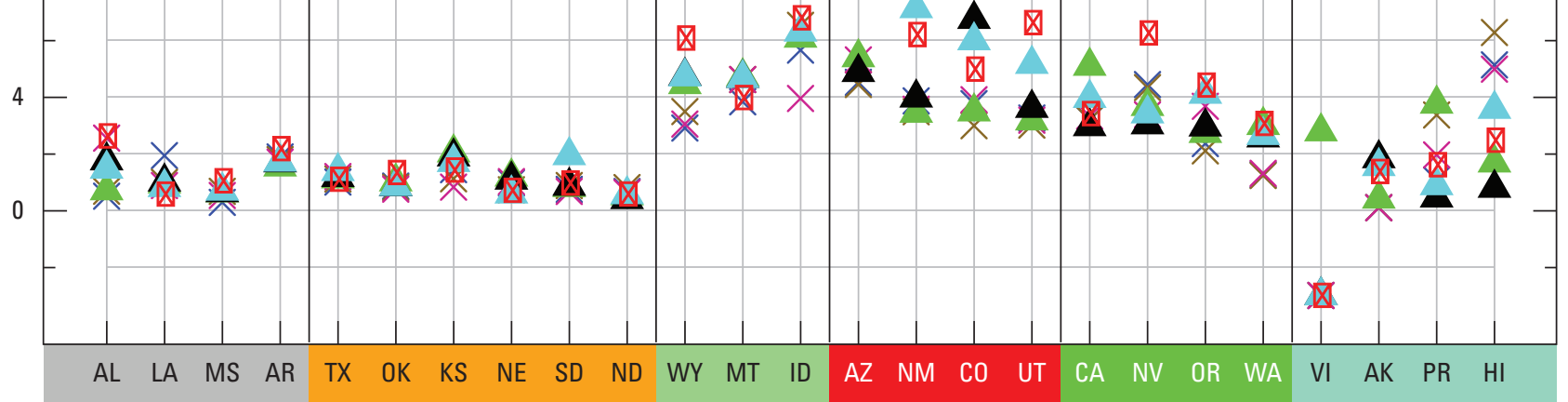

Year

X 1985

$\times \quad 1990$

X 1995

- 2000

State/territory

- 2005

- 2010

囚 2015

Figure 21. County irrigation application rate for combined crop and golf and total irrigation for 1985-2015. $A$, medians and $B$, interquartile ranges. 
B. Interquartile ranges

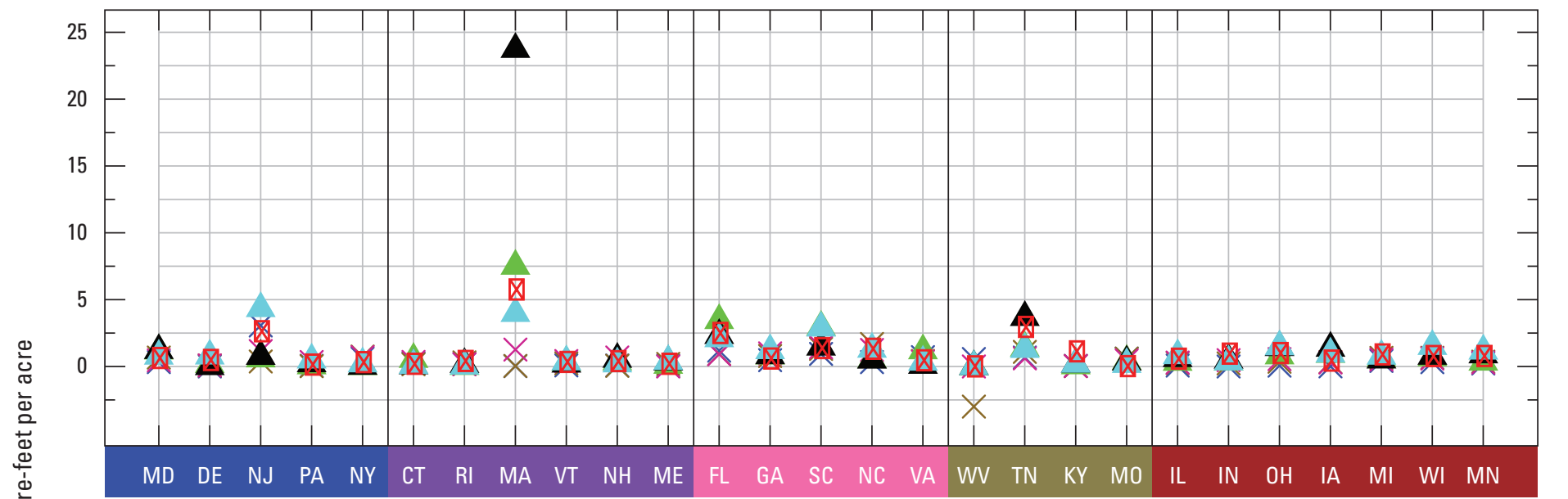

\section{EXPLANATION}

[State name abbreviations are

U.S. Postal Service abbreviations]

State and U.S. territory

region

Mid-Atlantic

New England

Southeast Coast

Central

Midwest

Gulf Coast

Plains

Northern Rockies

Southwest

Pacific West

Other

Year

X 1985

$\times \quad 1990$

X 1995

- 2000

$\triangle \quad 2005$

2010

囚 2015

Figure 21. County irrigation application rate for combined crop and golf and total irrigation for $1985-2015$. $A$, medians and $B$, interquartile ranges.-Continued 


\section{A. Thermoelectric power rates-0nce-through cooling system}

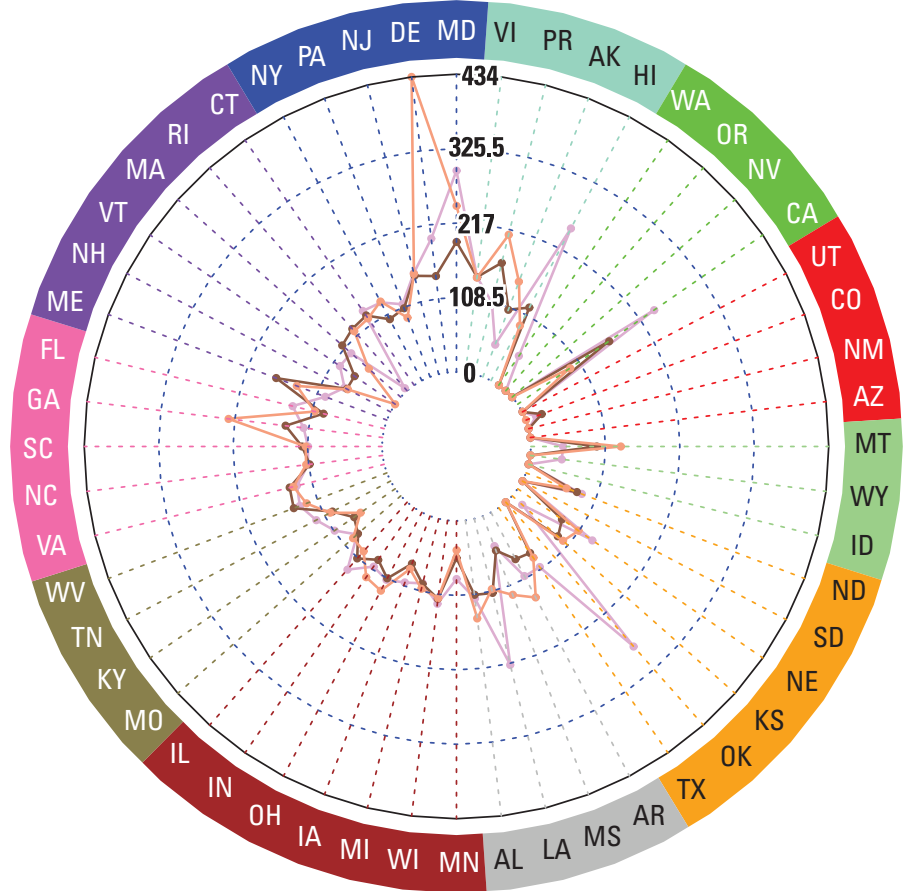

B. Thermoelectric power rates-Closed-loop cooling system

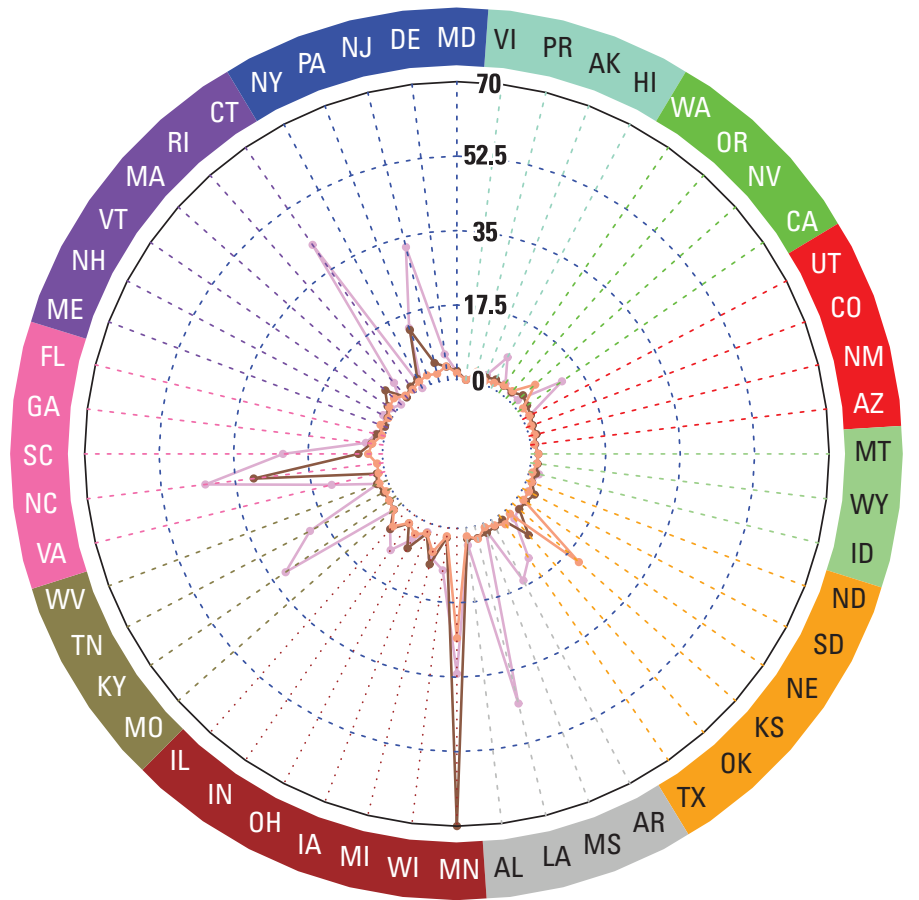

\section{EXPLANATION}

[State name abbreviations are U.S. Postal Service abbreviations] State and U.S. territory region

Mid-Atlantic

New England

Southeast Coast

Central

Midwest

Gulf Coast

Plains

Northern Rockies

Southwest

Pacific West

Other

Year

$\longrightarrow 2005$

$\longrightarrow 2010$

2015

434 Thermoelectric power rate, in gallons per day per megawatt hour

Figure 22. Thermoelectric power rates, by State, for 2005-15. A, once-through cooling system and $B$, closed-loop cooling system. 


\section{A. Consumptive use-Once-through cooling system}

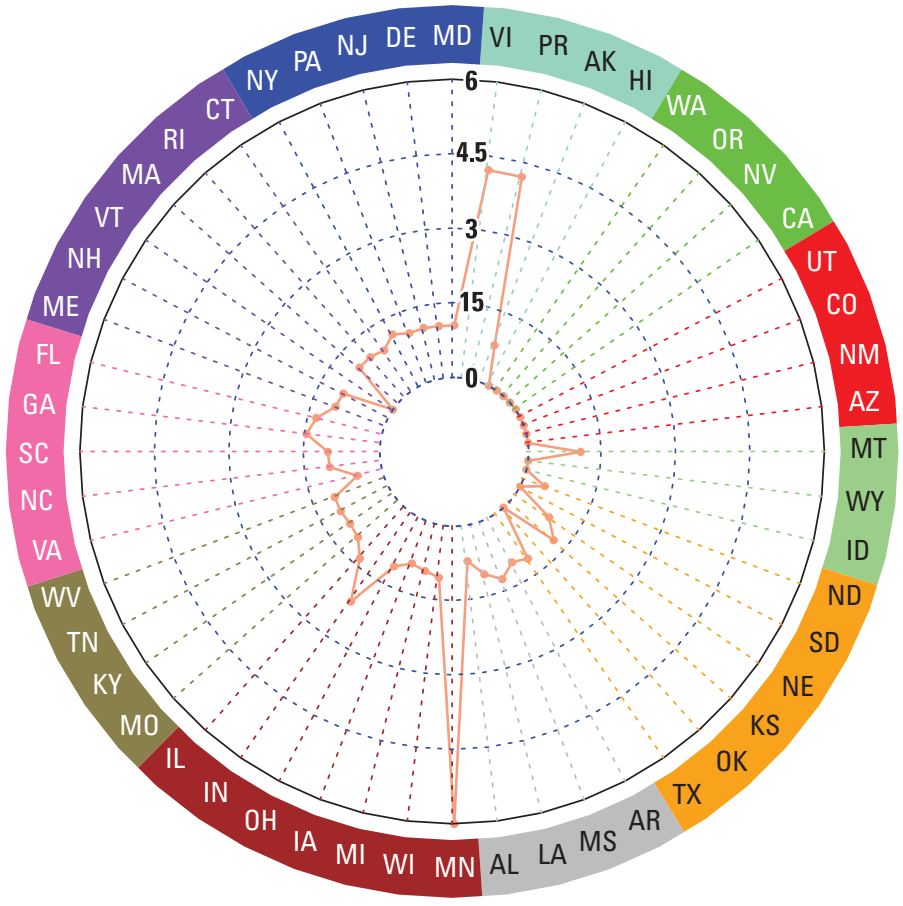

EXPLANATION

[State name abbreviations are U.S. Postal Service abbreviations]

\section{B. Consumptive use-Closed-loop cooling system}
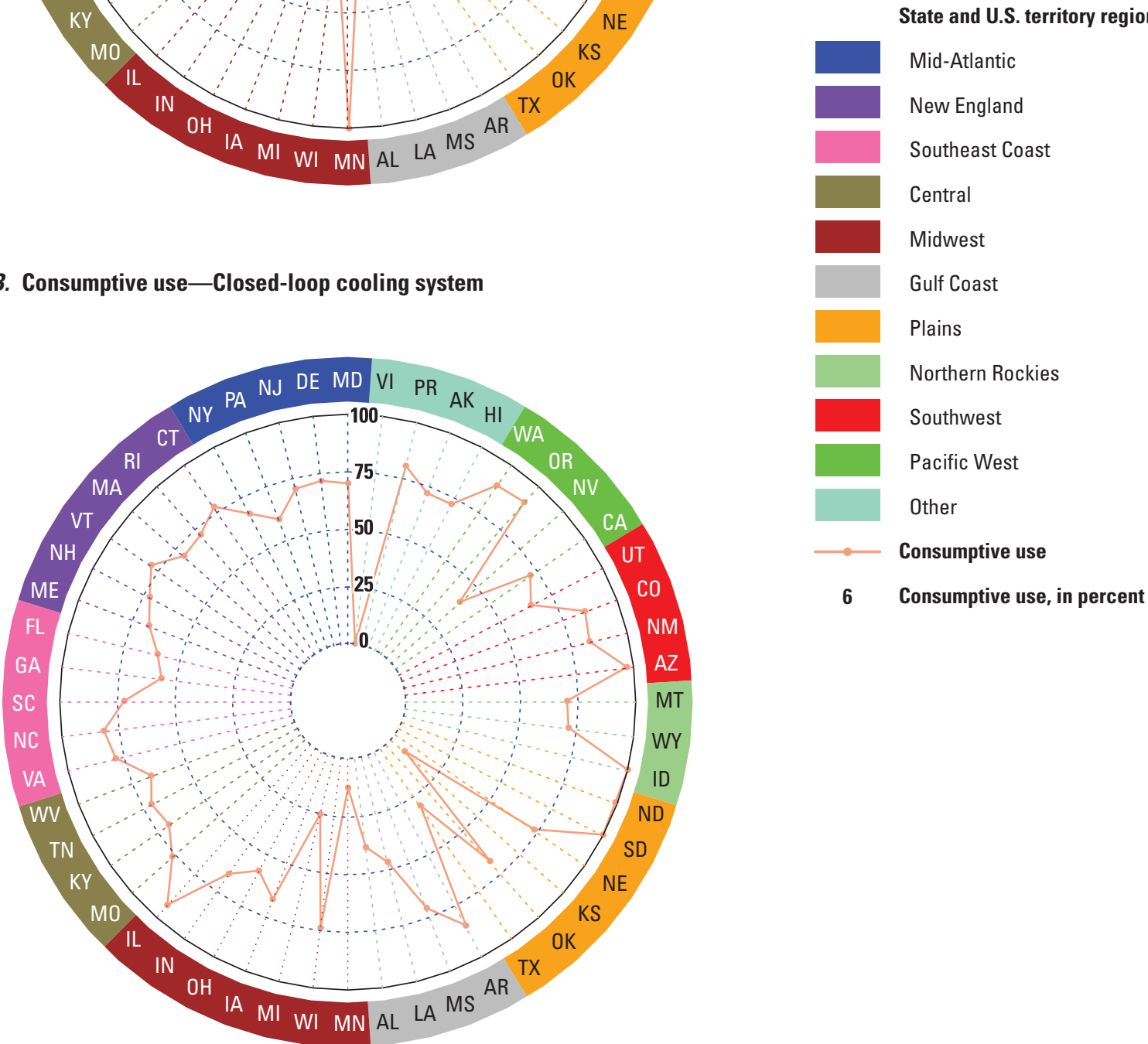

Figure 23. Consumptive use percentages for thermoelectric power, by State, for 2015. $A$, once-through cooling system and $B$, closed-loop cooling system. 


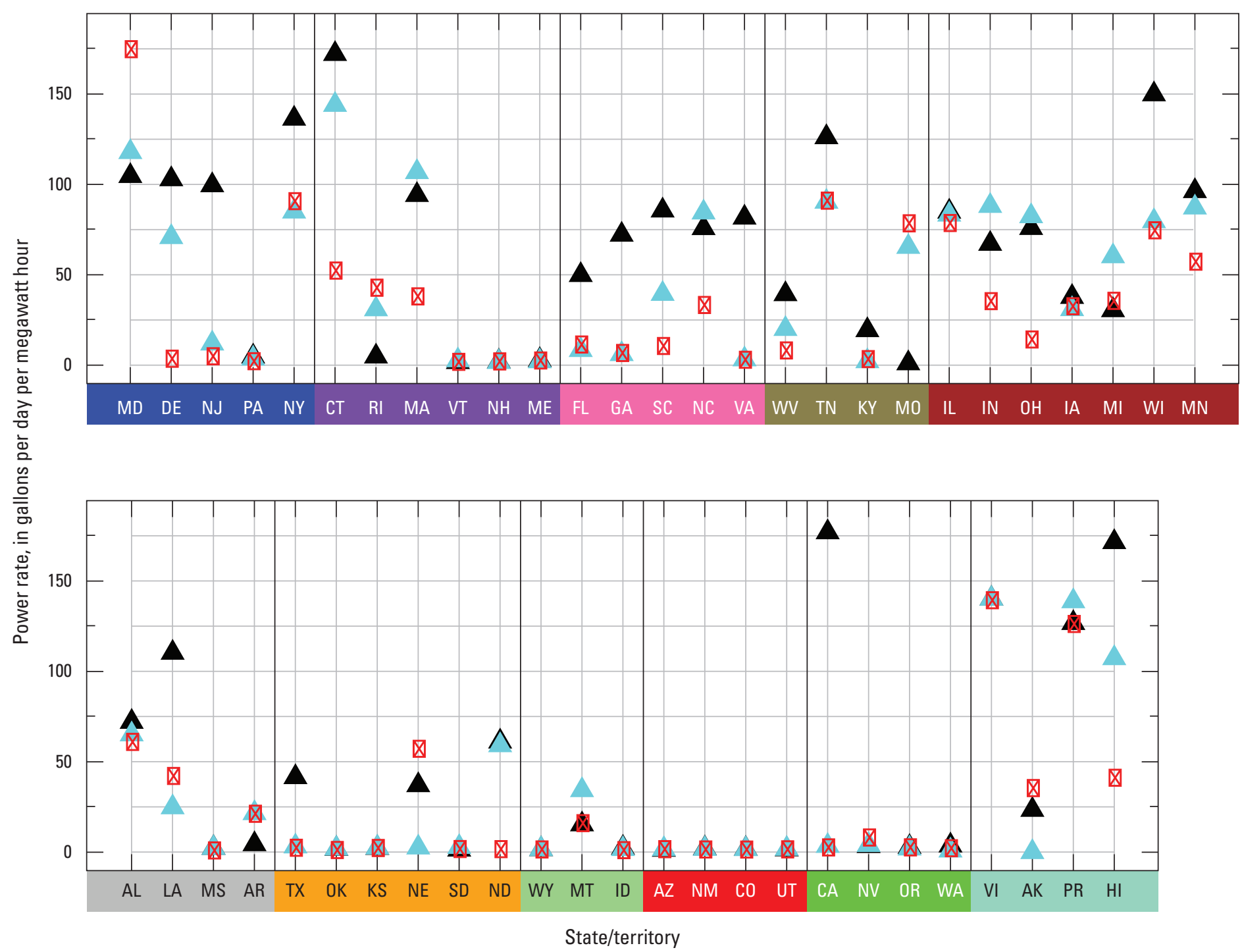

Figure 24. County thermoelectric power rate for 2005-15. $A$, medians and $B$, interquartile ranges. 


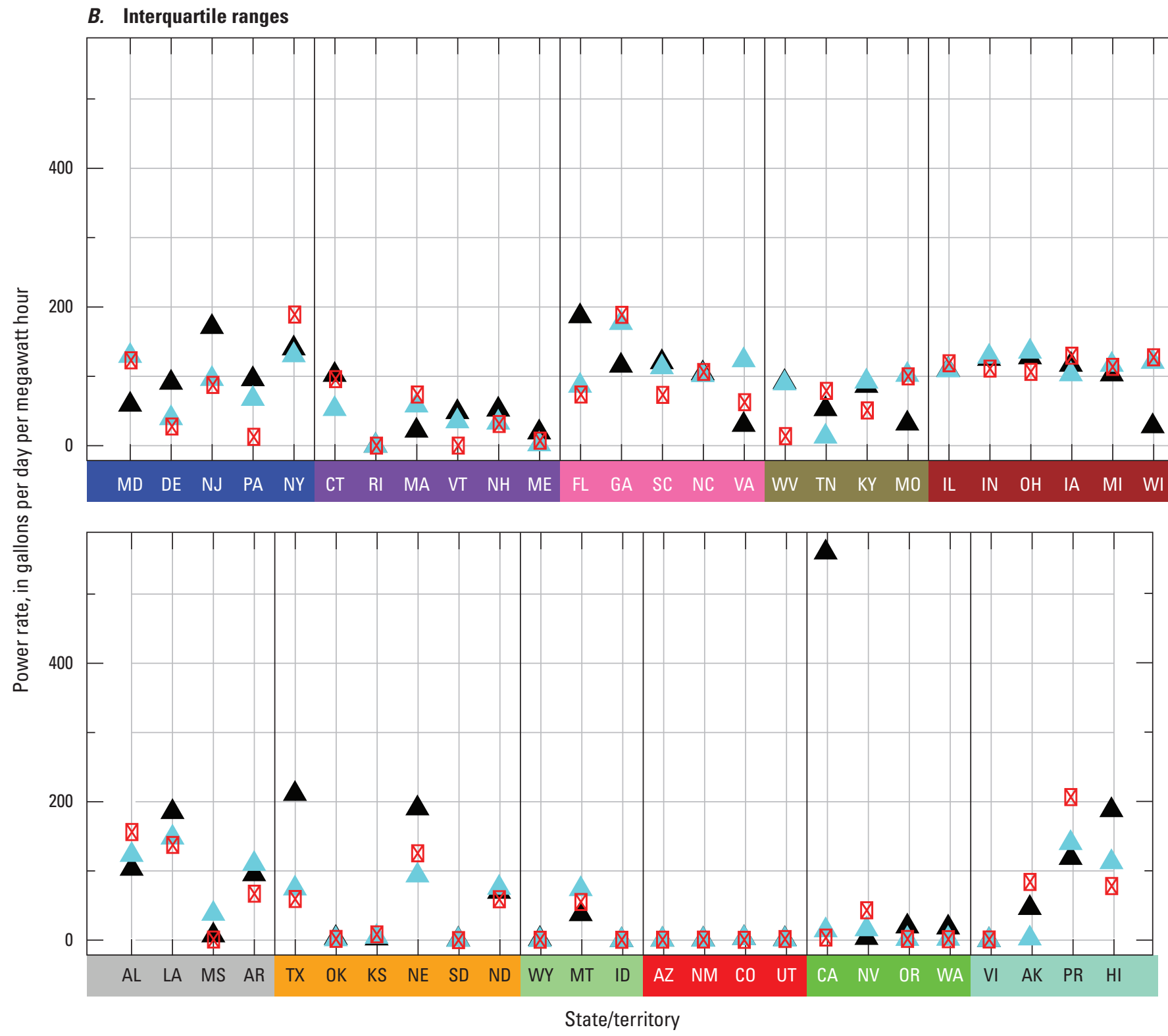

EXPLANATION

[State name abbreviations are

U.S. Postal Service abbreviations]
U.

State and U.S. territory region

Mid-Atlantic

New England

Southeast Coast

Central

Midwest

Gulf Coast

Plains

Northern Rockies

Southwest

Pacific West

Other

Year

- 2005

2010

囚 2015

Figure 24. County thermoelectric power rate for 2005-15. $A$, medians and $B$, interquartile ranges. - Continued 
and lower values in warmer, drier regions (table 23). These regional patterns might not require additional evaluation. Some of the variability is not systematic - the Mid-Atlantic and Southeast Coast regions include values that are high and low (table 23). These data may require additional evaluation.

The IQR values for thermoelectric power rates include values that are high and low. The IQR values normalized by region include high and low values in two of the regions and indicate no clear pattern (table 24). These values might need additional evaluation. The IQR values normalized by year do indicate systematic patterns - consistently low values in the Northern Rockies, Southwest, and Pacific West (table 24). The regional pattern might not require additional evaluation.

The analysis of variability by region at the scale of the United States could be implemented at smaller scales. A region could be selected, and then the variability of a wateruse component could be evaluated by State. However, because there are 11 regions and 5 water-use components, the process would require considerable effort and is beyond the scope of the current analysis.

\section{Guidance for Additional Uncertainty Assessments and Water-Use Compilations}

Uncertainty in the water-use estimates reported for the 5 -year compilations needs to be quantified to indicate data quality. The uncertainty information will indicate the suitability of using these data in other analyses, such as trend studies. Uncertainty arises as reported or estimated values differ from actual water use. Because of the many ways that water-use data have been collected, assembled, and estimated, multiple factors likely contribute to data uncertainty. For example, a water-use value may be estimated using a coefficient from a previous compilation (so not based on current climate and socioeconomic conditions) and may need to be disaggregated for reporting at the county scale. Similarly, a water-use value may be provided from a State agency or facility, but additional metadata are not available to indicate whether the value was based on a meter reading or was estimated using other information, such as pump capacity, pump run time, or number of service connections. These furnished water-use data may not specify source of water (so the proportion of groundwater and surface water needs to be determined). Identification and evaluation of these factors are needed before uncertainty can be quantified.

During this study, factors that may affect data quality and variability were evaluated through analysis of information sources, estimation methods, and 2015 water-use data characteristics. The prevalence of reported data, estimation methods, spatial scale of reporting or estimating date of source information or coefficients, and water source assumptions were evaluated. Information for these factors was compiled from available metadata about the water-use compilations or from 2015 method codes; however, this information was sometimes sparse or unavailable, especially for earlier compilations.

Data collection and documentation of methods and information sources for all categories have generally improved since the 1985 to the 2015 compilation. However, additional improvements are needed to provide metadata for the wateruse data. For example, more extensive documentation of information sources and estimation methods is needed so that users of the data understand compilation methods. Where reporting programs are in place for any of these categories, additional information is needed for determining data quality and uncertainty including, (1) requiring metadata on the provided data to better understand how these data were collected, measured, or estimated by each entity; (2) improving reporting information to document facility information coverages and reporting percentages; and (3) providing temporal and spatial reporting frequencies. An emphasis on improved data reporting, including metadata from State reporting programs, is needed to better quantify possible sources of error for data that are furnished to the USGS.

The addition of method codes in 2015 provided much needed metadata for users of the data; however, some refinements and revisions are needed to correct unclear or ambiguous coding. Some method codes could be more descriptive, such as revising the method code for communication (indicating information received as oral, emailed, or written communication), to better describe the entity supplying the water-use information. Conventions such as listing the method code describing the primary method first or not using method codes to describe ancillary data could be more consistently followed. Additionally, more information is needed to distinguish where withdrawals are not known to exist, where withdrawals are assumed to be zero, and where information is not available.

The method codes could be supplemented with additional coding to add more information. Representation of the spatial scale for furnished reported and estimated data is needed, along with an indication of the percentage of the data represented by each method. Sources could be better described; for example, a per capita rate coefficient could be assigned a code to indicate where the coefficient came from and a year for when the coefficient was determined. In addition, listing the actual source of the coefficient rather than indicating use from a previous compilation would provide more information for users of the data. Likewise, where data elements consist of more than one component, such as irrigated acres by system type, distinguishing between method codes and more documentation for each component are needed. Code descriptions could be clarified so that individuals assigning and using the methods could better distinguish how the data were provided or estimated. For example, more clarification is needed to determine if provided data have been modified and what types of modifications were performed. Additional codes also could be added to indicate if data from a non-compilation year are being used. 
Table 13. Median values for public supply withdrawal per capita use rates, in gallons per person per day, determined using total withdrawals divided by population served, normalized by region and year, for the compilations from 1985 through 2015.

\begin{tabular}{|c|c|c|c|c|c|c|c|}
\hline Region & 1985 & 1990 & 1995 & 2000 & 2005 & 2010 & 2015 \\
\hline \multicolumn{8}{|c|}{ Regional-scale characteristic medians } \\
\hline Mid-Atlantic & 132.74 & 156.53 & 151.24 & 121.48 & 119.26 & 115.61 & 113.65 \\
\hline New England & 133.77 & 126.90 & 140.98 & 125.87 & 121.59 & 109.22 & 109.29 \\
\hline Southeast Coast & 140.94 & 152.44 & 154.15 & 161.69 & 147.89 & 135.74 & 125.00 \\
\hline Central & 108.82 & 134.35 & 118.51 & 129.75 & 124.31 & 123.65 & 114.92 \\
\hline Midwest & 130.09 & 134.98 & 137.32 & 131.91 & 128.40 & 122.20 & 117.28 \\
\hline Gulf Coast & 125.44 & 141.65 & 152.80 & 162.58 & 153.77 & 158.95 & 148.11 \\
\hline Plains & 152.22 & 171.55 & 149.23 & 173.84 & 165.03 & 154.48 & 137.67 \\
\hline Northern Rockies & 286.60 & 248.11 & 214.32 & 237.57 & 244.11 & 245.73 & 214.85 \\
\hline Southwest & 225.23 & 210.05 & 230.38 & 212.29 & 185.34 & 195.01 & 184.60 \\
\hline Pacific West & 260.40 & 261.25 & 224.89 & 212.20 & 209.91 & 209.01 & 194.29 \\
\hline Other & 144.48 & 202.84 & 141.30 & 123.86 & 131.17 & 133.09 & 129.77 \\
\hline \multicolumn{8}{|c|}{ Median values normalized by region } \\
\hline Mid-Atlantic & 1.09 & 1.29 & 1.25 & 1.00 & 0.98 & 0.95 & 0.94 \\
\hline New England & 1.06 & 1.01 & 1.12 & 1.00 & 0.97 & 0.87 & 0.87 \\
\hline Southeast Coast & 0.95 & 1.03 & 1.04 & 1.09 & 1.00 & 0.92 & 0.85 \\
\hline Central & 0.88 & 1.09 & 0.96 & 1.05 & 1.01 & 1.00 & 0.93 \\
\hline Midwest & 1.00 & 1.04 & 1.06 & 1.01 & 0.99 & 0.94 & 0.90 \\
\hline Gulf Coast & 0.82 & 0.93 & 1.00 & 1.06 & 1.01 & 1.04 & 0.97 \\
\hline Plains & 0.99 & 1.11 & 0.97 & 1.13 & 1.07 & 1.00 & 0.89 \\
\hline Northern Rockies & 1.17 & 1.02 & 0.88 & 0.97 & 1.00 & 1.01 & 0.88 \\
\hline Southwest & 1.07 & 1.00 & 1.10 & 1.01 & 0.88 & 0.93 & 0.88 \\
\hline Pacific West & 1.23 & 1.23 & 1.06 & 1.00 & 0.99 & 0.98 & 0.92 \\
\hline Other & 1.09 & 1.52 & 1.06 & 0.93 & 0.99 & 1.00 & 0.98 \\
\hline \multicolumn{8}{|c|}{ Median values normalized by year (blue indicates a region that is high relative to other regions within a year) } \\
\hline Mid-Atlantic & 0.94 & 1.00 & 1.00 & 0.75 & 0.81 & 0.85 & 0.88 \\
\hline New England & 0.95 & 0.81 & 0.93 & 0.78 & 0.82 & 0.80 & 0.84 \\
\hline Southeast Coast & 1.00 & 0.97 & 1.02 & 1.00 & 1.00 & 1.00 & 0.96 \\
\hline Central & 0.77 & 0.86 & 0.78 & 0.80 & 0.84 & 0.91 & 0.89 \\
\hline Midwest & 0.92 & 0.86 & 0.91 & 0.82 & 0.87 & 0.90 & 0.90 \\
\hline Gulf Coast & 0.89 & 0.90 & 1.01 & 1.01 & 1.04 & 1.17 & 1.14 \\
\hline Plains & 1.08 & 1.10 & 0.99 & 1.08 & 1.12 & 1.14 & 1.06 \\
\hline Northern Rockies & 2.03 & 1.59 & 1.42 & 1.47 & 1.65 & 1.81 & 1.66 \\
\hline Southwest & 1.60 & 1.34 & 1.52 & 1.31 & 1.25 & 1.44 & 1.42 \\
\hline Pacific West & 1.85 & 1.67 & 1.49 & 1.31 & 1.42 & 1.54 & 1.50 \\
\hline Other & 1.03 & 1.30 & 0.93 & 0.77 & 0.89 & 0.98 & 1.00 \\
\hline
\end{tabular}


Table 14. Interquartile ranges for public supply withdrawal per capita use rates determined using total withdrawals divided by population served, normalized by region and year, for the compilations from 1985 through 2015.

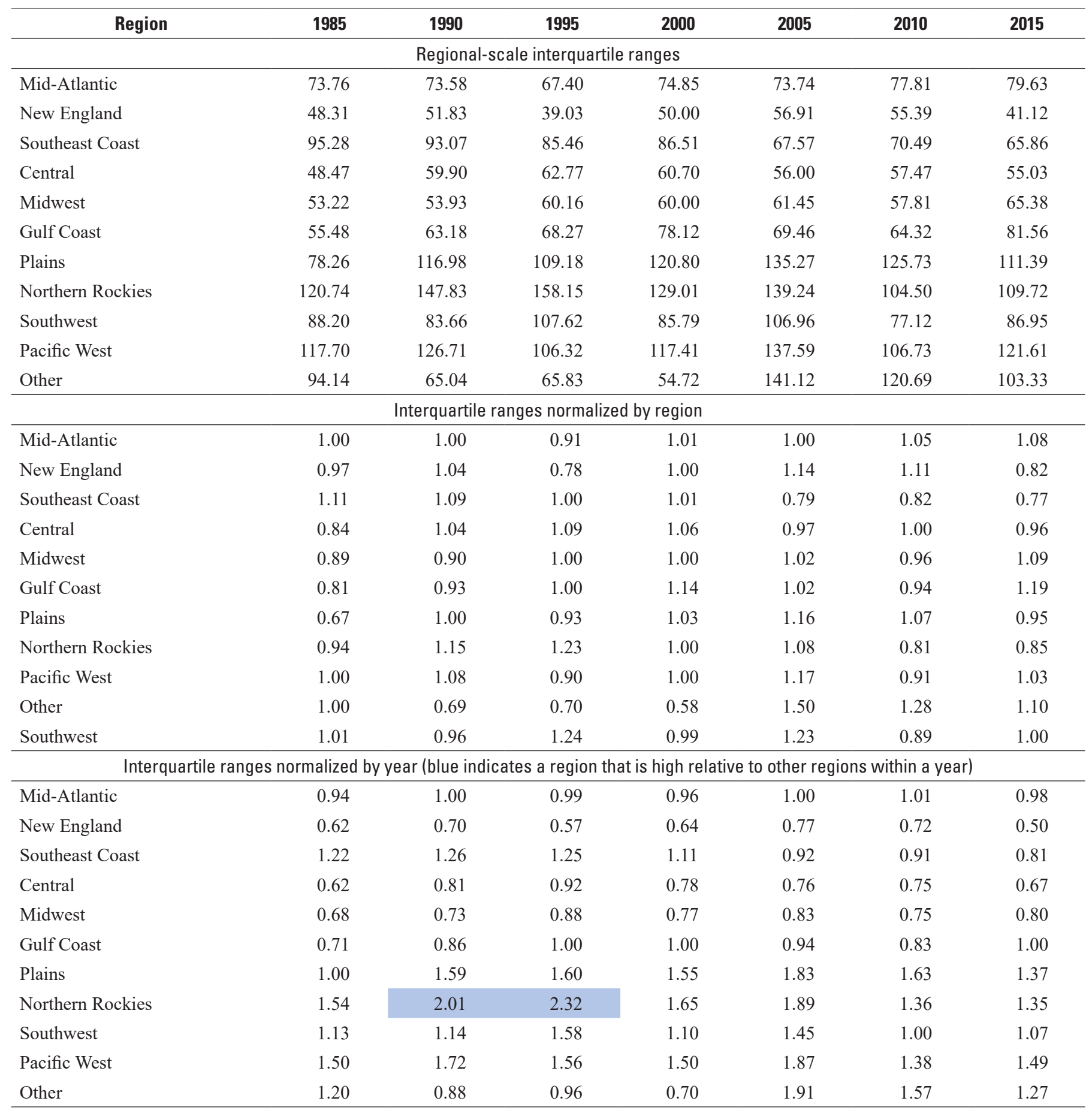


Table 15. Median values for public supply delivery per capita use rates, in gallons per person per day, determined using public supply deliveries divided by population served, normalized by region and year, for the compilations from 1985 through 2015.

[--, no data because public supply deliveries were not required during 2000]

\begin{tabular}{|c|c|c|c|c|c|c|c|}
\hline Region & 1985 & 1990 & 1995 & 2000 & 2005 & 2010 & 2015 \\
\hline \multicolumn{8}{|c|}{ Regional-scale characteristic medians } \\
\hline Mid-Atlantic & 90.04 & 75.00 & 68.54 & -- & 67.94 & 75.01 & 75.00 \\
\hline Southeast Coast & 90.28 & 75.01 & 91.64 & -- & 88.20 & 77.85 & 79.82 \\
\hline Central & 64.99 & 71.80 & 72.48 & -- & 80.76 & 80.50 & 80.29 \\
\hline Gulf Coast & 88.40 & 102.61 & 97.99 & -- & 97.07 & 99.99 & 94.49 \\
\hline Plains & 77.20 & 89.15 & 93.90 & -- & 99.39 & 87.31 & 76.64 \\
\hline Northern Rockies & 204.67 & 167.83 & 166.19 & -- & 169.63 & 182.42 & 183.64 \\
\hline Southwest & 171.57 & 155.23 & 156.40 & -- & 134.57 & 119.79 & 123.65 \\
\hline Pacific West & 148.64 & 153.70 & 133.08 & -- & 166.52 & 129.98 & 121.68 \\
\hline New England & 1.27 & 1.03 & 1.00 & -- & 1.00 & 0.95 & 0.72 \\
\hline Southeast Coast & 1.07 & 0.89 & 1.09 & -- & 1.05 & 0.93 & 0.95 \\
\hline Central & 0.85 & 0.94 & 0.95 & -- & 1.06 & 1.05 & 1.05 \\
\hline Midwest & 1.09 & 1.06 & 0.93 & -- & 1.05 & 0.95 & 0.90 \\
\hline Gulf Coast & 0.91 & 1.05 & 1.00 & -- & 1.00 & 1.03 & 0.97 \\
\hline Plains & 0.88 & 1.01 & 1.06 & -- & 1.13 & 0.99 & 0.87 \\
\hline Northern Rockies & 1.16 & 0.95 & 0.94 & -- & 0.96 & 1.04 & 1.04 \\
\hline Southwest & 1.18 & 1.07 & 1.08 & -- & 0.93 & 0.83 & 0.85 \\
\hline Central & 0.73 & 0.96 & 0.79 & -- & 0.92 & 1.00 & 1.00 \\
\hline Midwest & 0.84 & 0.98 & 0.70 & -- & 0.82 & 0.82 & 0.78 \\
\hline Gulf Coast & 0.99 & 1.37 & 1.07 & -- & 1.10 & 1.24 & 1.18 \\
\hline Plains & 0.86 & 1.19 & 1.02 & -- & 1.13 & 1.08 & 0.95 \\
\hline Northern Rockies & 2.29 & 2.24 & 1.81 & -- & 1.92 & 2.27 & 2.29 \\
\hline Southwest & 1.92 & 2.07 & 1.71 & -- & 1.53 & 1.49 & 1.54 \\
\hline Pacific West & 1.66 & 2.05 & 1.45 & -- & 1.89 & 1.61 & 1.52 \\
\hline Other & 0.76 & 0.72 & 0.64 & -- & 0.87 & 0.84 & 1.07 \\
\hline
\end{tabular}


Table 16. Interquartile ranges for public supply delivery per capita use rates determined using public supply deliveries divided by population served, normalized by region and year, for the compilations from 1985 through 2015.

[--, no data because public supply deliveries were not required during 2000]

\begin{tabular}{|c|c|c|c|c|c|c|c|}
\hline Region & 1985 & 1990 & 1995 & 2000 & 2005 & 2010 & 2015 \\
\hline \multicolumn{8}{|c|}{ Regional-scale interquartile ranges } \\
\hline Mid-Atlantic & 7.23 & 14.26 & 16.86 & -- & 11.78 & 0.08 & 5.41 \\
\hline Southeast Coast & 34.04 & 18.90 & 29.60 & -- & 16.54 & 0.26 & 0.26 \\
\hline Central & 23.54 & 23.76 & 19.93 & -- & 24.39 & 0.28 & 8.33 \\
\hline Gulf Coast & 29.22 & 37.68 & 33.12 & -- & 46.87 & 7.57 & 8.98 \\
\hline Plains & 37.88 & 51.77 & 49.23 & -- & 47.75 & 21.06 & 13.48 \\
\hline Northern Rockies & 84.60 & 83.74 & 90.62 & -- & 121.92 & 66.18 & 81.07 \\
\hline Southwest & 68.90 & 57.01 & 63.41 & -- & 74.32 & 61.89 & 67.56 \\
\hline Pacific West & 76.24 & 66.51 & 60.19 & -- & 95.67 & 45.42 & 32.14 \\
\hline
\end{tabular}

Interquartile ranges normalized by region (green indicates a year that is low relative to other years within a region, and blue indicates a year that is high relative to other years within a region)

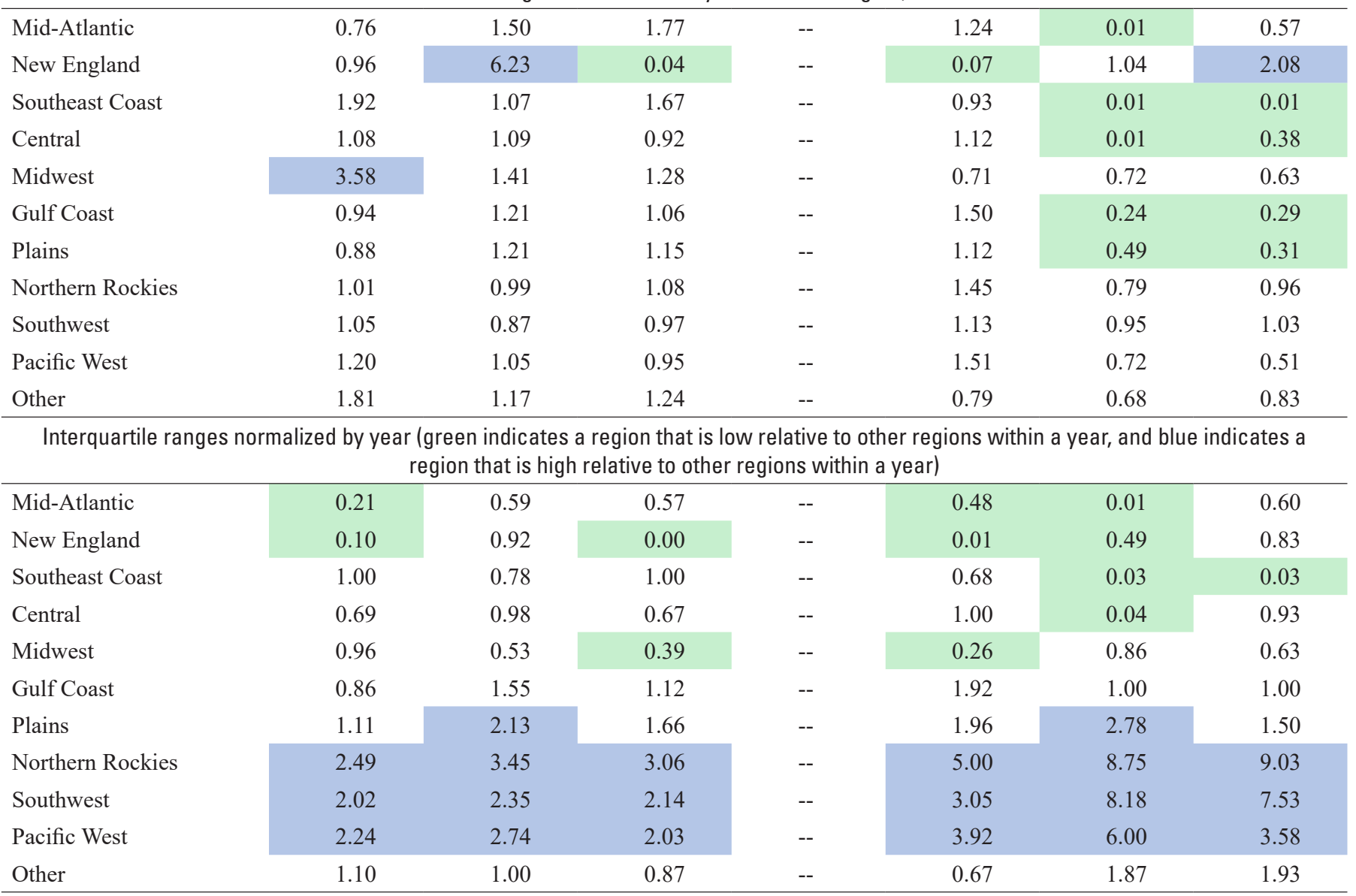


Table 17. Median values for self-supplied domestic population, in thousands of people, normalized by region and year, for the compilations from 1985 through 2015.

\begin{tabular}{|c|c|c|c|c|c|c|c|}
\hline Region & 1985 & 1990 & 1995 & 2000 & 2005 & 2010 & 2015 \\
\hline \multicolumn{8}{|c|}{ Regional-scale characteristic medians } \\
\hline Mid-Atlantic & 38.69 & 31.44 & 32.78 & 35.69 & 29.52 & 39.85 & 40.38 \\
\hline Southeast Coast & 11.21 & 15.11 & 14.97 & 10.97 & 15.97 & 15.76 & 15.90 \\
\hline Central & 6.34 & 6.67 & 5.49 & 4.64 & 3.51 & 4.18 & 4.11 \\
\hline Gulf Coast & 6.10 & 5.15 & 3.49 & 3.92 & 3.31 & 3.11 & 3.03 \\
\hline Plains & 2.42 & 1.81 & 1.92 & 1.69 & 1.48 & 1.18 & 1.10 \\
\hline Northern Rockies & 3.52 & 1.93 & 3.79 & 3.25 & 3.23 & 4.19 & 3.68 \\
\hline Southwest & 3.88 & 3.17 & 4.49 & 4.93 & 4.47 & 3.99 & 3.71 \\
\hline Pacific West & 11.94 & 9.28 & 13.03 & 11.90 & 13.68 & 13.19 & 12.01 \\
\hline New England & 0.73 & 0.93 & 0.94 & 1.03 & 1.07 & 1.00 & 1.12 \\
\hline Southeast Coast & 0.74 & 1.00 & 0.99 & 0.73 & 1.06 & 1.04 & 1.05 \\
\hline Central & 1.37 & 1.44 & 1.18 & 1.00 & 0.76 & 0.90 & 0.89 \\
\hline Midwest & 0.90 & 0.98 & 1.00 & 1.03 & 1.02 & 1.01 & 1.00 \\
\hline Gulf Coast & 1.75 & 1.48 & 1.00 & 1.12 & 0.95 & 0.89 & 0.87 \\
\hline Plains & 1.43 & 1.07 & 1.14 & 1.00 & 0.87 & 0.70 & 0.65 \\
\hline Northern Rockies & 1.00 & 0.55 & 1.08 & 0.92 & 0.92 & 1.19 & 1.05 \\
\hline Southwest & 0.97 & 0.80 & 1.12 & 1.24 & 1.12 & 1.00 & 0.93 \\
\hline
\end{tabular}

Median values normalized by year (green indicates a region that is low relative to other regions within a year, and blue indicates a region that is high relative to other regions within a year)

\begin{tabular}{|c|c|c|c|c|c|c|c|}
\hline Mid-Atlantic & 6.11 & 4.72 & 5.85 & 7.14 & 4.86 & 9.50 & 9.82 \\
\hline New England & 3.38 & 4.12 & 4.93 & 6.07 & 5.20 & 7.01 & 8.00 \\
\hline Southeast Coast & 1.77 & 2.27 & 2.67 & 2.19 & 2.63 & 3.76 & 3.87 \\
\hline Midwest & 1.71 & 1.78 & 2.16 & 2.50 & 2.04 & 2.92 & 2.94 \\
\hline Gulf Coast & 0.96 & 0.77 & 0.62 & 0.78 & 0.54 & 0.74 & 0.74 \\
\hline Southwest & 0.61 & 0.48 & 0.80 & 0.98 & 0.74 & 0.95 & 0.90 \\
\hline Pacific West & 1.88 & 1.39 & 2.33 & 2.38 & 2.25 & 3.15 & 2.92 \\
\hline Other & 0.65 & 0.78 & 1.00 & 1.00 & 1.00 & 0.72 & 0.19 \\
\hline
\end{tabular}


Table 18. Interquartile ranges for self-supplied domestic population, in thousands of people, normalized by region and year, for the compilations from 1985 through 2015.

\begin{tabular}{|c|c|c|c|c|c|c|c|}
\hline Region & 1985 & 1990 & 1995 & 2000 & 2005 & 2010 & 2015 \\
\hline \multicolumn{8}{|c|}{ Regional-scale interquartile ranges } \\
\hline Mid-Atlantic & 34.83 & 27.99 & 30.72 & 23.35 & 26.81 & 37.68 & 37.45 \\
\hline Southeast Coast & 15.43 & 19.56 & 16.41 & 16.62 & 24.20 & 17.89 & 19.12 \\
\hline Central & 7.05 & 7.30 & 7.38 & 6.87 & 5.92 & 5.78 & 5.79 \\
\hline Gulf Coast & 5.74 & 6.20 & 6.35 & 8.13 & 5.24 & 4.94 & 6.35 \\
\hline Plains & 2.53 & 2.42 & 2.37 & 2.59 & 2.17 & 1.73 & 1.42 \\
\hline Northern Rockies & 5.66 & 3.78 & 3.94 & 4.36 & 4.50 & 4.28 & 4.71 \\
\hline Southwest & 6.72 & 8.12 & 7.91 & 8.71 & 8.04 & 7.90 & 7.88 \\
\hline Pacific West & 20.07 & 21.38 & 27.11 & 26.02 & 25.40 & 25.63 & 24.98 \\
\hline New England & 0.69 & 0.78 & 0.78 & 1.00 & 1.03 & 1.04 & 1.36 \\
\hline Southeast Coast & 0.86 & 1.09 & 0.92 & 0.93 & 1.35 & 1.00 & 1.07 \\
\hline Central & 1.03 & 1.06 & 1.08 & 1.00 & 0.86 & 0.84 & 0.84 \\
\hline Midwest & 0.91 & 0.79 & 0.89 & 1.00 & 1.08 & 1.13 & 1.17 \\
\hline Gulf Coast & 0.93 & 1.00 & 1.02 & 1.31 & 0.85 & 0.80 & 1.02 \\
\hline Plains & 1.07 & 1.02 & 1.00 & 1.09 & 0.92 & 0.73 & 0.60 \\
\hline Northern Rockies & 1.30 & 0.87 & 0.90 & 1.00 & 1.03 & 0.98 & 1.08 \\
\hline Southwest & 0.85 & 1.03 & 1.00 & 1.10 & 1.02 & 1.00 & 1.00 \\
\hline
\end{tabular}

Interquartile ranges normalized by year (green indicates a region that is low relative to other regions within a year, and blue indicates a region that is high relative to other regions within a year)

\begin{tabular}{|c|c|c|c|c|c|c|c|}
\hline Mid-Atlantic & 4.94 & 3.45 & 3.89 & 2.68 & 3.34 & 4.77 & 4.75 \\
\hline New England & 2.64 & 2.59 & 2.66 & 3.11 & 3.46 & 3.58 & 4.68 \\
\hline Southeast Coast & 2.19 & 2.41 & 2.08 & 1.91 & 3.01 & 2.26 & 2.43 \\
\hline Midwest & 1.91 & 1.45 & 1.67 & 1.70 & 2.00 & 2.12 & 2.20 \\
\hline Gulf Coast & 0.81 & 0.76 & 0.80 & 0.93 & 0.65 & 0.63 & 0.81 \\
\hline Southwest & 0.95 & 1.00 & 1.00 & 1.00 & 1.00 & 1.00 & 1.00 \\
\hline Pacific West & 2.85 & 2.63 & 3.43 & 2.99 & 3.16 & 3.24 & 3.17 \\
\hline Other & 0.75 & 0.58 & 0.75 & 0.60 & 0.78 & 0.44 & 0.35 \\
\hline
\end{tabular}


Table 19. Median values for self-supplied domestic per capita use rates, in gallons per person per day, determined using self-supplied withdrawals divided by self-supplied domestic population, normalized by region and year, for the compilations from 1985 through 2015.

\begin{tabular}{|c|c|c|c|c|c|c|c|}
\hline Region & 1985 & 1990 & 1995 & 2000 & 2005 & 2010 & 2015 \\
\hline \multicolumn{8}{|c|}{ Regional-scale characteristic medians } \\
\hline Mid-Atlantic & 75.30 & 74.97 & 80.04 & 79.95 & 79.94 & 79.98 & 80.00 \\
\hline New England & 63.38 & 71.90 & 67.47 & 73.52 & 73.47 & 72.99 & 50.76 \\
\hline Southeast Coast & 75.02 & 75.00 & 75.05 & 74.99 & 75.00 & 74.98 & 76.60 \\
\hline Central & 55.01 & 62.44 & 62.42 & 58.07 & 71.02 & 70.92 & 70.98 \\
\hline Midwest & 76.10 & 74.07 & 73.12 & 75.02 & 75.01 & 75.00 & 72.01 \\
\hline Gulf Coast & 77.51 & 79.73 & 77.32 & 78.92 & 84.68 & 84.34 & 84.15 \\
\hline Plains & 76.95 & 89.32 & 88.78 & 92.48 & 89.58 & 88.49 & 94.50 \\
\hline Northern Rockies & 77.66 & 77.84 & 78.05 & 77.93 & 78.34 & 78.14 & 77.60 \\
\hline Southwest & 75.40 & 75.52 & 81.72 & 113.37 & 136.04 & 131.77 & 112.03 \\
\hline Pacific West & 122.55 & 113.51 & 111.79 & 120.36 & 152.98 & 126.97 & 121.77 \\
\hline Other & 35.00 & 36.30 & 33.36 & 43.85 & 64.70 & 78.84 & 92.82 \\
\hline \multicolumn{8}{|c|}{ Median values normalized by region (blue indicates a year that is high relative to other years within a region) } \\
\hline Mid-Atlantic & 0.94 & 0.94 & 1.00 & 1.00 & 1.00 & 1.00 & 1.00 \\
\hline New England & 0.88 & 1.00 & 0.94 & 1.02 & 1.02 & 1.02 & 0.71 \\
\hline Southeast Coast & 1.00 & 1.00 & 1.00 & 1.00 & 1.00 & 1.00 & 1.02 \\
\hline Central & 0.88 & 1.00 & 1.00 & 0.93 & 1.14 & 1.14 & 1.14 \\
\hline Midwest & 1.01 & 0.99 & 0.97 & 1.00 & 1.00 & 1.00 & 0.96 \\
\hline Gulf Coast & 0.97 & 1.00 & 0.97 & 0.99 & 1.06 & 1.06 & 1.06 \\
\hline Plains & 0.86 & 1.00 & 0.99 & 1.04 & 1.00 & 0.99 & 1.06 \\
\hline Northern Rockies & 1.00 & 1.00 & 1.00 & 1.00 & 1.01 & 1.00 & 1.00 \\
\hline Southwest & 0.67 & 0.67 & 0.73 & 1.01 & 1.21 & 1.18 & 1.00 \\
\hline Pacific West & 1.01 & 0.93 & 0.92 & 0.99 & 1.26 & 1.04 & 1.00 \\
\hline Other & 0.80 & 0.83 & 0.76 & 1.00 & 1.48 & 1.80 & 2.12 \\
\hline \multicolumn{8}{|c|}{ Median values normalized by year (green indicates a region that is low relative to other regions within a year) } \\
\hline Mid-Atlantic & 1.00 & 1.00 & 1.04 & 1.03 & 1.02 & 1.01 & 1.00 \\
\hline New England & 0.84 & 0.96 & 0.87 & 0.94 & 0.94 & 0.93 & 0.63 \\
\hline Southeast Coast & 1.00 & 1.00 & 0.97 & 0.96 & 0.96 & 0.95 & 0.96 \\
\hline Central & 0.73 & 0.83 & 0.81 & 0.75 & 0.91 & 0.90 & 0.89 \\
\hline Midwest & 1.01 & 0.99 & 0.95 & 0.96 & 0.96 & 0.95 & 0.90 \\
\hline Gulf Coast & 1.03 & 1.06 & 1.00 & 1.01 & 1.08 & 1.07 & 1.05 \\
\hline Plains & 1.02 & 1.19 & 1.15 & 1.19 & 1.14 & 1.12 & 1.18 \\
\hline Northern Rockies & 1.03 & 1.04 & 1.01 & 1.00 & 1.00 & 0.99 & 0.97 \\
\hline Southwest & 1.00 & 1.01 & 1.06 & 1.45 & 1.74 & 1.67 & 1.40 \\
\hline Pacific West & 1.63 & 1.51 & 1.45 & 1.54 & 1.95 & 1.61 & 1.52 \\
\hline Other & 0.46 & 0.48 & 0.43 & 0.56 & 0.83 & 1.00 & 1.16 \\
\hline
\end{tabular}


Table 20. Interquartile ranges for self-supplied domestic per capita use rates, determined using self-supplied withdrawals divided by self-supplied domestic population, normalized by region and year, for the compilations from 1985 through 2015.

\begin{tabular}{lccccccc}
\hline \multicolumn{1}{c}{ Region } & $\mathbf{1 9 8 5}$ & $\mathbf{1 9 9 0}$ & $\mathbf{1 9 9 5}$ & $\mathbf{2 0 0 0}$ & $\mathbf{2 0 0 5}$ & $\mathbf{2 0 1 0}$ & $\mathbf{2 0 1 5}$ \\
\hline Mid-Atlantic & \multicolumn{7}{c}{ Regional-scale interquartile ranges } \\
New England & 2.85 & 0.25 & 0.10 & 2.99 & 0.16 & 0.16 & 0.12 \\
Southeast Coast & 0.25 & 0.26 & 0.35 & 0.77 & 0.19 & 0.18 & 5.78 \\
Central & 0.42 & 0.38 & 0.44 & 0.45 & 0.32 & 0.49 & 0.49 \\
Midwest & 5.64 & 0.70 & 1.25 & 1.39 & 1.23 & 1.01 \\
Gulf Coast & 0.66 & 0.78 & 0.49 & 0.40 & 0.47 & 0.53 & 0.60 \\
Plains & 0.83 & 1.27 & 1.60 & 1.31 & 1.33 & 1.84 \\
Northern Rockies & 13.31 & 3.78 & 6.89 & 14.40 & 4.43 & 4.89 & 7.96 \\
Southwest & 2.19 & 2.64 & 1.54 & 1.53 & 2.25 & 4.40 \\
Pacific West & 8.40 & 10.09 & 21.61 & 10.93 & 62.51 & 30.04 \\
Other & 26.59 & 7.87 & 1.49 & 35.50 & 42.02 & 41.35 & 26.72 \\
\hline
\end{tabular}

Interquartile ranges normalized by region (green indicates a year that is low relative to other years within a region, and blue indicates a year that is high relative to other years within a region)

\begin{tabular}{|c|c|c|c|c|c|c|c|}
\hline Mid-Atlantic & 17.37 & 1.54 & 0.62 & 18.19 & 0.97 & 1.00 & 0.73 \\
\hline New England & 0.96 & 1.00 & 1.36 & 2.99 & 0.73 & 0.70 & 22.59 \\
\hline Southeast Coast & 0.96 & 0.85 & 1.00 & 1.02 & 0.73 & 1.11 & 1.11 \\
\hline Midwest & 1.25 & 1.47 & 0.93 & 0.76 & 0.89 & 1.00 & 1.13 \\
\hline Gulf Coast & 0.62 & 0.96 & 1.21 & 0.98 & 1.00 & 1.39 & 5.99 \\
\hline Southwest & 0.39 & 0.47 & 1.00 & 0.51 & 2.89 & 1.39 & 1.24 \\
\hline Pacific West & 0.83 & 0.25 & 0.05 & 1.11 & 1.31 & 1.29 & 1.00 \\
\hline Other & 1.12 & 1.34 & 0.82 & 1.00 & 0.69 & 0.55 & 1.00 \\
\hline
\end{tabular}

Interquartile ranges normalized by year (green indicates a region that is low relative to other regions within a year, and blue indicates a region that is high relative to other regions within a year)

\begin{tabular}{|c|c|c|c|c|c|c|c|}
\hline Mid-Atlantic & 1.00 & 0.20 & 0.07 & 1.95 & 0.12 & 0.09 & 0.03 \\
\hline New England & 0.09 & 0.20 & 0.23 & 0.50 & 0.14 & 0.10 & 1.31 \\
\hline Southeast Coast & 0.15 & 0.30 & 0.30 & 0.29 & 0.24 & 0.27 & 0.11 \\
\hline Midwest & 0.23 & 0.61 & 0.33 & 0.26 & 0.36 & 0.29 & 0.14 \\
\hline Gulf Coast & 0.29 & 1.00 & 1.07 & 0.85 & 1.00 & 1.00 & 1.81 \\
\hline Southwest & 2.94 & 7.92 & 14.48 & 7.14 & 47.06 & 16.30 & 6.08 \\
\hline Pacific West & 9.32 & 6.18 & 1.00 & 23.21 & 31.63 & 22.43 & 7.29 \\
\hline Other & 6.83 & 18.26 & 9.50 & 11.36 & 8.99 & 5.22 & 3.97 \\
\hline
\end{tabular}


Table 21. Median values for irrigation application rates, in acre-feet per acre, determined using irrigation withdrawals divided by irrigated acres, normalized by region and year, for the compilations from 1985 through 2015.

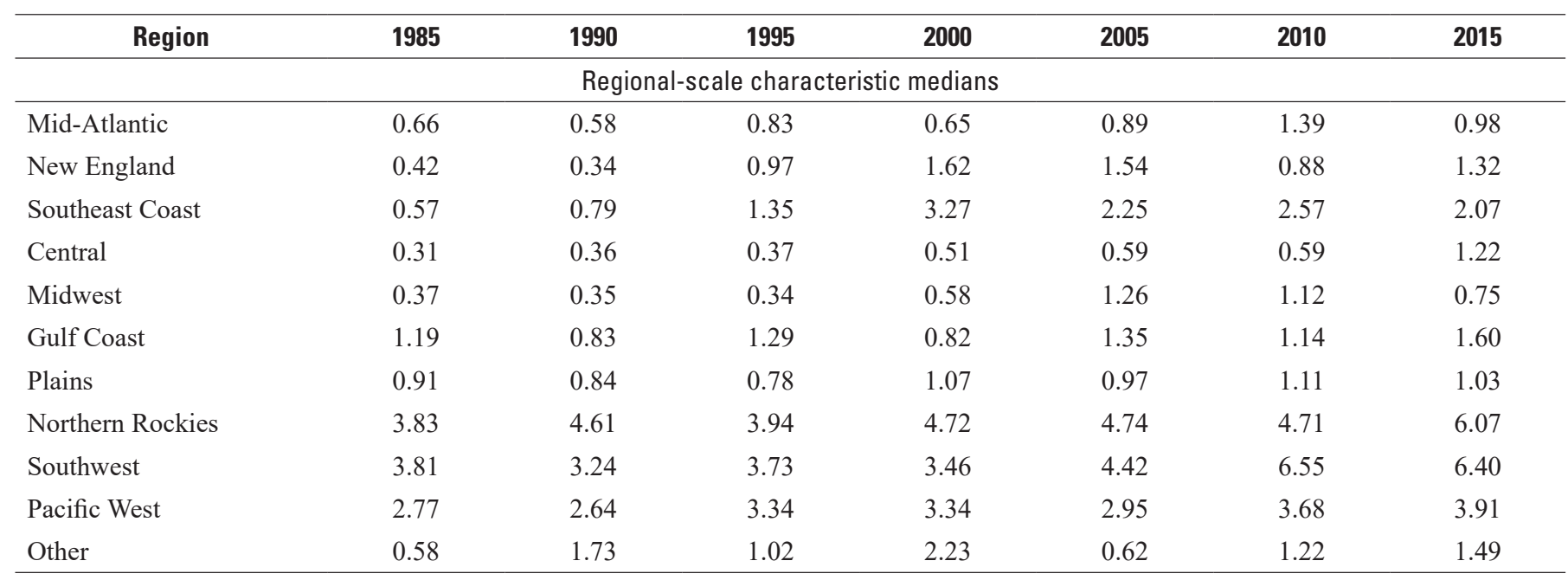

Median values normalized by region (green indicates a year that is low relative to other years within a region, and blue indicates a year that is high relative to other years within a region)

\begin{tabular}{|c|c|c|c|c|c|c|c|}
\hline Mid-Atlantic & 0.80 & 0.70 & 1.00 & 0.78 & 1.07 & 1.68 & 1.18 \\
\hline New England & 0.43 & 0.35 & 1.00 & 1.68 & 1.59 & 0.91 & 1.37 \\
\hline Southeast Coast & 0.28 & 0.38 & 0.65 & 1.58 & 1.09 & 1.24 & 1.00 \\
\hline Midwest & 0.64 & 0.61 & 0.59 & 1.00 & 2.17 & 1.93 & 1.29 \\
\hline Gulf Coast & 1.00 & 0.70 & 1.08 & 0.69 & 1.13 & 0.96 & 1.35 \\
\hline Northern Rockies & 0.81 & 0.98 & 0.84 & 1.00 & 1.01 & 1.00 & 1.29 \\
\hline Southwest & 1.00 & 0.85 & 0.98 & 0.91 & 1.16 & 1.72 & 1.68 \\
\hline Pacific West & 0.83 & 0.79 & 1.00 & 1.00 & 0.89 & 1.10 & 1.17 \\
\hline Other & 0.48 & 1.42 & 0.84 & 1.83 & 0.51 & 1.00 & 1.22 \\
\hline
\end{tabular}

Median values normalized by year (green indicates a region that is low relative to other regions within a year, and blue indicates a region that is high relative to other regions within a year)

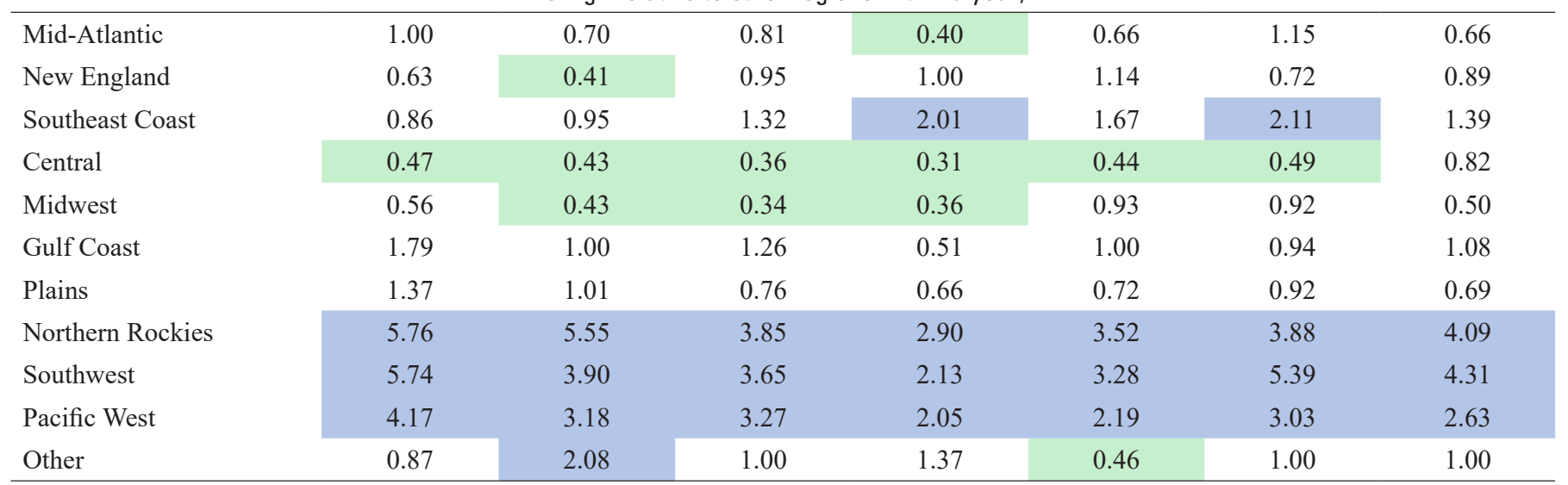


Table 22. Interquartile ranges for irrigation application rates determined using irrigation withdrawals divided by irrigated acres, normalized by region and year, for the compilations from 1985 through 2015.

\begin{tabular}{|c|c|c|c|c|c|c|c|}
\hline Region & 1985 & 1990 & 1995 & 2000 & 2005 & 2010 & 2015 \\
\hline \multicolumn{8}{|c|}{ Regional-scale interquartile ranges } \\
\hline Mid-Atlantic & 0.33 & 0.37 & 0.46 & 0.16 & 0.22 & 0.78 & 0.48 \\
\hline Southeast Coast & 0.70 & 0.93 & 0.98 & 1.19 & 0.82 & 1.30 & 1.32 \\
\hline Central & 0.57 & 0.31 & 0.24 & 0.23 & 0.26 & 0.18 & 0.57 \\
\hline Gulf Coast & 1.05 & 0.76 & 0.83 & 0.66 & 1.25 & 0.76 & 1.02 \\
\hline Plains & 0.54 & 0.74 & 0.63 & 0.50 & 0.56 & 0.68 & 0.69 \\
\hline Northern Rockies & 2.33 & 3.22 & 2.39 & 2.20 & 1.67 & 1.44 & 1.73 \\
\hline Southwest & 2.49 & 2.53 & 2.83 & 2.37 & 2.42 & 4.41 & 4.57 \\
\hline Pacific West & 1.07 & 0.98 & 0.86 & 1.37 & 1.16 & 1.47 & 1.51 \\
\hline
\end{tabular}

Interquartile ranges normalized by region (green indicates a year that is low relative to other years within a region, and blue indicates a year that is high relative to other years within a region)

\begin{tabular}{|c|c|c|c|c|c|c|c|}
\hline Mid-Atlantic & 0.88 & 1.00 & 1.23 & 0.43 & 0.58 & 2.10 & 1.29 \\
\hline New England & 0.27 & 0.64 & 1.34 & 1.20 & 0.96 & 1.00 & 1.30 \\
\hline Southeast Coast & 0.71 & 0.95 & 1.00 & 1.21 & 0.84 & 1.33 & 1.35 \\
\hline Midwest & 0.11 & 0.57 & 0.77 & 1.00 & 1.26 & 1.53 & 1.26 \\
\hline Gulf Coast & 1.26 & 0.92 & 1.00 & 0.80 & 1.51 & 0.92 & 1.23 \\
\hline Southwest & 0.98 & 1.00 & 1.12 & 0.94 & 0.95 & 1.74 & 1.81 \\
\hline Pacific West & 0.92 & 0.85 & 0.74 & 1.18 & 1.00 & 1.27 & 1.30 \\
\hline Other & 1.37 & 1.84 & 2.58 & 0.25 & 0.56 & 1.00 & 0.44 \\
\hline
\end{tabular}

Interquartile ranges normalized by year (green indicates a region that is low relative to other regions within a year, and blue indicates a region that is high relative to other regions within a year)

\begin{tabular}{|c|c|c|c|c|c|c|c|}
\hline Mid-Atlantic & 0.47 & 0.49 & 0.56 & 0.26 & 0.28 & 1.00 & 0.62 \\
\hline New England & 0.11 & 0.24 & 0.45 & 0.55 & 0.35 & 0.36 & 0.47 \\
\hline Southeast Coast & 1.00 & 1.23 & 1.18 & 1.92 & 1.06 & 1.66 & 1.69 \\
\hline Midwest & 0.09 & 0.46 & 0.58 & 1.00 & 1.00 & 1.20 & 1.00 \\
\hline Gulf Coast & 1.49 & 1.00 & 1.00 & 1.07 & 1.61 & 0.97 & 1.31 \\
\hline Southwest & 3.56 & 3.32 & 3.41 & 3.83 & 3.11 & 5.63 & 5.85 \\
\hline Pacific West & 1.52 & 1.29 & 1.04 & 2.21 & 1.49 & 1.87 & 1.93 \\
\hline Other & 1.11 & 1.38 & 1.78 & 0.23 & 0.42 & 0.73 & 0.32 \\
\hline
\end{tabular}


Table 23. Median values for thermoelectric power rates, in gallons per megawatt hour, determined using thermoelectric withdrawals divided by power generated, normalized by region and year, for the compilations from 2005 through 2015.

[Calculations performed for compilation years with categories based on cooling system types]

\begin{tabular}{|c|c|c|c|}
\hline Region & 2005 & 2010 & 2015 \\
\hline \multicolumn{4}{|c|}{ Regional-scale characteristic medians } \\
\hline Mid-Atlantic & 102.87 & 70.87 & 4.88 \\
\hline New England & 3.83 & 16.81 & 20.29 \\
\hline Southeast Coast & 75.83 & 8.39 & 10.57 \\
\hline Central & 29.33 & 42.75 & 43.28 \\
\hline Midwest & 75.91 & 82.42 & 35.56 \\
\hline Gulf Coast & 38.21 & 23.16 & 31.61 \\
\hline Plains & 19.65 & 2.68 & 1.92 \\
\hline Northern Rockies & 2.38 & 1.71 & 1.41 \\
\hline Southwest & 1.65 & 1.72 & 1.43 \\
\hline Pacific West & 3.49 & 2.70 & 2.55 \\
\hline Other & 133.47 & 123.04 & 83.61 \\
\hline
\end{tabular}

Median values normalized by region (green indicates a year that is low relative to other years within a region, and blue indicates a year that is high relative to other years within a region)

\begin{tabular}{llll}
\hline Mid-Atlantic & 1.45 & 1.00 & 0.07 \\
New England & 0.23 & 1.00 & 1.21 \\
Southeast Coast & 7.17 & 0.79 & 1.00 \\
Central & 0.69 & 1.00 & 1.01 \\
Midwest & 1.00 & 1.09 & 0.47 \\
Gulf Coast & 1.21 & 0.73 & 1.00 \\
Plains & 7.34 & 1.00 & 0.72 \\
Northern Rockies & 1.39 & 1.00 & 0.82 \\
Southwest & 1.00 & 1.04 & 0.87 \\
Pacific West & 1.29 & 1.00 & 0.94 \\
Other & 1.08 & 1.00 & 0.68 \\
\hline Median values normalized by year (green indicates a region that is low relative to other regions within a year, and blue indicates a region that & \\
\hline Mid-Atlantic & is high relative to other regions within a year) & 0.46 \\
New England & 3.51 & 4.22 & 1.92 \\
Southeast Coast & 0.13 & 1.00 & 1.00 \\
Central & 2.59 & 0.50 & 4.09 \\
Midwest & 1.00 & 2.54 & 3.36 \\
Gulf Coast & 2.59 & 4.90 & 2.99 \\
Plains & 1.30 & 1.38 & 0.18 \\
Northern Rockies & 0.67 & 0.16 & 0.13 \\
Southwest & 0.08 & 0.10 & 0.14 \\
Pacific West & 0.06 & 0.10 & 0.24 \\
Other & 0.12 & 0.16 & 7.91 \\
\hline
\end{tabular}


Table 24. Interquartile ranges for thermoelectric power rates determined using thermoelectric withdrawals divided by power generated, normalized by region and year, for the compilations from 2005 through 2015.

[Calculations performed for compilation years with categories based on cooling system types]

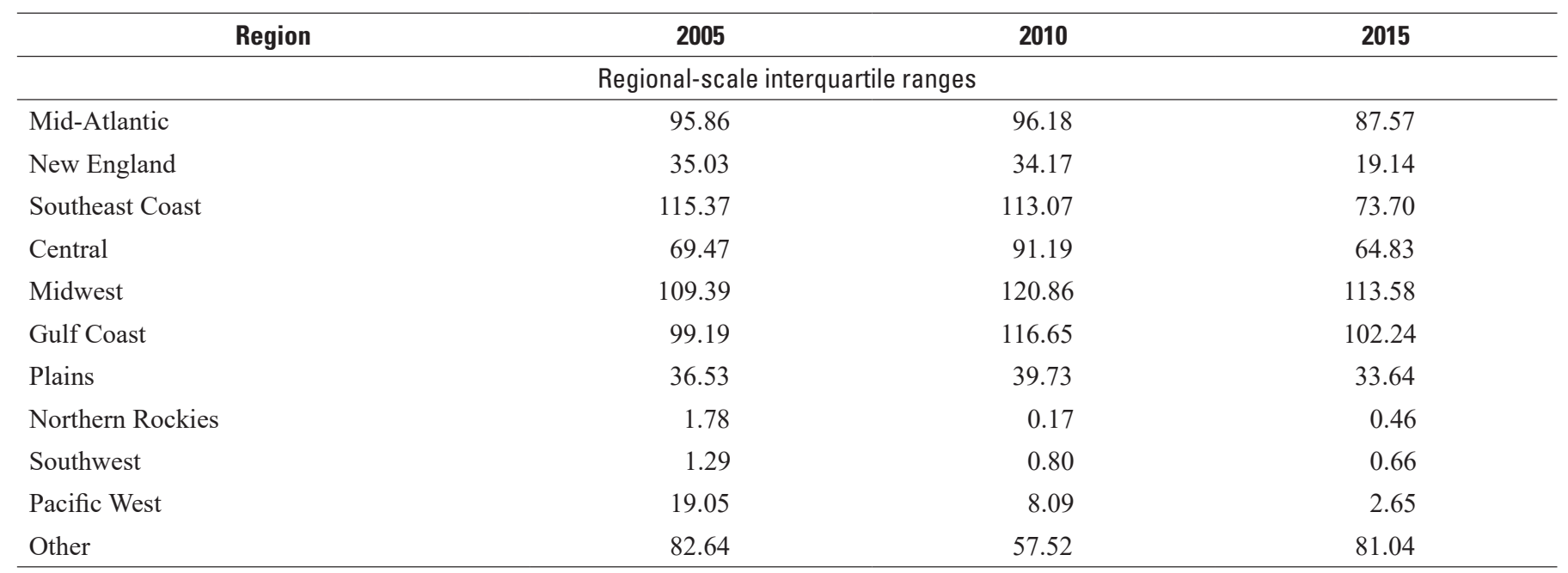

Interquartile ranges normalized by region (green indicates a year that is low relative to other years within a region, and blue indicates a year that is high relative to other years within a region)

\begin{tabular}{llll}
\hline Mid-Atlantic & 1.00 & 1.00 & 0.91 \\
New England & 1.03 & 1.00 & 0.56 \\
Southeast Coast & 1.02 & 1.00 & 0.65 \\
Central & 1.00 & 1.31 & 0.93 \\
Midwest & 0.96 & 1.06 & 1.14 \\
Gulf Coast & 0.97 & 1.09 & 1.00 \\
Plains & 1.00 & 0.38 & 0.92 \\
Northern Rockies & 3.85 & 1.00 & 1.00 \\
Southwest & 1.60 & 1.00 & 0.82 \\
Pacific West & 2.36 & 0.71 & 0.33 \\
Other & 1.02 & 1.00 \\
\hline
\end{tabular}

Interquartile ranges normalized by year (green indicates a region that is low relative to other regions within a year, and blue indicates a region that is high relative to other regions within a year)

\begin{tabular}{llll}
\hline Mid-Atlantic & 1.38 & 1.67 & 1.35 \\
New England & 0.50 & 0.59 & 0.30 \\
Southeast Coast & 1.66 & 1.97 & 1.14 \\
Central & 1.00 & 1.59 & 1.00 \\
Midwest & 1.57 & 2.10 & 1.75 \\
Gulf Coast & 1.43 & 2.03 & 1.58 \\
Plains & 0.53 & 0.69 & 0.52 \\
Northern Rockies & 0.03 & 0.00 & 0.01 \\
Southwest & 0.02 & 0.01 & 0.01 \\
Pacific West & 0.27 & 0.14 & 0.04 \\
Other & 1.19 & 1.00 & 1.25 \\
\hline
\end{tabular}


For compilations before 2015, the addition of method codes for compilations to all water-use categories would improve the understanding of the water-use values. Most data elements for compilations before 2015 have a method code of NZZZ (unknown) in the AWUDS database. These instances with method code NZZZ could be revised to indicate the primary information sources and estimation methods and these revisions would provide necessary metadata for users of the water-use compilation data.

More consistency in data compilation methods and reporting requirements is needed so that variations from year to year are more likely to reflect actual changes in water-use amounts. Comparisons and evaluations of trends also are difficult because of the changes in reporting requirements between mandatory and optional for some category data elements. Data on public supply deliveries for domestic use, golf course irrigation, and consumptive use have not been reported consistently throughout the compilations from 1985 through 2015. Consistent reporting of these elements in compilations would support comparisons and determination of changes with time.

The next step towards quantifying uncertainty is to identify and highlight States, regions, and water-use data elements with unexpected patterns of variability or consistency. This identification was accomplished through maps, rates, percentages, medians, and IQRs of water-use data. Additional investigation is needed to determine whether the variability is the result of actual changes in water use or because of errors or changes in methodology. Regions with potentially anomalous patterns or unexpected consistency need further investigations including analysis of States within that region, counties within each State, and changes in values with time. Additional evaluations could include (1) investigating information sources and the proportions of reported versus estimated data; (2) investigating the consistency or inconsistency of methods and assumptions used for data estimation; (3) assessing the appropriateness of rates, percentages, and coefficients; (4) assessing the completeness of the water-use value; and (5) assessing if variability might indicate actual changes in water use.

Additional work would investigate where the patterns of unexpected variability or consistency can be attributed to one or more factors. For example, comparisons of State values with time may indicate a change in trend after a particular compilation year that coincides with a change in methodology. Per capita rates give an indication of water usage per person but are not completely independent of space and time because outdoor water use may be more prevalent in arid, warmer, or dryer conditions. Where per capita rates appear to be anomalous, water use and population need to be assessed for potential errors or effects of changes in methodology.

Potential uncertainty because of these factors would then need to be quantified. For example, per capita rate coefficients that have sufficient metadata to describe the applicable system size, customer use types, system losses, and year of relevance would be assigned a lower uncertainty than rate coefficients that do not have sufficient metadata or that were derived for a year other than the compilation year. States and regions using consistent methodology likely would have lower uncertainty and could be used to determine bounds on data uncertainty where inconsistent methods have been used. For example, using these methodologies to estimate water use where data are reported could provide additional checks on the accuracies of the estimation methods and permit statistical analysis to identify confidence intervals. Identification of these uncertainties for each water-use compilation value would provide more informed uses of the data.

\section{Summary}

The U.S. Geological Survey Water-Use Program, in cooperation with local, State, and Federal agencies, is responsible for compiling national water-use estimates every 5 years, beginning in 1950 . These water-use data may vary because of actual changes in water use, because of changes in estimation methods, or because of errors. Uncertainty information is necessary to inform users about the limitations of the data, to indicate if a result is adequate for its intended purpose, and to ascertain if the data are consistent with other results. However, before uncertainty can be assessed, the potential factors affecting data quality, such as information sources and estimation methods, need to be evaluated. Likewise, where these factors might have had an adverse effect need to be determined through analysis of the variability and consistency of the water-use values. The evaluations in this report focused primarily on the public supply, irrigation, and thermoelectric water-use categories for the 1985-2015 U.S. Geological Survey compilations. Self-supplied domestic water use also was included in some discussions to provide a more complete understanding of residential water use.

Sources of information for the areal aggregate county data collected for the compilations were derived from many types of data from many sources, depending on the category of use and the information available for each State. Site specific furnished reported data generally are available for some data elements, such as public supply and thermoelectric withdrawals, public supply population served, and thermoelectric power generation. Furnished reported data for crop irrigation, where available, is generally at larger county, regional, or State scales.

Where reported data are missing, such as for public supply deliveries for domestic use and self-supplied domestic withdrawals, estimates are generated to fill in the gaps and may involve multiple approaches for different categories of water use. Frequently used estimation methods were identified for the public supply, self-supplied domestic, irrigation, and thermoelectric categories. Some estimation methods are consistently applied and rely on coefficients such as per capita use rates or crop water requirements or applicate rates. However, these rates are sometimes based on previous years data and may need to be periodically reviewed. Use of information from neighboring climatically similar States might be a reasonable approach for determining appropriate coefficients. 
Variability in the water-use data were evaluated in several ways using rates, percentages, medians, and interquartile ranges of State and county-level data. Analysis of patterns in the data values were evaluated for a given State throughout time and for State values compared to neighboring climatically similar States. Outliers, or unusual patterns of water-use information, could be caused by a variety of reasons, some relating to actual changes in water use or to changes in methods and errors. These types of graphical comparisons provide a means of qualitatively and quantitatively highlighting areas of unexpected variability or consistency for further investigation.

These evaluations provide the foundation that is needed to understand data quality and reliability. Work is needed to continue the assessment of water-use data quality, variability, and uncertainty for the 1985-2015 compilations by relating factors affecting water use to areas of potentially anomalous values. After identification of these factors, applicable uncertainties could be developed and related to the water-use estimates. Several areas where additional reporting, documentation, and collection of metadata could address data limitations and gaps for additional water-use work also were identified. Additional metadata and uncertainty information are needed for users of the data to better understand the water-use data and interpret changes in water use across the United States and with time.

\section{References Cited}

Dickens, J.M., Forbes, B.T., Cobean, D.S., and Tadayon, S., 2011, Documentation of methods and inventory of irrigation data collected for the 2000 and 2005 U.S. Geological Survey estimated use of water in the United States, comparison of USGS-compiled irrigation data to other sources, and recommendations for future compilations: U.S. Geological Survey Scientific Investigations Report 2011-5166, 60 p. [Also available at https://pubs.usgs.gov/sir/2011/5166/.]

Diehl, T.H., and Harris, M.A., 2014, Withdrawals and consumption of water by thermoelectric power plants in the United States, 2010: U.S. Geological Survey Scientific Investigations Report 2014-5184, 28 p. [Also available at https://doi.org/10.3133/sir20145184.]

Diehl, T.H., Harris, M.A., Murphy, J.C., Hutson, S.S., and Ladd, D.E., 2013, Methods for estimating water consumption for thermoelectric power plants in the United States: U.S. Geological Survey Scientific Investigations Report 2013-5188, 78 p. [Also available at https://doi.org/10.3133/ sir20135188].

Dieter, C.A., Maupin, M.A., Caldwell, R.R., Harris, M.A., Ivahnenko, T.I., Lovelace, J.K., Barber, N.L., and Linsey, K.S., 2018, Estimated use of water in the United States in 2015: U.S. Geological Survey Circular 1441, 65 p. [Also available at https://doi.org/10.3133/cir1441.]
Hutson, S.S., Barber, N.L., Kenny, J.F., Linsey, K.S., Lumia, D.S., and Maupin, M.A., 2004, Estimated use of water in the United States in 2000: U.S. Geological Survey Circular 1268, 46 p. [Also available at https://doi.org/10.3133/ cir1268.]

Kenny, J.F., Barber, N.L., Hutson, S.S., Linsey, K.S., Lovelace, J.K., and Maupin, M.A., 2009, Estimated use of water in the United States in 2005: U.S. Geological Survey Circular 1344, 52 p. [Also available at https://doi.org/ 10.3133/cir1344.]

Lovelace, J.K., 2009a, Methods for estimating water withdrawals for aquaculture in the United States, 2005: U.S. Geological Survey Scientific Investigations Report 2009-5042, 13 p. [Also available at https://doi.org/10.3133/ sir20095042.]

Lovelace, J.K., 2009b, Methods for estimating water withdrawals for mining in the United States, 2005: U.S. Geological Survey Scientific Investigations Report 2009-5053, 7 p. [Also available at https://doi.org/10.3133/ sir20095053.]

Lovelace, J.K., 2009c, Methods for estimating water withdrawals for livestock in the United States, 2005: U.S. Geological Survey Scientific Investigations Report 2009-5041, 7 p. [Also available at https://doi.org/10.3133/ sir20095041.]

Maupin, M.A., Kenny, J.F., Hutson, S.S., Lovelace, J.K., Barber, N.L., and Linsey, K.S., 2014, Estimated use of water in the United States in 2010: U.S. Geological Survey Circular 1405, 56 p. [Also available at https://doi.org/ 10.3133/cir1405.]

Painter, J.A., Brant, J.T., Caldwell, R.R., Haynes, J.V., and Read, A.L., 2020, Documentation of methods and inventory of irrigation information collected for the 2015 U.S. Geological Survey estimated use of water in the United States: U.S. Geological Survey Scientific Investigations Report 2020-5139, 39 p. [Also available at https://doi.org/ 10.3133/sir20205139.]

Senay, G.B., Bohms, S., Singh, R.K., Gowda, P.H., Velpuri, N.M., Alemu, H., and Verdin, J.P., 2013, Operational evapotranspiration mapping using remote sensing and weather datasets-A new parameterization for the SSEB approach: Journal of the American Water Resources Association, v. 49, no. 3, p. 577-591.

Solley, W.B., Merk, C.F., and Pierce, R.R., 1988, Estimated use of water in the United States in 1985: U.S.

Geological Survey Circular 1004, 82 p. [Also available at https://doi.org/10.3133/cir1004.] 
Solley, W.B., Pierce, R.R., and Perlman, H.A., 1993, Estimated use of water in the United States in 1990: U.S. Geological Survey Circular 1081, 76 p. [Also available at https://doi.org/10.3133/cir1081.]

Solley, W.B., Pierce, R.R., and Perlman, H.A., 1998, Estimated use of water in the United States in 1995: U.S. Geological Survey Circular 1200, 71 p. [Also available at https://doi.org/10.3133/cir1200.]

Sullivan, S.L., Luukkonen, C.L., and Belitz, K., 2021, Public supply, self-supplied domestic, irrigation, and thermoelectric water-use data from 5-year compilation datasets from 1985 to 2015 used to assess data variability and uncertainty: U.S. Geological Survey data release, https://doi.org/ 10.5066/P9TA1DI9.

U.S. Geological Survey, 2021, USGS water data for the Nation: U.S. Geological Survey National Water Information System database, accessed July 29, 2021, at https://doi.org/ 10.5066/F7P55KJN. 



\section{Glossary}

aggregate water-use data Data on water use and related information that are presented as a total for a political or hydrologic area, such as county, basin, and aquifer. The aggregate value may be a sum of site-specific water-use values, an estimated value, or a combination.

closed-loop cooling system Also known as a recirculation cooling system. Water is withdrawn from a source, circulated through heat exchangers, cooled, and then reused in the same process. Recirculating cooling systems may use induced draft cooling towers, forced draft cooling towers, cooling ponds, or canals.

consumptive use The part of water withdrawn that is evaporated, transpired, incorporated into products or crops, consumed by humans or livestock, or otherwise removed from the immediate water environment. Also referred to as water consumed.

cooling system An equipment system that provides water for cooling purposes, such as to condensers at powerplants or at factories. May include water intakes, outlets, cooling towers, ponds, canals, pumps, and pipes.

domestic water use Water used for indoor household purposes such as drinking, food preparation, bathing, washing clothes and dishes, and flushing toilets and outdoor purposes such as watering lawns and gardens and washing cars. Domestic water use includes water provided to households by a public water supply (domestic deliveries from public suppliers) and self-supplied water from a private source, such as a well or spring, or captured rainwater.

irrigation application rate Rate, in acre-feet per acre, determined as the total groundwater, surface water, and reclaimed wastewater irrigation withdrawals divided by the total number of irrigated acres (calculated separately for the total, crop, and golf course irrigation categories). irrigation water use Water that is applied by an irrigation system to sustain growth in agricultural and horticultural vegetation, including parks, nurseries, turf farms, and cemeteries and other self-supplied landscape watering uses. Irrigation includes water that is applied for preirrigation, frost protection, chemical application, weed control, field preparation, crop cooling, harvesting, dust suppression, leaching of salts from the root zone, and conveyance losses. Included in the total or provided separately may be water used for irrigation of golf courses.

irrigation district A cooperative, self-governing public corporation set up as a subdivision of the State government, with definite geographic boundaries, organized, and having taxing power to obtain and distribute water for irrigation of lands within the district.

megawatt-hour (MWh) An electrical energy unit of measure equal to 1 megawatt of power supplied to, or taken from, an electric circuit steadily for 1 hour.

microirrigation system An irrigation system that wets only a discrete portion of the soil surface near the plant by means of applicators (such as orifices, emitters, porous tubing, or perforated pipe) and operated under low pressure. The applicators may be placed on or below the surface of the ground or suspended from supports.

open-loop cooling system Also known as once-through cooling system. Cooling system in which the water is withdrawn from a source, circulated through the heat exchangers, and then returned to a body of water at a higher temperature.

public supply delivery per capita use rate Rate, in gallons per person per day, determined as the total public supply deliveries for domestic use divided by the publicly supplied population. 
public supply water use Water withdrawn from ground and surface sources by public and private water suppliers that furnish water to at least 25 people or have a minimum of 15 connections. Public suppliers provide water for use by cities, towns, rural water districts, mobile home parks, Native American Indian reservations, and military bases for a variety of uses, such as domestic, commercial, industrial, thermoelectric power, and public water use or for public services or system losses. Within the public supply category, reported or estimated data are determined for withdrawals by source of water, population served, and, for selected compilation years, domestic deliveries.

public supply withdrawal per capita use rate Rate, in gallons per person per day, determined as the total public supply withdrawals divided by the publicly supplied population.

public water use Water supplied from a public supplier and used for such purposes as firefighting, street washing, flushing of water lines, and maintaining municipal parks and swimming pools.

Generally, public-use water is not billed by the public supplier.

self-supplied domestic per capita use rate Rate, in gallons per person per day, determined as the total self-supplied domestic withdrawals divided by the self-supplied domestic population.

self-supplied water use Water withdrawn from a groundwater or surface-water source by a user rather than being obtained from a public supply source.

sprinkler irrigation system An irrigation system in which water is applied by means of perforated pipes or nozzles operated under pressure to form a spray pattern.

surface irrigation system Irrigation by means of flood, furrow, or gravity methods. Flood irrigation is the application of irrigation water in which the entire soil surface is covered by ponded water. Furrow is a partial surface-flooding method of irrigation normally used with clean-tilled crops in which water is applied in furrows or rows of sufficient capacity to contain the design irrigation stream. Gravity is an irrigation method in which water is not pumped but flows in ditches or pipes and is distributed by gravity. thermoelectric power rate Rate, in gallons per megawatt hour, determined as the total groundwater withdrawals, surface-water withdrawals, and public supply deliveries for thermoelectric uses divided by the amount of power generated (with the once-through and closed-loop cooling categories combined)

thermoelectric power generation Net electrical power generated, transmitted, and distributed for consumer use by the thermoelectric plant.

thermoelectric power water use Water used in the process of generating electricity from heat with steam-driven turbine generators. Term used in previous water-use Circulars to describe the combined public-supply deliveries to thermoelectric power plants and self-supplied thermoelectric power withdrawals. Thermoelectric power plants use different fuel types, such as fossil fuels, nuclear fission, solar energy, and geothermal energy to heat water into steam that then turns turbines to generate electricity. These different fuel types were the basis for the U.S. Geological Survey water-use category divisions in 1985-95. Because the amount of water withdrawn and consumed at thermoelectric power plants depends on the type of cooling system (once-through (open-loop) cooling and recirculating (closed-loop) cooling), more recent (2005 and later) U.S. Geological Survey compilations use the cooling system type as the basis for the compilation category divisions.

water use In a restrictive sense, the term refers to water that is withdrawn for a specific purpose, such as for public supply, domestic use, irrigation, thermoelectric power cooling, or industrial processing. In some previous water-use Circulars, water use for the domestic, commercial, industrial, and thermoelectric categories included self-supplied withdrawals and deliveries from public supply, and some categories included reclaimed wastewater use. More broadly, water use pertains to the interaction of humans with and effects on the hydrologic cycle, and includes elements such as water withdrawal, delivery, consumptive use, wastewater release, reclaimed wastewater, return flow, and instream use.

water withdrawal Water removed from a groundwater or surface-water source for use. 


\section{Appendix 1}

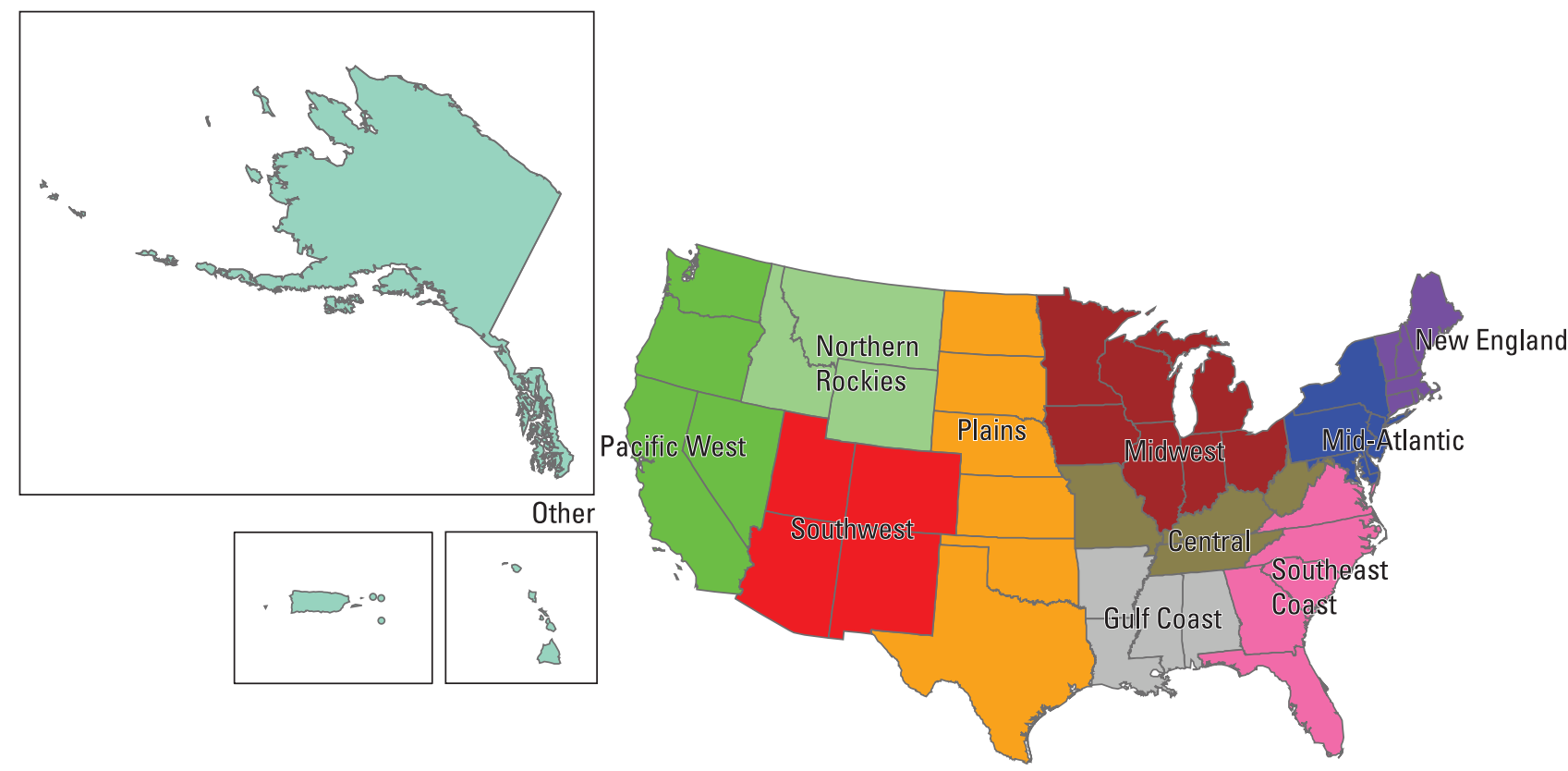

Figure 1.1. Map showing State and U.S. territory regions for the purpose of analysis in this report.

Table 1.1. Summary of State reporting decisions for public supply population served and irrigation water-use values.

[Shading denotes documentation is available. S, split; T, total]

\begin{tabular}{|c|c|c|c|c|c|c|c|c|c|c|c|c|c|c|c|c|c|c|c|c|c|c|}
\hline \multirow{3}{*}{$\begin{array}{r}\text { State } \\
\text { Alabama }\end{array}$} & \multicolumn{11}{|c|}{$\begin{array}{c}\text { Population served } \\
\text { (groundwater/surface water split or total) }\end{array}$} & \multicolumn{11}{|c|}{ Irrigation (crop and golf split or total) } \\
\hline & \multirow{2}{*}{$\begin{array}{c}1985 \\
\mathrm{~S}\end{array}$} & \multirow{2}{*}{$\begin{array}{c}1990 \\
\mathrm{~S}\end{array}$} & \multirow{2}{*}{$\begin{array}{c}1995 \\
\mathrm{~S}\end{array}$} & \multicolumn{2}{|c|}{2000} & \multicolumn{2}{|c|}{2005} & \multicolumn{2}{|c|}{2010} & \multicolumn{2}{|c|}{2015} & \multirow{2}{*}{$\begin{array}{c}1985 \\
\mathrm{~T}\end{array}$} & \multirow{2}{*}{$\begin{array}{c}1990 \\
\mathrm{~T}\end{array}$} & \multirow{2}{*}{$\begin{array}{c}1995 \\
\mathrm{~T}\end{array}$} & \multicolumn{2}{|c|}{2000} & \multicolumn{2}{|c|}{2005} & \multicolumn{2}{|c|}{2010} & \multicolumn{2}{|c|}{2015} \\
\hline & & & & $\mathrm{S}$ & & & $\mathrm{T}$ & & $\mathrm{T}$ & & $\mathrm{T}$ & & & & & $\mathrm{T}$ & $\mathrm{S}$ & & $\mathrm{S}$ & & $\mathrm{S}$ & \\
\hline Alaska & $\mathrm{S}$ & $\mathrm{S}$ & $\mathrm{S}$ & $\mathrm{S}$ & & & $\mathrm{T}$ & & $\mathrm{T}$ & $\mathrm{S}$ & & $\mathrm{T}$ & $\mathrm{T}$ & $\mathrm{T}$ & & $\mathrm{T}$ & $\mathrm{S}$ & & $\mathrm{S}$ & & $\mathrm{S}$ & \\
\hline Arizona & $\mathrm{S}$ & $\mathrm{S}$ & $\mathrm{S}$ & $\mathrm{S}$ & & & $\mathrm{T}$ & $\mathrm{S}$ & & $\mathrm{S}$ & & $\mathrm{T}$ & $\mathrm{T}$ & $\mathrm{T}$ & & $\mathrm{T}$ & & $\mathrm{T}$ & $\mathrm{S}$ & & $\mathrm{S}$ & \\
\hline Arkansas & $\mathrm{S}$ & $S$ & $\mathrm{~S}$ & $\mathrm{~S}$ & & & $\mathrm{~T}$ & $\mathrm{~S}$ & & & $\mathrm{~T}$ & $\mathrm{~T}$ & $\mathrm{~T}$ & $\mathrm{~T}$ & & $\mathrm{~T}$ & & $\mathrm{~T}$ & $\mathrm{~S}$ & & & $\mathrm{~T}$ \\
\hline California & $\mathrm{S}$ & $\mathrm{S}$ & $\mathrm{S}$ & $\mathrm{S}$ & & $\mathrm{S}$ & & $\mathrm{S}$ & & $\mathrm{S}$ & & $\mathrm{T}$ & $\mathrm{T}$ & $\mathrm{T}$ & $\mathrm{S}$ & & & $\mathrm{T}$ & $\mathrm{S}$ & & $\mathrm{S}$ & \\
\hline Colorado & $\mathrm{S}$ & S & S & & $\mathrm{T}$ & $\mathrm{S}$ & & $\mathrm{S}$ & & $\mathrm{S}$ & & $\mathrm{T}$ & $\mathrm{T}$ & $\mathrm{T}$ & & $\mathrm{T}$ & $\mathrm{S}$ & & $\mathrm{S}$ & & $\mathrm{S}$ & \\
\hline Connecticut & $\mathrm{S}$ & $\mathrm{S}$ & $\mathrm{S}$ & & $\mathrm{T}$ & & $\mathrm{T}$ & & $\mathrm{T}$ & $\mathrm{S}$ & & $\mathrm{T}$ & $\mathrm{T}$ & $\mathrm{T}$ & $\mathrm{S}$ & & & $\mathrm{T}$ & & $\mathrm{T}$ & $\mathrm{S}$ & \\
\hline Delaware & $\mathrm{S}$ & $\mathrm{S}$ & $\mathrm{S}$ & $\mathrm{S}$ & & $\mathrm{S}$ & & $\mathrm{S}$ & & $\mathrm{S}$ & & $\mathrm{T}$ & $\mathrm{T}$ & $\mathrm{T}$ & $\mathrm{S}$ & & & $\mathrm{T}$ & $\mathrm{S}$ & & $\mathrm{S}$ & \\
\hline Florida & $\mathrm{S}$ & $S$ & $S$ & $\mathrm{~S}$ & & $\mathrm{~S}$ & & $\mathrm{~S}$ & & $\mathrm{~S}$ & & $\mathrm{~T}$ & $\mathrm{~T}$ & $\mathrm{~T}$ & $\mathrm{~S}$ & & $\mathrm{~S}$ & & $\mathrm{~S}$ & & $\mathrm{~S}$ & \\
\hline Georgia & $\mathrm{S}$ & $\mathrm{S}$ & $\mathrm{S}$ & $\mathrm{S}$ & & $\mathrm{S}$ & & $\mathrm{S}$ & & $\mathrm{S}$ & & $\mathrm{T}$ & $\mathrm{T}$ & $\mathrm{T}$ & $\mathrm{S}$ & & $\mathrm{S}$ & & $\mathrm{S}$ & & $\mathrm{S}$ & \\
\hline Hawaii & $\mathrm{S}$ & $\mathrm{S}$ & $\mathrm{S}$ & & $\mathrm{T}$ & $\mathrm{S}$ & & & $\mathrm{T}$ & & $\mathrm{T}$ & $\mathrm{T}$ & $\mathrm{T}$ & $\mathrm{T}$ & & $\mathrm{T}$ & & $\mathrm{T}$ & & $\mathrm{T}$ & & $\mathrm{T}$ \\
\hline Idaho & $\mathrm{S}$ & $\mathrm{S}$ & $\mathrm{S}$ & & $\mathrm{T}$ & & $\mathrm{T}$ & & $\mathrm{T}$ & & $\mathrm{T}$ & $\mathrm{T}$ & $\mathrm{T}$ & $\mathrm{T}$ & $\mathrm{S}$ & & $\mathrm{S}$ & & $\mathrm{S}$ & & $\mathrm{S}$ & \\
\hline Illinois & $\mathrm{S}$ & $\mathrm{S}$ & $\mathrm{S}$ & & $\mathrm{T}$ & $\mathrm{S}$ & & $\mathrm{S}$ & & $\mathrm{S}$ & & $\mathrm{T}$ & $\mathrm{T}$ & $\mathrm{T}$ & & $\mathrm{T}$ & $\mathrm{S}$ & & $\mathrm{S}$ & & $\mathrm{S}$ & \\
\hline Indiana & $\mathrm{S}$ & S & S & $\mathrm{S}$ & & & $\mathrm{T}$ & & $\mathrm{T}$ & & $\mathrm{T}$ & $\mathrm{T}$ & $\mathrm{T}$ & $\mathrm{T}$ & & $\mathrm{T}$ & & $\mathrm{T}$ & & $\mathrm{T}$ & $\mathrm{S}$ & \\
\hline Iowa & $\mathrm{S}$ & $\mathrm{S}$ & $\mathrm{S}$ & $\mathrm{S}$ & & & $\mathrm{T}$ & & $\mathrm{T}$ & & $\mathrm{T}$ & $\mathrm{T}$ & $\mathrm{T}$ & $\mathrm{T}$ & $\mathrm{S}$ & & $\mathrm{S}$ & & $\mathrm{S}$ & & $\mathrm{S}$ & \\
\hline
\end{tabular}


Table 1.1. Summary of State reporting decisions for public supply population served and irrigation water-use values.-Continued [Shading denotes documentation is available. S, split; T, total]

\begin{tabular}{|c|c|c|c|c|c|c|c|c|c|c|c|c|c|c|c|c|c|c|c|c|c|c|}
\hline \multirow{3}{*}{$\begin{array}{r}\text { State } \\
\text { Kansas } \\
\end{array}$} & \multicolumn{11}{|c|}{$\begin{array}{c}\text { Population served } \\
\text { (groundwater/surface water split or total) }\end{array}$} & \multicolumn{11}{|c|}{ Irrigation (crop and golf split or total) } \\
\hline & \multirow{2}{*}{$\begin{array}{c}1985 \\
\mathrm{~S}\end{array}$} & \multirow{2}{*}{$\begin{array}{c}1990 \\
S \\
\end{array}$} & \multirow{2}{*}{1995} & \multicolumn{2}{|c|}{2000} & \multicolumn{2}{|c|}{2005} & \multicolumn{2}{|c|}{2010} & \multicolumn{2}{|c|}{2015} & \multirow{2}{*}{$\begin{array}{c}1985 \\
\mathrm{~T}\end{array}$} & \multirow{2}{*}{$\begin{array}{c}1990 \\
T\end{array}$} & \multirow{2}{*}{$\begin{array}{c}1995 \\
\mathrm{~T}\end{array}$} & \multicolumn{2}{|c|}{2000} & \multicolumn{2}{|c|}{2005} & \multicolumn{2}{|c|}{2010} & \multicolumn{2}{|c|}{2015} \\
\hline & & & & & $\mathrm{T}$ & & $\mathrm{T}$ & & $\mathrm{T}$ & & $\mathrm{T}$ & & & & $\mathrm{S}$ & & $\mathrm{S}$ & & $\mathrm{S}$ & & $\mathrm{S}$ & \\
\hline Kentucky & $\mathrm{S}$ & $\mathrm{S}$ & $\mathrm{S}$ & & $\mathrm{T}$ & & $\mathrm{T}$ & & $\mathrm{T}$ & & $\mathrm{T}$ & $\mathrm{T}$ & $\mathrm{T}$ & $\mathrm{T}$ & & $\mathrm{T}$ & & $\mathrm{T}$ & & $\mathrm{T}$ & S & \\
\hline Louisiana & $\mathrm{S}$ & $\mathrm{S}$ & $\mathrm{S}$ & $\mathrm{S}$ & & $\mathrm{S}$ & & $\mathrm{S}$ & & $\mathrm{S}$ & & $\mathrm{T}$ & $\mathrm{T}$ & $\mathrm{T}$ & $\mathrm{S}$ & & & $\mathrm{T}$ & & $\mathrm{T}$ & & $\mathrm{T}$ \\
\hline Maine & $\mathrm{S}$ & $\mathrm{S}$ & $\mathrm{S}$ & & $\mathrm{T}$ & $\mathrm{S}$ & & $\mathrm{S}$ & & $\mathrm{S}$ & & $\mathrm{T}$ & $\mathrm{T}$ & $\mathrm{T}$ & & $\mathrm{T}$ & $\mathrm{S}$ & & $\mathrm{S}$ & & $\mathrm{S}$ & \\
\hline Maryland & $\mathrm{S}$ & $\mathrm{S}$ & $\mathrm{S}$ & $\mathrm{S}$ & & $\mathrm{S}$ & & $\mathrm{S}$ & & $\mathrm{S}$ & & $\mathrm{T}$ & $\mathrm{T}$ & $\mathrm{T}$ & $\mathrm{S}$ & & & $\mathrm{T}$ & $\mathrm{S}$ & & $\mathrm{S}$ & \\
\hline Massachusetts & $\mathrm{S}$ & $\mathrm{S}$ & $\mathrm{S}$ & & $\mathrm{T}$ & & $\mathrm{T}$ & $\mathrm{S}$ & & $\mathrm{S}$ & & $\mathrm{T}$ & $\mathrm{T}$ & $\mathrm{T}$ & $\mathrm{S}$ & & $\mathrm{S}$ & & $\mathrm{S}$ & & $\mathrm{S}$ & \\
\hline Michigan & $\mathrm{S}$ & $\mathrm{S}$ & $\mathrm{S}$ & $\mathrm{S}$ & & & $\mathrm{T}$ & & $\mathrm{T}$ & & $\mathrm{T}$ & $\mathrm{T}$ & $\mathrm{T}$ & $\mathrm{T}$ & & $\mathrm{T}$ & $\mathrm{S}$ & & $\mathrm{S}$ & & $\mathrm{S}$ & \\
\hline Minnesota & $\mathrm{S}$ & $\mathrm{S}$ & $\mathrm{S}$ & $\mathrm{S}$ & & $\mathrm{S}$ & & $\mathrm{S}$ & & $\mathrm{S}$ & & $\mathrm{T}$ & $\mathrm{T}$ & $\mathrm{T}$ & & $\mathrm{T}$ & $\mathrm{S}$ & & $\mathrm{S}$ & & $\mathrm{S}$ & \\
\hline Mississippi & $\mathrm{S}$ & $\mathrm{S}$ & $\mathrm{S}$ & & $\mathrm{T}$ & $\mathrm{S}$ & & $\mathrm{S}$ & & $\mathrm{S}$ & & $\mathrm{T}$ & $\mathrm{T}$ & $\mathrm{T}$ & & $\mathrm{T}$ & & $\mathrm{T}$ & & $\mathrm{T}$ & & $\mathrm{T}$ \\
\hline Missouri & $\mathrm{S}$ & S & $\mathrm{S}$ & $\mathrm{S}$ & & $\mathrm{S}$ & & & $\mathrm{T}$ & $\mathrm{S}$ & & $\mathrm{T}$ & $\mathrm{T}$ & $\mathrm{T}$ & & $\mathrm{T}$ & & $\mathrm{T}$ & & $\mathrm{T}$ & & $\mathrm{T}$ \\
\hline Montana & $\mathrm{S}$ & $\mathrm{S}$ & $\mathrm{S}$ & $\mathrm{S}$ & & $\mathrm{S}$ & & & $\mathrm{T}$ & $\mathrm{S}$ & & $\mathrm{T}$ & $\mathrm{T}$ & $\mathrm{T}$ & & $\mathrm{T}$ & & $\mathrm{T}$ & & $\mathrm{T}$ & & $\mathrm{T}$ \\
\hline Nebraska & $\mathrm{S}$ & $\mathrm{S}$ & $\mathrm{S}$ & $\mathrm{S}$ & & & $\mathrm{T}$ & & $\mathrm{T}$ & & $\mathrm{T}$ & $\mathrm{T}$ & $\mathrm{T}$ & $\mathrm{T}$ & & $\mathrm{T}$ & & $\mathrm{T}$ & & $\mathrm{T}$ & & $\mathrm{T}$ \\
\hline Nevada & $\mathrm{S}$ & $\mathrm{S}$ & $\mathrm{S}$ & $\mathrm{S}$ & & & $\mathrm{T}$ & & $\mathrm{T}$ & & $\mathrm{T}$ & $\mathrm{T}$ & $\mathrm{T}$ & $\mathrm{T}$ & $\mathrm{S}$ & & & $\mathrm{T}$ & $\mathrm{S}$ & & S & \\
\hline $\begin{array}{l}\text { New } \\
\text { Hampshire }\end{array}$ & $\mathrm{S}$ & $\mathrm{S}$ & S & $\mathrm{S}$ & & $\mathrm{S}$ & & $\mathrm{S}$ & & S & & $\mathrm{T}$ & $\mathrm{T}$ & $\mathrm{T}$ & $\mathrm{S}$ & & $\mathrm{S}$ & & S & & S & \\
\hline New Jersey & $\mathrm{S}$ & $\mathrm{S}$ & $\mathrm{S}$ & $\mathrm{S}$ & & $\mathrm{S}$ & & $\mathrm{S}$ & & $\mathrm{S}$ & & $\mathrm{T}$ & $\mathrm{T}$ & $\mathrm{T}$ & $\mathrm{S}$ & & $\mathrm{S}$ & & & $\mathrm{T}$ & & $\mathrm{T}$ \\
\hline New Mexico & $\mathrm{S}$ & $\mathrm{S}$ & $\mathrm{S}$ & & $\mathrm{T}$ & $\mathrm{S}$ & & & $\mathrm{T}$ & S & & $\mathrm{T}$ & $\mathrm{T}$ & $\mathrm{T}$ & & $\mathrm{T}$ & & $\mathrm{T}$ & $\mathrm{S}$ & & S & \\
\hline New York & $\mathrm{S}$ & $\mathrm{S}$ & $\mathrm{S}$ & & $\mathrm{T}$ & & $\mathrm{T}$ & $\mathrm{S}$ & & $\mathrm{S}$ & & $\mathrm{T}$ & $\mathrm{T}$ & $\mathrm{T}$ & $\mathrm{S}$ & & $\mathrm{S}$ & & S & & $\mathrm{S}$ & \\
\hline North Carolina & $\mathrm{S}$ & $\mathrm{S}$ & $\mathrm{S}$ & $\mathrm{S}$ & & $\mathrm{S}$ & & $\mathrm{S}$ & & $\mathrm{S}$ & & $\mathrm{T}$ & $\mathrm{T}$ & $\mathrm{T}$ & $\mathrm{S}$ & & $\mathrm{S}$ & & $\mathrm{S}$ & & $\mathrm{S}$ & \\
\hline North Dakota & $\mathrm{S}$ & $\mathrm{S}$ & $\mathrm{S}$ & $\mathrm{S}$ & & & $\mathrm{T}$ & & $\mathrm{T}$ & & $\mathrm{T}$ & $\mathrm{T}$ & $\mathrm{T}$ & $\mathrm{T}$ & & $\mathrm{T}$ & & $\mathrm{T}$ & & $\mathrm{T}$ & & $\mathrm{T}$ \\
\hline Ohio & $\mathrm{S}$ & $\mathrm{S}$ & $\mathrm{S}$ & $\mathrm{S}$ & & $\mathrm{S}$ & & $\mathrm{S}$ & & $\mathrm{S}$ & & $\mathrm{T}$ & $\mathrm{T}$ & $\mathrm{T}$ & $\mathrm{S}$ & & $\mathrm{S}$ & & $\mathrm{S}$ & & $\mathrm{S}$ & \\
\hline Oklahoma & $\mathrm{S}$ & $\mathrm{S}$ & $\mathrm{S}$ & $\mathrm{S}$ & & $\mathrm{S}$ & & $\mathrm{S}$ & & $\mathrm{S}$ & & $\mathrm{T}$ & $\mathrm{T}$ & $\mathrm{T}$ & & $\mathrm{T}$ & & $\mathrm{T}$ & & $\mathrm{T}$ & & $\mathrm{T}$ \\
\hline Oregon & $\mathrm{S}$ & $\mathrm{S}$ & $\mathrm{S}$ & $\mathrm{S}$ & & $\mathrm{S}$ & & $\mathrm{S}$ & & $\mathrm{S}$ & & $\mathrm{T}$ & $\mathrm{T}$ & $\mathrm{T}$ & & $\mathrm{T}$ & & $\mathrm{T}$ & $\mathrm{S}$ & & $\mathrm{S}$ & \\
\hline Pennsylvania & $\mathrm{S}$ & $\mathrm{S}$ & $\mathrm{S}$ & & $\mathrm{T}$ & $\mathrm{S}$ & & $\mathrm{S}$ & & $\mathrm{S}$ & & $\mathrm{T}$ & $\mathrm{T}$ & $\mathrm{T}$ & & $\mathrm{T}$ & $\mathrm{S}$ & & $\mathrm{S}$ & & $\mathrm{S}$ & \\
\hline Puerto Rico & $\mathrm{S}$ & $\mathrm{S}$ & $\mathrm{S}$ & $\mathrm{S}$ & & & $\mathrm{T}$ & & $\mathrm{T}$ & & $\mathrm{T}$ & $\mathrm{T}$ & $\mathrm{T}$ & $\mathrm{T}$ & $\mathrm{S}$ & & & $\mathrm{T}$ & & $\mathrm{T}$ & & $\mathrm{T}$ \\
\hline Rhode Island & $\mathrm{S}$ & $\mathrm{S}$ & $\mathrm{S}$ & $\mathrm{S}$ & & & $\mathrm{T}$ & $\mathrm{S}$ & & S & & $\mathrm{T}$ & $\mathrm{T}$ & $\mathrm{T}$ & & $\mathrm{T}$ & $\mathrm{S}$ & & & $\mathrm{T}$ & S & \\
\hline South Carolina & $\mathrm{S}$ & $\mathrm{S}$ & $\mathrm{S}$ & & $\mathrm{T}$ & $\mathrm{S}$ & & $\mathrm{S}$ & & $\mathrm{S}$ & & $\mathrm{T}$ & $\mathrm{T}$ & $\mathrm{T}$ & $\mathrm{S}$ & & $\mathrm{S}$ & & $\mathrm{S}$ & & $\mathrm{S}$ & \\
\hline South Dakota & $\mathrm{S}$ & $\mathrm{S}$ & $\mathrm{S}$ & $\mathrm{S}$ & & $\mathrm{S}$ & & $\mathrm{S}$ & & & $\mathrm{T}$ & $\mathrm{T}$ & $\mathrm{T}$ & $\mathrm{T}$ & & $\mathrm{T}$ & & $\mathrm{T}$ & $\mathrm{S}$ & & & $\mathrm{T}$ \\
\hline Tennessee & $\mathrm{S}$ & $\mathrm{S}$ & $\mathrm{S}$ & & $\mathrm{T}$ & & $\mathrm{T}$ & & $\mathrm{T}$ & $\mathrm{S}$ & & $\mathrm{T}$ & $\mathrm{T}$ & $\mathrm{T}$ & $\mathrm{S}$ & & $\mathrm{S}$ & & $\mathrm{S}$ & & $\mathrm{S}$ & \\
\hline Texas & $\mathrm{S}$ & $\mathrm{S}$ & $\mathrm{S}$ & & $\mathrm{T}$ & & $\mathrm{T}$ & & $\mathrm{T}$ & & $\mathrm{T}$ & $\mathrm{T}$ & $\mathrm{T}$ & $\mathrm{T}$ & & $\mathrm{T}$ & & $\mathrm{T}$ & & $\mathrm{T}$ & & $\mathrm{T}$ \\
\hline $\begin{array}{l}\text { U.S. Virgin } \\
\text { Islands }\end{array}$ & $\mathrm{S}$ & S & S & $\mathrm{S}$ & & $\mathrm{S}$ & & & $\mathrm{T}$ & $\mathrm{S}$ & & $\mathrm{T}$ & $\mathrm{T}$ & $\mathrm{T}$ & & $\mathrm{T}$ & & $\mathrm{T}$ & & $\mathrm{T}$ & & $\mathrm{T}$ \\
\hline Utah & $\mathrm{S}$ & $\mathrm{S}$ & $\mathrm{S}$ & & $\mathrm{T}$ & & $\mathrm{T}$ & & $\mathrm{T}$ & & $\mathrm{T}$ & $\mathrm{T}$ & $\mathrm{T}$ & $\mathrm{T}$ & & $\mathrm{T}$ & & $\mathrm{T}$ & $\mathrm{S}$ & & $\mathrm{S}$ & \\
\hline Vermont & $\mathrm{S}$ & $\mathrm{S}$ & $\mathrm{S}$ & $\mathrm{S}$ & & $\mathrm{S}$ & & $\mathrm{S}$ & & $\mathrm{S}$ & & $\mathrm{T}$ & $\mathrm{T}$ & $\mathrm{T}$ & $\mathrm{S}$ & & $\mathrm{S}$ & & $\mathrm{S}$ & & $\mathrm{S}$ & \\
\hline Virginia & $\mathrm{S}$ & $\mathrm{S}$ & $\mathrm{S}$ & $\mathrm{S}$ & & $\mathrm{S}$ & & $\mathrm{S}$ & & $\mathrm{S}$ & & $\mathrm{T}$ & $\mathrm{T}$ & $\mathrm{T}$ & $\mathrm{S}$ & & $\mathrm{S}$ & & $S$ & & $\mathrm{~S}$ & \\
\hline Washington & $\mathrm{S}$ & $\mathrm{S}$ & $\mathrm{S}$ & & $\mathrm{T}$ & & $\mathrm{T}$ & & $\mathrm{T}$ & & $\mathrm{T}$ & $\mathrm{T}$ & $\mathrm{T}$ & $\mathrm{T}$ & $\mathrm{S}$ & & $\mathrm{S}$ & & S & & $\mathrm{S}$ & \\
\hline West Virginia & $\mathrm{S}$ & $\mathrm{S}$ & $\mathrm{S}$ & $\mathrm{S}$ & & $\mathrm{S}$ & & $\mathrm{S}$ & & $\mathrm{S}$ & & $\mathrm{T}$ & $\mathrm{T}$ & $\mathrm{T}$ & & $\mathrm{T}$ & & $\mathrm{T}$ & & $\mathrm{T}$ & $\mathrm{S}$ & \\
\hline Wisconsin & $\mathrm{S}$ & $\mathrm{S}$ & $\mathrm{S}$ & $\mathrm{S}$ & & $\mathrm{S}$ & & $\mathrm{S}$ & & $\mathrm{S}$ & & $\mathrm{T}$ & $\mathrm{T}$ & $\mathrm{T}$ & & $\mathrm{T}$ & & $\mathrm{T}$ & & $\mathrm{T}$ & & $\mathrm{T}$ \\
\hline Wyoming & $\mathrm{S}$ & $\mathrm{S}$ & $\mathrm{S}$ & $\mathrm{S}$ & & $\mathrm{S}$ & & $\mathrm{S}$ & & $\mathrm{S}$ & & $\mathrm{T}$ & $\mathrm{T}$ & $\mathrm{T}$ & $\mathrm{S}$ & & & $\mathrm{T}$ & & $\mathrm{T}$ & & $\mathrm{T}$ \\
\hline
\end{tabular}


For additional information contact:

Director, Upper Midwest Water Science Center U.S. Geological Survey

5840 Enterprise Drive

Lansing, MI 48911

For additional information, visit:

https://usgs.gov/centers/umid-water

Publishing support provided by the Indianapolis and Rolla Publishing Service Centers 


\section{患}

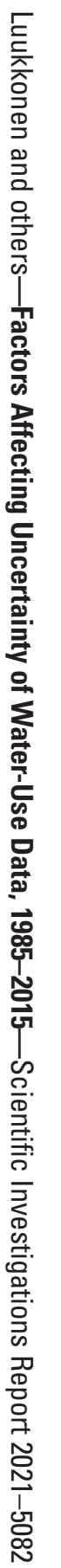

